\title{
Seismic anisotropy and stress of the Canterbury plains
}

by

Rob Holt

A thesis

submitted to the Victoria University of Wellington in fulfilment of the requirements for the degree of Master of Science in Geophysics.

Victoria University of Wellington

2013 



\begin{abstract}
The $M_{w}=7.1$ Darfield (Canterbury) earthquake struck on 4 September 2010, approximately $45 \mathrm{~km}$ west of Christchurch, New Zealand. It revealed a previously unknown fault (the Greendale fault) and caused billions of dollars of damage due to high peak ground velocities and extensive liquefaction. It also triggered the $M_{w}=6.3$ Christchurch earthquake on 22 February 2011, which caused further damage and the loss of 185 lives.

The objective of this research was to determine the relationship between stress and seismic properties in a seismically active region using manuallypicked $P$ and $S$ wave arrival times from the aftershock sequence between 8 September 2010-13 January 2011 to estimate shear-wave splitting (SWS) parameters, $V_{P} / V_{S}$-ratios, anisotropy (delay-time tomography), focal mechanisms, and tectonic stress on the Canterbury plains.

The maximum horizontal stress direction was highly consistent in the plains, with an average value of $S_{\operatorname{Hax}}=116 \pm 18^{\circ}$. However, the estimates showed variation in $S_{H \max }$ near the fault, with one estimate rotating by as much as $30^{\circ}$ counter-clockwise. This suggests heterogeneity of stress at the fault, though the cause remains unclear. Orientations of the principal stresses predominantly indicate a strike-slip regime, but there are possible thrust regimes to the west and north/east of the fault. The SWS fast directions $(\phi)$ on the plains show alignment with $S_{H \max }$ at the majority of stations, indicating stress controlled anisotropy. However, structural effects appear more dominant in the neighbouring regions of the Southern Alps and Banks Peninsula.
\end{abstract}




\section{Contents}

1 Introduction 3

1.1 The Darfield Earthquake . . . . . . . . . . . . . . . . 3

1.2 Objectives . . . . . . . . . . . . . . . 5

1.3 Tectonic setting . . . . . . . . . . . . . 6

1.4 Related work . . . . . . . . . . . . . . . 7

1.4.1 Work by the author . . . . . . . . . . . 7

1.4.2 Stress- vs. structure-induced anisotropy . . . . . . . 7

1.4.3 Work using the same data . . . . . . . . . . . 8

1.4.4 Fault strength and stress rotation . . . . . . . . 9

2 Theory 11

2.1 Seismic anisotropy and shear-wave splitting . . . . . . . . 11

2.1.1 Shear-wave splitting for hexagonal symmetry . . . . . . 14

2.1.2 Causes of shear-wave splitting in the crust . . . . . . . 15

2.2 Focal mechanisms . . . . . . . . . . . . . . . . . . 17

2.2.1 Focal mechanisms and radiation patterns . . . . . . . 18

2.3 The stress tensor and Coulomb failure . . . . . . . . . . . . 22

2.3.1 Directional statistics and significance tests . . . . . . . 24

3 Shear-wave splitting $\quad 27$

3.1 The MFAST Package . . . . . . . . . . . . . . . . . 27

3.1.1 Sources of error/uncertainty . . . . . . . . . . . . . 32

3.1.2 Restriction of $\delta t$ measurements . . . . . . . . . . 35 
$3.1 .3 \delta t$ tomography . . . . . . . . . . . . . 36

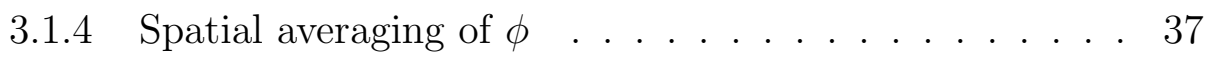

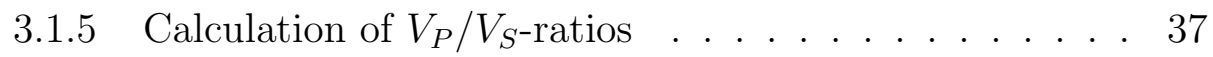

3.2 Results and Discussion . . . . . . . . . . . . . . . . 38

3.2.1 $\phi$ on the Canterbury plains . . . . . . . . . 38

3.2.2 Delay time tomography and spatial averaging . . . . 51

$3.3 V_{P} / V_{S}$-ratio and $V_{P} / V_{S}$-ratio vs. $\delta t \ldots \ldots \ldots . \ldots . \ldots$

3.4 Conclusions .................... . . 60

4 Focal mechanisms and stress inversion 63

4.1 Method .................... 63

4.1.1 Earthquake relocations with NonLinLoc . . . . . . 63

4.1 .2 Focal mechanism estimation . . . . . . . . . . . . 64

4.1.3 Stress inversion of focal mechanism . . . . . . . . . . . 64

4.1.4 Selection of events for stress inversion . . . . . . . . 66

4.2 Results and Discussion . . . . . . . . . . . . . . 67

4.2.1 Focal Mechanisms . . . . . . . . . . . . . . 67

4.2.2 $\beta_{F M}$ and $\beta_{S W S}$ comparison . . . . . . . . . . . 67

4.2 .3 Stress inversion . . . . . . . . . . . . . . . 69

4.3 Comparison of SWS and Stress estimates . . . . . . . . . 79

4.4 Conclusions . . . . . . . . . . . . . . . . . . . . . . . 82

5 Conclusions $\quad 83$

A Glossary of variables $\quad 95$

A.1 Glossary of variables . . . . . . . . . . . . . . . 95

A.1.1 $\beta_{S W S}$ and $\beta_{F M} \ldots \ldots \ldots \ldots . \ldots . \ldots . \ldots . \ldots 9$

$\begin{array}{ll}\text { B Correlation tables } & 97\end{array}$

$\begin{array}{ll}C \text { GNS Science data } & 107\end{array}$

C.1 GNS Science temporary stations . . . . . . . . . . . . . 107

C.2 GeoNet permanent stations . . . . . . . . . . . . . . 111 


\section{List of Figures}

1.1 Map of study area . . . . . . . . . . . . . . . 5 5

2.1 Examples of shear-wave splitting . . . . . . . . . . . . 12

2.2 Fault geometry describing fault slip . . . . . . . . . . . . . . 18

2.3 Relationship between nodal planes and first motions . . . . . . 20

2.4 Take-off angles and the focal sphere . . . . . . . . . . . . . . . 20

2.5 Focal mechanism from first motions . . . . . . . . . . . . . . . 21

2.6 Shear-wave radiation patterns . . . . . . . . . . . . . . . 21

2.7 Stress directions for infinitesimal cube within the crust . . . . 23

3.1 Plots illustrating the steps of the MFAST program (A grade) . 28

3.2 Plots illustrating the steps of the MFAST program (C grade) . 29

3.3 Rotation and time-shifting to find $\beta_{S W S} \ldots \ldots \ldots$. . . . . . 32

3.4 Diagram illustrating ambiguity related to cycle skipping . . . . 33

3.5 Diagram of incidence angles . . . . . . . . . . . . . . . 35

3.6 Rose diagrams for $\phi$ at stations . . . . . . . . . . . . . . . . 40

3.7 MCHD/Dar6 splitting plotted at epicenter . . . . . . . . . . . 43

3.8 STLD/MQZ splitting plotted at epicenter . . . . . . . . . . . 44

3.9 Cch4/CARD splitting plotted at epicenter . . . . . . . . . . 46

3.10 Densities for various correlations for station CARD . . . . . . 48

3.11 Densities for various correlations for station CARD with divided colour groups . . . . . . . . . . . . . . . . . 49

3.12 CARD locations for $\beta_{S W S}$ dependent anisotropy . . . . . . . . 50 
$3.13 \phi$ vs. $\beta_{S W S}$ for several stations . . . . . . . . . . . 51

3.14 Results from $\delta t$ tomography for all data . . . . . . . . . . . 53

3.15 Results from $\delta t$ tomography for data with $i_{s}<60^{\circ} \ldots$. . . . . 54

3.16 Jack-knife / grid movement tests for consistency of $\delta t$ tomography for all data . . . . . . . . . . . . . . 56

3.17 Jack-knife / grid movement tests for consistency of $\delta t$ tomography for data with $i_{s}<60^{\circ} \ldots \ldots \ldots$. . . . . . 57

3.18 Comparison of $\delta t$ and seismicity for all data . . . . . . . 58

$3.19 V_{P} / V_{S}$-ratio map . . . . . . . . . . . . . . . . 60

4.1 Mapping the uncertainty of hypocentres . . . . . . . . 65

4.2 Clusters for stress inversion . . . . . . . . . . . . 66

4.3 Comparison of reliable and unreliable focal mechanisms . . . . 67

4.4 Histogram of focal mechanism rake . . . . . . . . . . . . 68

4.5 All focal mechanisms at location . . . . . . . . . . . . . . . 69

4.6 Histograms of angular difference between $\beta_{F M}$ and $\beta_{S W S}$ for all stations . . . . . . . . . . . . . . . . . . 72

4.7 Histograms of angular difference between $\beta_{F M}$ and $\beta_{S W S}$ for all stations (cont.) . . . . . . . . . . . . 73

$4.8 S_{H \max }$ comparison with $\bar{\phi} \ldots \ldots \ldots \ldots . \ldots . \ldots . \ldots 74$

4.9 Principal stress directions at western end of fault . . . . . . 75

4.10 Principal stress directions north-east of fault . . . . . . . . . 75

4.11 Principal stress directions along middle of Greendale fault . . 75

4.12 Principal stress directions for remaining clusters . . . . . . . . 76

4.13 3D stress inversion with regular grid . . . . . . . . . 78

C.1 Temporal data for station SAND . . . . . . . . . . . 108

C.2 Temporal and $\phi$ data for station CARD . . . . . . . . . . . . . 109

C.3 Temporal and $\phi$ data for station LNSD . . . . . . . . . . . . . 110

C.4 Temporal and $\phi$ data for station CRLZ . . . . . . . . . . . . . 112

C.5 Temporal and $\phi$ data for station MQZ . . . . . . . . . . 113

C.6 Temporal and $\phi$ data for station OXZ . . . . . . . . . . . . . . 114 


\section{Acknowledgments}

I wish to acknowledge: my supervisors Martha Savage and John Townend for their excellent support and many enlightening discussions; the Frank Evison Research Scholarship in Geophysics for generously funding this research; the Victoria University of Wellington (VUW) Summer Scholarship program for funding the conversion of this work into a paper; Ellen Syracuse for doing a large share of the phase picking and supplying earthquake relocations; Kirsty Allan for cutting the waveforms and doing some picking; VUW students Gemma Potaka, Pia Skorstengaard, and Rory Hart for assisting with picking the data; and GeoNet for making their data available. Kevin Fenaughty and Steve Sherburn for help in obtaining the first motions for GeoNet data. Andrew Mellanby for his help with all problems Linux related. Carolin Boese for help with NonLinLoc and Adrian Shelley for designing a version of his synthetic splitting script to model re-splitting of waves for me. Richard Arnold for supplying me with the focal mechanism, stress inversions, and circular statistics codes and for his succinct and comprehensive explanation of their workings.

I would like to thank my office mates Annika, Clement, Jane, Julie and Liz for their help and for making our office a great environment to do research, and my family and friends for their support and for asking how I am even when all I seem to do is talk about my thesis. 


\section{Chapter 1}

\section{Introduction}

\subsection{The Darfield Earthquake}

The $M_{w}=7.1$ earthquake on 4 September 2010 at Darfield, New Zealand caused surface rupture, revealing a previously unknown fault (Quigley et al., 2010). The Greendale fault is predominantly a right-lateral strike slip fault with an average slip of $2.5 \mathrm{~m}$ and maximum of $5 \mathrm{~m}$ in this episode (Quigley et al., 2010). It is the first earthquake to have produced a ground surface rupture in New Zealand since the $M_{L}=6.3$ earthquake in Edgecumbe in 1987 (Anderson and Webb, 1989). The earthquake caused high peak ground accelerations (c. $1.25 \mathrm{~g}$ Gledhill et al., 2011) and extensive liquefaction, the process where sediment is condensed by vibration forcing the surrounding fluid to the surface. This caused billions of dollars of damage to residences and services throughout the region (Cubrinovski et al., 2010). The $M_{w}=6.3$ Christchurch earthquake on 22 February 2011 was an aftershock of the Darfield earthquake (Gledhill et al., 2011), which caused further destruction as well as the loss of 185 lives.

Following the Darfield earthquake, Victoria University of Wellington, the University of Auckland and the University of Wisconsin-Madison, temporarily deployed a network of 13 broadband seismometers in the surrounding area (with some along the estimated fault trace), which recorded aftershocks 
between 8 September 2010 and 13 January 2011. The temporary network recorded approximately 3000 earthquakes, the majority of which were shallow events (5-15 km depth). The data set was augmented by data from a 10 station deployment by GNS Science from 8 September 2010 to 27 September 2010 , and by data from three permanent GeoNet stations in the region from 8 September 2010 to 11 April 2011 (Fig. 1.1). Locations and focal mechanisms were only produced for earthquakes between 8 September 2010 and 13 January 2011, as the 3 permanent stations provided insufficient data for either of these processes. 


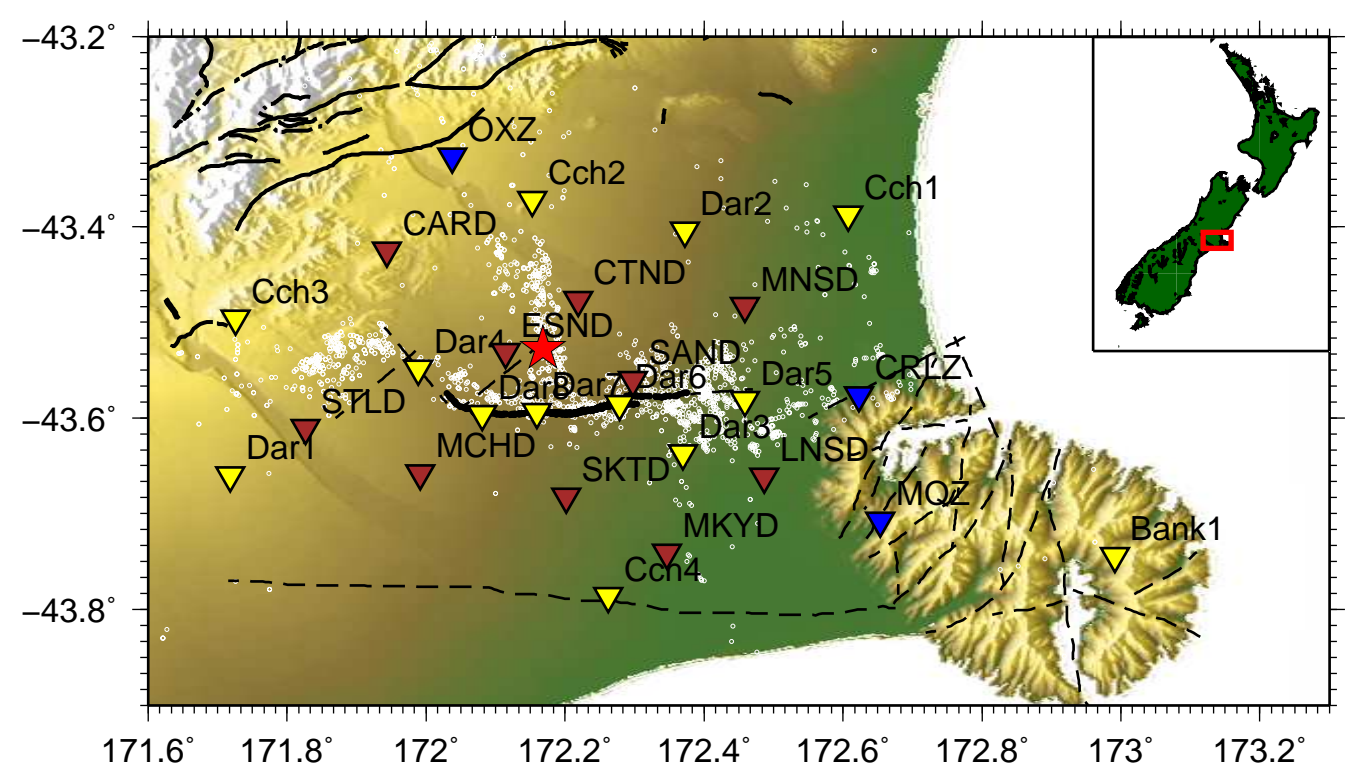

Figure 1.1: Map of study area/aftershock sequence for earthquakes between 8 September 2010 and 13 January 2011. Aftershock locations from Syracuse et al. (2012) marked with open white circles. Solid black lines show mapped faults from GNS active fault database. Thick solid black line is the Greendale fault, mapped by Quigley et al. (2010). Dashed black lines are inferred faults mapped by Beavan et al. (2010, 2011) and Ring and Hampton (2012). Coloured triangles represent VUW temporary stations (yellow), GNS temporary stations (brown) and GeoNet permanent stations (blue). Red star marks Darfield earthquake epicentre.

\subsection{Objectives}

The Darfield earthquake and its resultant aftershock sequence have revealed a major hazard in the Canterbury region in the form of the Greendale fault. It is also raises the question of whether there are other unmapped faults in the region. The aftershock sequence has also provided raw data with which to better understand the characteristics of the fault and the surrounding 
area, such as: The frictional strength of the fault, the age of the fault, the presence of liquid/gas filled cracks in the region, and the tectonic stress field of the region.

The objectives of this research are to:

- Estimate the principal tectonic stress orientations through focal mechanism inversion and compare them with fault strike to assess the strength of the fault;

- Estimate shear-wave splitting (SWS) parameters for comparison with stress estimates to identify areas of structural and stress controlled anisotropy;

- Estimate regions of anisotropy using delay-time $(\delta t)$ tomography;

- Compare estimates of initial polarisations from SWS measurements and focal mechanisms to assess the possibility of re-splitting of waves;

\subsection{Tectonic setting}

The Greendale fault is a predominantly E-W striking fault and is located on the Canterbury plains of New Zealand's South Island. The Canterbury plains are primarily made up of coalesced flood-plains (Forsyth et al., 2008) overlying Paleozoic and Mesozoic greywacke and schist (Cook et al., 1989). While there is historic evidence for significant earthquakes in the Canterbury region (Downes and Yetton, 2012), no faults had been mapped in the Darfield area (Forsyth et al., 2008). The Greendale fault lies in a region that was once overlain with rivers and any evidence of previous earthquakes is likely to have been affected by cultivation of the land over the past 200 years. A recent seismic reflection survey of Pegasus Bay in Canterbury (Barnes, 2011) has shown that there are a number of offshore faults in the area, some of which are believed to have been reactivated after lying dormant for millions of years. E-W normal faults have been identified from seismic and gravity studies in 
the areas surrounding the Darfield fault (Ghisetti and Sibson, 2012; Jongens et al., 2012, and references therein) and were formed in the Late Cretaceous.

The maximum horizontal compressive stress $\left(S_{H \max }\right)$ of the region has been estimated between $110-120^{\circ}$ at the Central Southern Alps (Leitner et al., 2001); $115 \pm 16^{\circ}$ at North Canterbury-Marlborough (Balfour et al., 2005); $115 \pm 10^{\circ}$ at the central Alpine Fault (Boese et al., 2012) ; and $114 \pm 9^{\circ}$ from borehole breakouts off the coast of South Canterbury (Sibson et al., 2011). Recent work by Townend et al. (2012) using focal mechanism inversions found highly uniform $S_{H \max }$ (average c. $115^{\circ}$ ) across most of the South Island.

\subsection{Related work}

\subsubsection{Work by the author}

Temporal changes in shear-wave splitting parameters were investigated in my Postgraduate Diploma thesis (Holt, 2011), where none were found. The key findings of that work were detailed in Syracuse et al. (2012). The same analysis of temporal change in splitting parameters is made for the new GNS temporary station data and is shown in Appendix $\mathrm{C}$ as well as new data for the permanent stations.

\subsubsection{Stress- vs. structure-induced anisotropy}

Seismic anisotropy is the directional dependence of seismic velocity and can be estimated using the phenomenon of shear-wave splitting (SWS). This is described in more detail in Section. 2.1. Early studies of seismic anisotropy using SWS asserted that crustal anisotropy was due to stress-induced crack alignment (Crampin, 1985; Crampin and Lovell, 1991). More recent studies, especially those conducted in the vicinity of large faults, have shown other effects. Zinke and Zoback (2000) observed spatial variation of the fast direction of anisotropy $(\phi)$ when investigating two earthquake clusters near the 
Calaveras Fault in central California. Near-fault measurements of $\phi$ were mostly fault-parallel, whereas measurements further from the fault were parallel to the stress field. Zhang and Schwartz (1994) measured both stressand structure-parallel $\phi$ at the Loma Prieta section of the San Andreas Fault. They concluded that these results were due to effects near the surface and that it was possible for these two effects to be interspersed at the same location. Studies conducted to the north of Canterbury in the Wellington region (Gledhill, 1991) and the Marlborough Fault System (Balfour et al., 2005) also show both stress- and fault-parallel anisotropy. To the west of Canterbury, lab measurements of seismic anisotropy for schist from the Alpine Fault (Okaya et al., 1995) reveal that the foliations in the schist cause anisotropy.

The parameters obtained from SWS $(\phi, \delta t)$ can be used to constrain regions of high/low anisotropy and changing stress/mineral alignment using $\delta t$ tomography and spatial averaging of $\phi$ respectively (Audoine et al., 2004; Johnson et al., 2011; Unglert et al., 2011).

\subsubsection{Work using the same data}

Syracuse et al. (2012) used a subset of the data used in this research (excluding the GeoNet permanent station data beyond 13 January 2010 and the GNS Science temporary deployment) and the method described in this paper to calculate SWS measurements and relocate 2825 of the earthquakes. Syracuse et al. (2012) observed that the majority of aftershocks occurred outside of the regions of greatest slip; fault- and stress-parallel $\phi$ near the Greendale fault; and predominantly stress-parallel $\phi$ in the surrounding area, suggesting that the Greendale fault was pre-existing and that anisotropy is dominated by stress in the region. This thesis expands on the work of Syracuse et al. (2012) with further analysis e.g. delay-time tomography, correlation of shear-wave splitting parameters, a new set of 2000 focal mechanisms and stress inversions for the Canterbury region. 


\subsubsection{Fault strength and stress rotation}

For the Darfield earthquake, high geologically determined stress drop (13.9 \pm 3.7 MPa from Quigley et al., 2012) and a high seismologically determined apparent stress (15.85 MPa from Fry and Gerstenberger, 2011) both suggest that the fault accumulated a large amount of stress before failure and was thus frictionally strong. Sibson et al. (2011) asserted that the E-W striking Greendale fault is either a new fault that formed at $30^{\circ}$ to the maximum compressive stress $\left(S_{1}\right)$, consistent with Andersonian fault mechanics ( $A n$ derson, 1951), or that it was pre-existing, frictionally strong fault that was optimally aligned with $S_{1}$ for reactivation (Sibson, 1985). Fault strikes at larger angles to $S_{1}$ potentially have low frictional strength or high pore fluid pressures (Townend and Zoback, 2001, 2004; Balfour et al., 2005).

Rice (1992) hypothesised that higher pore-fluid pressure at the San Andreas Fault (SAF) relative to the surrounding rock could cause a spatial variation of the local stress field, though stress measurements from boreholes near the SAF have shown that this is not the case (Townend and Zoback, 2004). Local variations in the stress field could also occur when the local stress is large enough to rotate the regional stress (Zoback, 1992). Post-seismic changes in stress orientation at faults have been attributed to significant stress drops (Zhao et al., 1997; Hardebeck and Hauksson, 2001; Hasegawa et al., 2011) or local variations in the fault trace that result in different loading states (Bohnhoff et al., 2006). Rotation of stress immediately after an earthquake and subsequent rotation back to its original orientation years after an earthquake has also been reported, indicating fault healing (Tadokoro and Ando, 2002). For the lower magnitude $M_{w}=6.3$ Christchurch earthquake that followed the Darfield earthquake, Townend et al. (2012) found no post-seismic rotation of $S_{H \max }$. 


\section{Chapter 2}

\section{Theory}

This chapter presents the background theory behind the methods used in this research. There is a list of the variables used in Appendix A.

\subsection{Seismic anisotropy and shear-wave split- ting}

Anisotropy refers to the directional dependence of a property in a medium. Seismic anisotropy describes the dependence of seismic wave velocities on the direction of propagation through a given medium. Seismic anisotropy is found in the solid inner core, mantle and crust and is caused by either mineral alignment or preferential alignment of open micro-cracks.

The term "shear-wave splitting" (SWS) refers to the phenomenon in which the shear component of a wave travelling through an anisotropic medium is 'split' into two orthogonal polarisations, with one moving faster than the other. For a near-vertically propagating wave, $\phi$ is the polarisation of the faster wave with respect to North measured at the surface. $\delta t$ is the time difference between the two waveforms (Fig.2.1). 


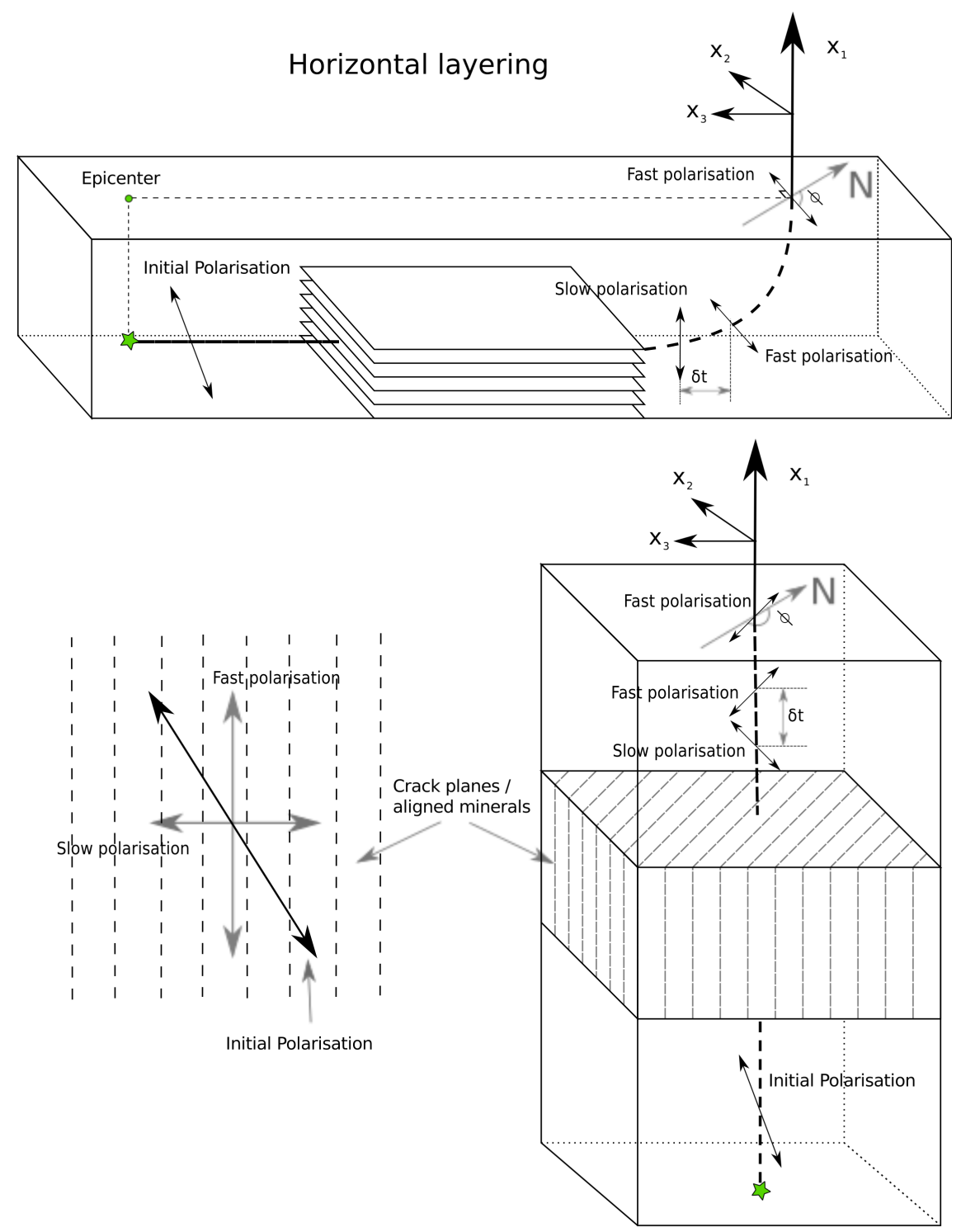

Vertical micro-cracks / mineral alignment 
Figure 2.1: (previous page) Cartoon of shear-wave splitting for the simple case of hexagonal (radial) anisotropy for vertical (horizontal layers) and horizontal symmetry (vertical micro-cracks/mineral alignment) respectively. $\phi$ the is angle between fast polarisation and North. For splitting caused by horizontal layering, fast polarisation is expected to be perpendicular to the event-station azimuth. $x_{1}$ is propagation direction and $x_{2}, x_{3}$ are orthogonal. Bottom left diagram shows initial shear wave polarisation incident on anisotropic medium and orthogonal fast and slow polarisations. $P$-wave is not shown but oscillates in direction of propagation.

Babǔska and Cara (1991) quantified the seismic anisotropy of a given medium as follows. The anisotropy of a medium is characterised by the fourth-order stiffness tensor $c_{i j k l}$ which relates its stress and strain tensors according to Hooke's Law:

$$
\sigma_{i j}=c_{i j k l} \varepsilon_{k l}
$$

$c_{i j k l}$ has 81 elastic coefficients. This can be reduced to a 6 x6 stiffness matrix $C_{i j}$ with 21 independent elastic coefficients using symmetry relationships and thermodynamic considerations (Eq. 2.2).

$$
C_{i j}=\left(\begin{array}{cccccc}
c_{1111} & c_{1122} & c_{1133} & c_{1123} & c_{1113} & c_{1112} \\
\cdot & c_{2222} & c_{2233} & c_{2223} & c_{2213} & c_{2212} \\
\cdot & \cdot & c_{3333} & c_{3323} & c_{3313} & c_{3312} \\
\cdot & \cdot & \cdot & c_{2323} & c_{2313} & c_{2312} \\
\cdot & \cdot & \cdot & \cdot & c_{1313} & c_{1312} \\
\cdot & \cdot & \cdot & \cdot & \cdot & c_{1212}
\end{array}\right)
$$

This matrix can characterise any type of crystal structure from lowest (triclinic) to highest (hexagonal) symmetry. For a homogeneous anisotropic medium, the displacement vector $\mathbf{u}$ describing particle motion at co-ordinates $\mathbf{r}$ and time $\mathbf{t}$ can be written as:

$$
\mathbf{u}(\mathbf{r}, t)=\mathbf{a} f(t-\mathbf{n} \cdot \mathbf{r} / c)
$$


where c represents the phase velocity, $\mathbf{n}$ is the normal vector perpendicular to the phase surface, and $\mathbf{a}$ is a vector describing the phase and amplitude of the wave. The particle motion and stiffness tensor can be equated using the elastodynamic equations and the symmetry of the stress and strain tensors (Babǔska and Cara, 1991) yielding an eigenvalue problem:

$$
m_{i l} a_{l}=c^{2} a_{i}
$$

where $\mathbf{a}$ are the eigenvectors and $c^{2}$ the eigenvalues and $m_{i l}$ are the elements of the Cristoffel matrix:

$$
m_{i l}=c_{i j k l} n_{j} n_{k} / \rho
$$

Due to the symmetry of the Cristoffel matrix the eigenvectors are mutually perpendicular. These relationships provide a mechanism for finding the phase velocity for different propagation directions in a given anisotropic medium. This is illustrated for the simple case of hexagonal symmetry in the following section.

\subsubsection{Shear-wave splitting for hexagonal symmetry}

Hexagonal (radial) symmetry is often assumed in the case of shear-wave splitting, as most rock types can be approximated as such (Savage, 1999). It is also an accurate way of approximating other causes, such as horizontal layering or stress-induced anisotropy, as these also approximate radial symmetry. The following is an example from Babǔska and Cara (1991) of how seismic anisotropy causes shear-wave splitting for the simplified case of hexagonal symmetry. This uses the model of an anisotropic medium comprising a series of isotropic layers (Horizontal layering in Fig. 2.1). Equation 2.6 shows the stiffness matrix for hexagonal symmetry, which has only five independent coefficients and two dependent ones. The Cristoffel matrix for propagation in the $x_{1}$ direction (Eq. 2.7) is found using the above relations and yields a diagonal matrix, indicating oscillation in the $x_{1}, x_{2}, x_{3}$ directions. The eigenvectors and velocities are shown in Eqs. 2.8 and 2.9 respectively. As $A>N>L$ 
there is a difference in velocities for the shear-wave components (N,L) and thus a separation of the shear-waves by the delay time $\delta t$.

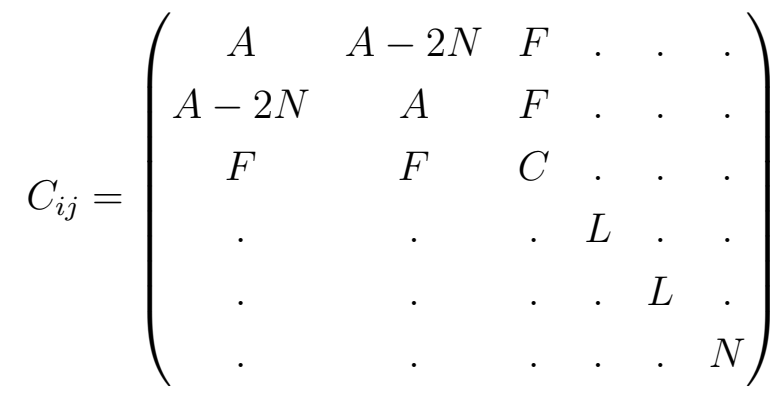

$$
\begin{aligned}
& m_{i j}=\frac{1}{\rho}\left(\begin{array}{ccc}
A & 0 & 0 \\
0 & N & 0 \\
0 & 0 & L
\end{array}\right) \\
& \lambda_{1}=\frac{A}{\rho} \quad \lambda_{2}=\frac{N}{\rho} \quad \lambda_{3}=\frac{L}{\rho} \\
& V_{P}=\sqrt{\frac{A}{\rho}} \quad V_{S_{\text {Fast }}}=\sqrt{\frac{N}{\rho}} \quad V_{S_{\text {Slow }}}=\sqrt{\frac{L}{\rho}}
\end{aligned}
$$

\subsubsection{Causes of shear-wave splitting in the crust}

There are four potential causes of shear-wave splitting in the crust:

1. Extensive-dilatancy anisotropy (EDA);

2. Fracturing of rock in fault zones;

3. Mineral alignment intrinsic in the rock;

4. Horizontal layering or interbedding of rock;

The first cause is referred to as 'stress-induced anisotropy' and the second and third are grouped as 'structure-induced anisotropy'. The final cause is referred to as 'transverse isotropy' and is also a form of structure induced anisotropy. (1) Extensive-dilatancy anisotropy (EDA) refers to anisotropy 
where micro-cracks perpendicular to the maximum compressive stress $\left(S_{1}\right)$ in the region are closed and those parallel to $S_{1}$ remain open (Crampin, 1994). The micro-cracks are assumed to be penny shaped and vertically aligned (Crampin, 1999), creating crack planes (modelled as dashed lines in Fig. 2.1). EDA is inferred when the majority of $\phi$ measurements are parallel/sub -parallel to $S_{1}$ for a given region. (2) Shearing within a faultzone can cause minerals to align with the direction of shear. This may result in fault-parallel $\phi$ measurements for waves that traverse the fault-zone (Zinke and Zoback, 2000). (3) Anisotropy from mineral alignment occurs when minerals align to form foliation planes and is inferred to be present when $\phi$ aligns with known foliations. In the presence of EDA cracks, the anisotropy due to the foliations has to be higher than that of the cracks to be detected. High percentage, mineral aligned anisotropy (10-20\%) has been found for metamorphic schist (Okaya et al., 1995) and gneiss (Kaneshima, 1990). (4) Paulssen (2004) hypothesized that for distant earthquakes, the majority of the raypath is near horizontal and that horizontal layering/interbedding with a smaller thickness than the dominant wavelength can cause the SH and SV components to split, resulting in $\phi$ measurements perpendicular to the backazimuth (upper diagram in Fig. 2.1).

More than one of these effects can be detected at the same station, either simultaneously (Zhang and Schwartz, 1994), or the dominant effect can vary with time due to some change/event in the region (Tadokoro and Ando, 2002). Unglert et al. (2011) proposed correlation of path-normalised $\delta t$ with $V_{P} / V_{S}$-ratio as an indicator of stress-controlled anisotropy, and no correlation as an indicator of structure-controlled anisotropy based on results from Aso Caldera, Kyushu, which showed such correlations only for stations where $\phi$ was sub-parallel with the local $S_{1}$. 


\subsection{Focal mechanisms}

The following is a description of focal mechanisms based on Chapter 4 of Stein and Wysession (2003). A focal mechanism is a set of three angles (strike, dip and rake) that describe the movement of a fault during an earthquake (Fig. 2.2). Strike $(\xi)$ represents the azimuth of the fault plane intersection with surface $\left(0^{\circ} \leq \xi \leq 360^{\circ}\right)$. Dip $(\delta)$ represents the inclination of the fault plane relative to the Earth's surface $\left(0^{\circ} \leq \delta \leq 90^{\circ}\right)$ and is mapped using the right-hand rule. Rake $(\lambda)$ represents the direction of movement of the hanging wall block relative to the foot wall measured from the horizontal $\left(-180^{\circ} \leq \lambda \leq 180^{\circ}\right)$.

Slip along a plane results in regions of compression and dilatation in the surrounding rock. These regions are defined by the slip direction, the fault plane and its perpendicular, hypothetical auxiliary plane (Fig. 2.3). These two planes are collectively known as the nodal planes and while they cannot be distinguished mathematically, they can be distinguished by other methods e.g. for focal mechanisms near a mapped fault, the mechanisms fault plane is expected to be parallel with the surface trace of the fault. The "first motion" is the polarity of the first peak of the $P$-wave of an earthquake and is indicative of which quadrant of the source mechanism it radiates from. An upward first motion indicates compression and downward dilatation. The simplest way to determine a focal mechanism is to plot first motions at their station locations by take-off angle and event-station azimuth on the lower hemisphere of the focal sphere (imaginary sphere surrounding the epicentre, see Figure 2.4) on a 2D projection (stereonet) and determine the two perpendicular planes/great circle arcs that best separate the data (Fig. 2.5). Focal mechanisms are usually plotted as "beach balls", with compression indicated by dark quadrants and dilatation by white, from which the nature of the slip can be determined (Fig. 2.5). This work uses the Bayesian method of Walsh et al. (2009) to determine focal mechanisms, which is described in more detail in Chapter 4. 


\subsubsection{Focal mechanisms and radiation patterns}

Focal mechanism parameters are of interest in anisotropy studies as they can be used to estimate a radiation pattern of the initial polarisations (in this case the polarisation of a wave at its genesis $\beta_{F M}$, see Appendix A for disambiguation) for a given event. These estimates can be compared with those from shear-wave splitting to test whether waves have undergone multiple instances of splitting. $S$-wave radiation patterns are calculated using the focal mechanism parameters $(\xi, \delta, \lambda)$ and a range of take-off angles $\left(i_{n}\right)$ and event-station azimuths $\left(\theta_{n}\right)$ in trigonometric relations (Eqs. 2.10, 2.11 from Aki and Richards, 1980). The ratio of these is used to find the $S$-wave polarisation relative to the raypath, which is then added to $\theta_{n}$ to give $\beta_{F M}$ relative to North (Eq. 2.12). Radiation patterns are consistent for all focal mechanisms in that they are perpendicular across the nodal planes (except where the planes meet) and they always point towards the centres of the compressional/dilatational quadrants e.g. Fig. 2.6.

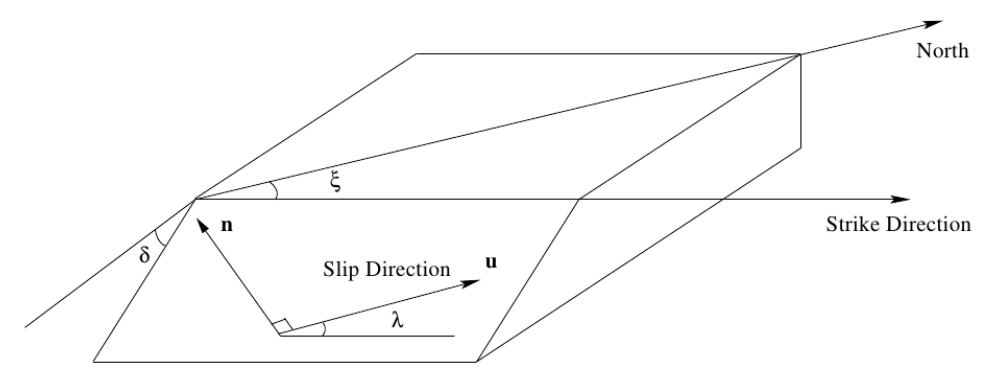

Figure 2.2: Fault geometry describing fault slip, (from Stein and Wysession (2003), modified by Walsh (2008)), $\mathbf{u}$ is slip vector, $\mathbf{n}$ is normal vector 


$$
\begin{aligned}
F^{S V}= & \sin \lambda \cos 2 \delta \cos 2 i_{n} \sin \left(\theta_{n}-\xi\right) \\
& -\cos \lambda \cos \delta \cos 2 i_{n} \cos \left(\theta_{n}-\xi\right) \\
& +\frac{1}{2} \cos \lambda \sin \delta-\sin 2 i_{n} \sin 2\left(\theta_{n}-\xi\right) \\
& -\frac{1}{2} \sin \lambda \sin 2 \delta \sin 2 i_{n}\left(1+\sin ^{2}\left(\theta_{n}-\xi\right)\right) \\
F^{S H}= & \cos \lambda \cos \delta \cos i_{n} \sin \left(\theta_{n}-\xi\right) \\
& +\cos \lambda \sin \delta \sin i_{n} \cos 2\left(\theta_{n}-\xi\right) \\
& +\sin \lambda \cos 2 \delta-\cos i_{n} \cos \left(\theta_{n}-\xi\right) \\
& -\frac{1}{2} \sin \lambda \sin 2 \delta \sin i_{n}+\sin 2\left(\theta_{n}-\xi\right) \\
& \beta_{F M}=\tan ^{-1}\left(F^{S H} / F^{S V}\right)+\theta_{n}
\end{aligned}
$$




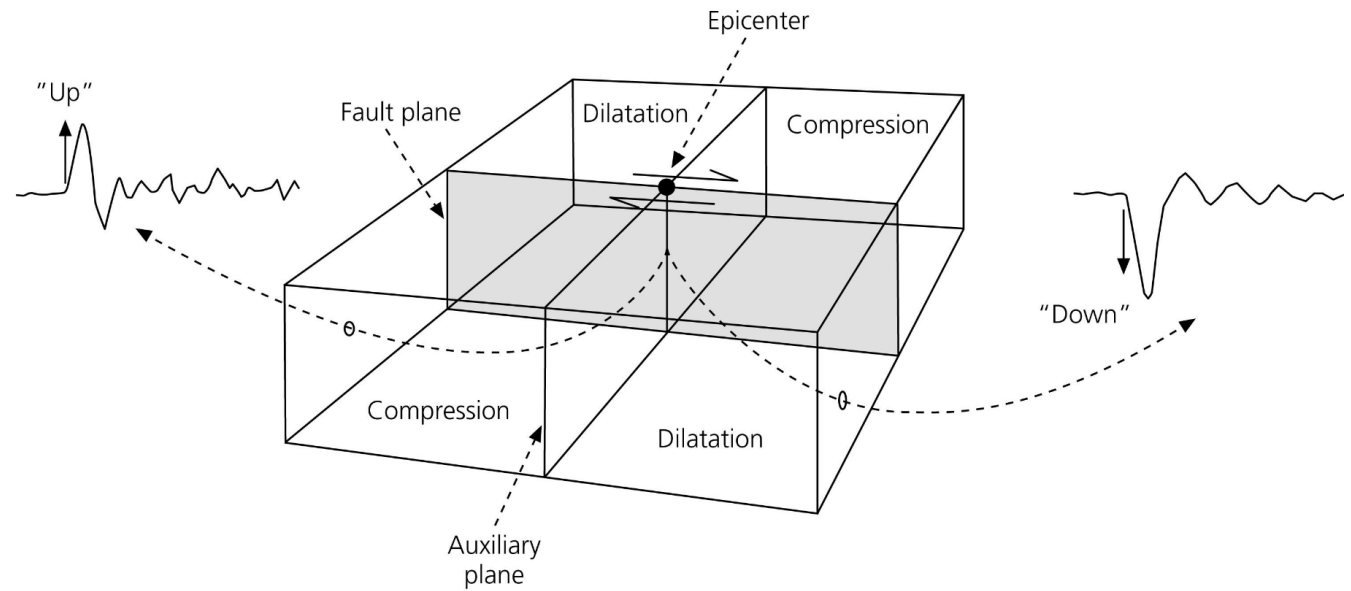

Figure 2.3: Relationship between nodal planes, compression/dilatation and first motions. Earthquake causes compression/dilatation, seismic waves indicate location of quadrants by first motions. Half-arrows indicate slip direction (figure from Stein and Wysession, 2003).

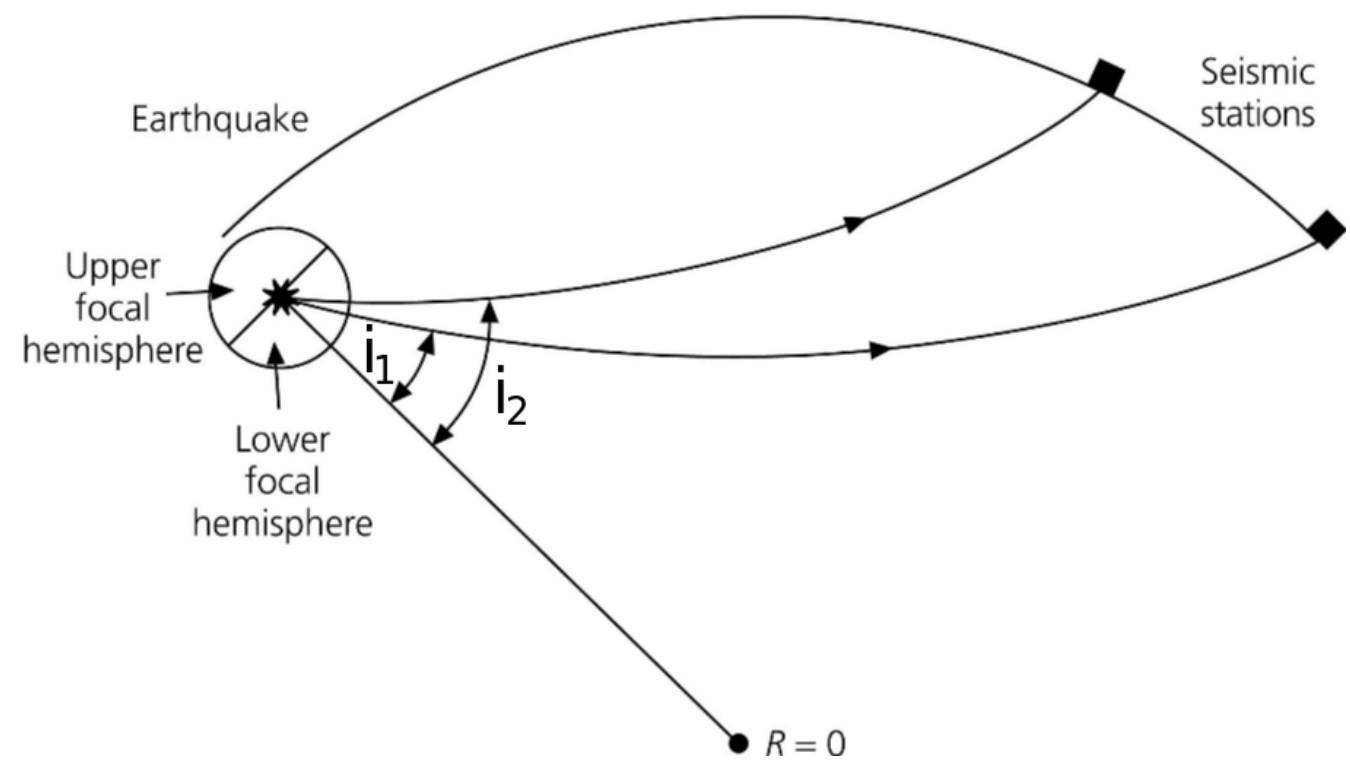

Figure 2.4: Example of focal sphere surrounding earthquake and take-off angles for different stations $\left(i_{1}, i_{2}\right)$ measured relative to the center of the Earth (figure from Stein and Wysession, 2003). 


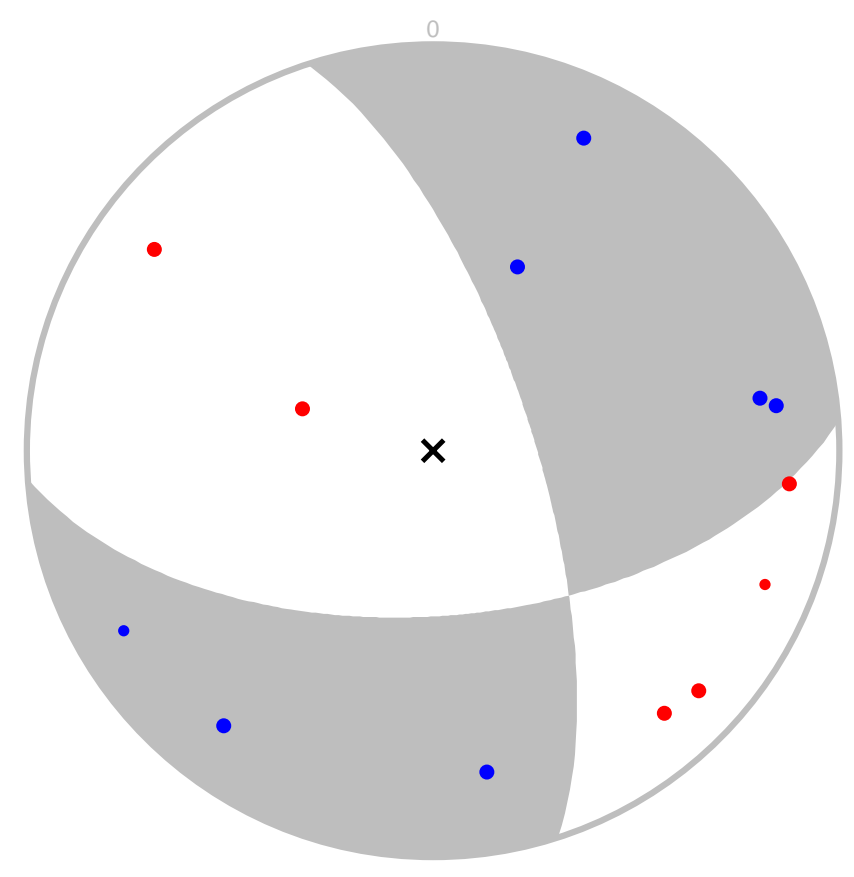

Figure 2.5: First motions plotted on a stereonet by azimuth and take-off angle from epicenter (black cross), blue is UP (compressional) red is DOWN (dilatational). Grey and white quadrants represent "Beach ball" derived from first motions, grey is compressional quadrants, white dilatational

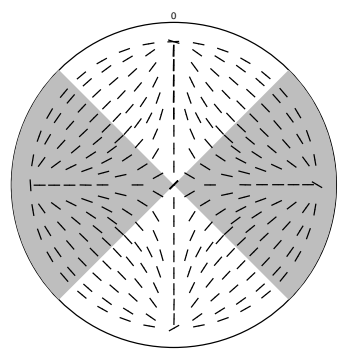

(a) Strike-slip faulting

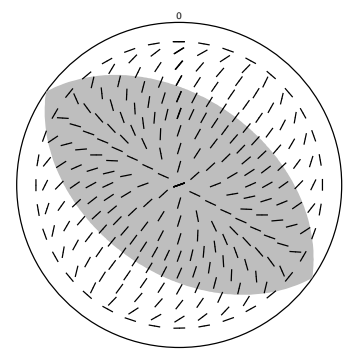

(b) Reverse faulting

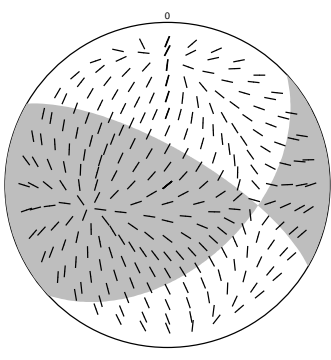

(c) Dip-slip faulting

Figure 2.6: Shear-wave radiation patterns (Calculated from Eqs. 2.10-2.12) for different fault geometries plotted above corresponding focal mechanisms. Vectors represent polarisation for a given take-off angle/azimuth relative to North (top of page). Labels identify different fault geometries. 


\subsection{The stress tensor and Coulomb failure}

The stress tensor is a $3 \times 3$ matrix which represents the stresses acting on an infinitesimally small cube of rock within the crust (Eq. 2.13, Fig. 2.7). The stress on each face of the cube is represented by one compressive/dilatational vector normal to the plane (e.g. $S_{11}$ in bold) and two orthogonal shear vectors (e.g. $\left.S_{12}, S_{13}\right)$ in the plane. Symmetry of the shear stresses is required for the cube to be in equilibrium, i.e. $S_{13}=S_{31}, S_{12}=S_{21}, S_{23}=S_{32}$.

$$
S_{i j}=\left(\begin{array}{lll}
S_{11} & S_{12} & S_{13} \\
S_{21} & S_{22} & S_{23} \\
S_{31} & S_{32} & S_{33}
\end{array}\right)
$$

The most convenient representations of the stresses acting on a given medium are the principal stress axes. These are found by rotating the co-ordinate axes such that there are no longer any shear stresses, leaving a diagonal matrix with stresses in the direction of the axes (Eq. 2.14). Geophysical convention dictates that $S_{1}$ is the maximum, $S_{2}$ the intermediate, and $S_{3}$ the minimum compressive stress. These are used to calculate the stress-ratio ( $\nu$, Eq. 2.15), which indicates the shape of the stress ellipsoid.

$$
\begin{gathered}
S_{i j}^{\prime}=\left(\begin{array}{ccc}
S_{1} & 0 & 0 \\
0 & S_{2} & 0 \\
0 & 0 & S_{3}
\end{array}\right) \\
\nu=\frac{S_{2}-S_{3}}{S_{1}-S_{3}}
\end{gathered}
$$

The Earth's surface is not expected to support any shear stress as it is a fluid/rock interface. Consequently, one vertical and two horizontal principal stresses are expected near the surface. Several studies have found that this is the case not just near the surface, but also to greater depths (Zoback and Zoback, 2002, and references therein). Normal faulting is expected when $S_{1}$ is vertical and reverse faulting when it is incident on the fault plane and $S_{3}$ is vertical. Strike-slip faulting is expected when $S_{2}$ is vertical. The rock 


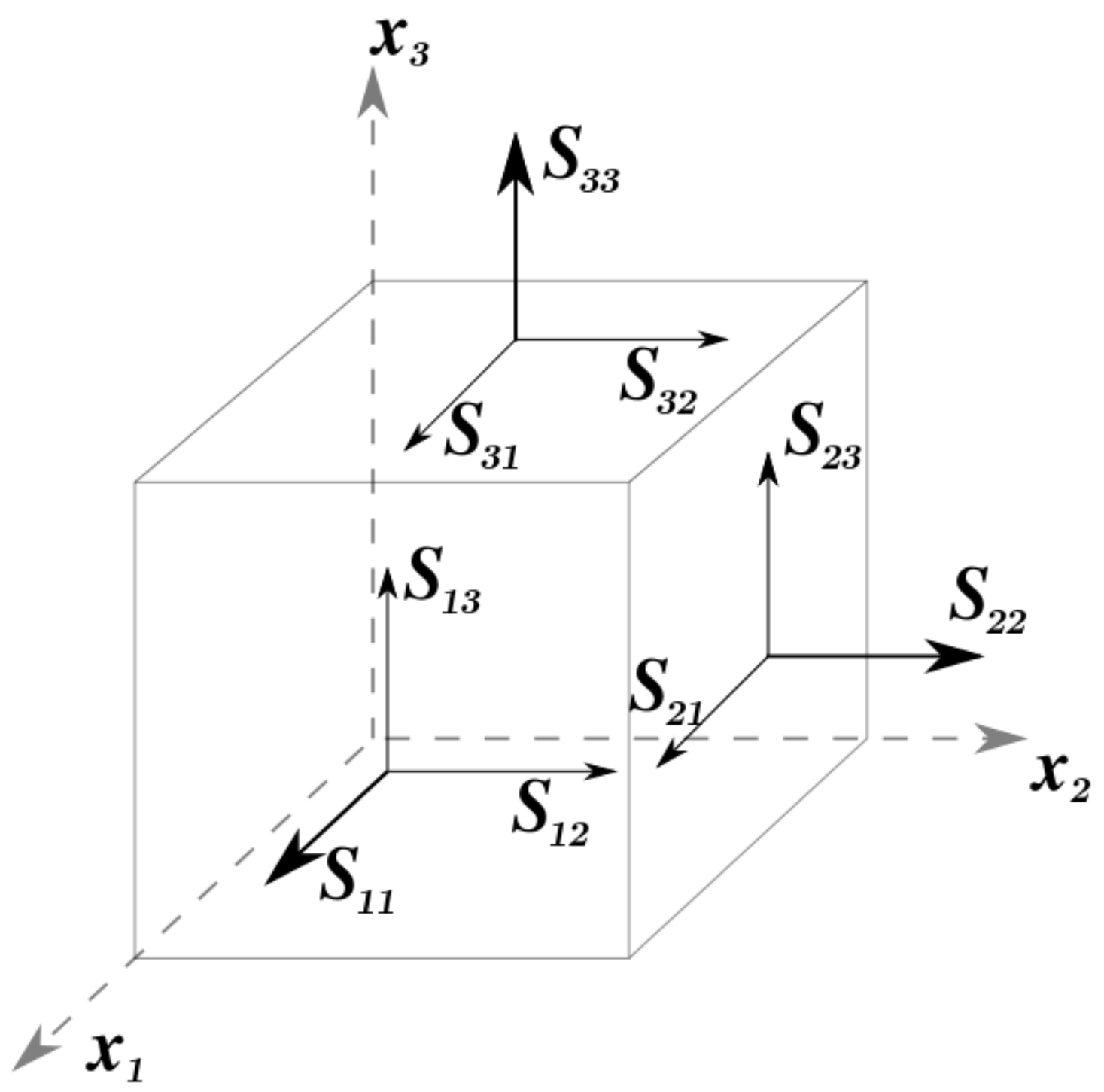

Figure 2.7: Stress directions for an infinitesimally small cube within the crust. Each set of axes represents stresses on faces of the cube normal to co-ordinate axes $\left(x_{1}, x_{2}, x_{3}\right)$ e.g. $S_{21}$ is stress on the face normal to $x_{2}$ in direction $x_{1}, S_{33}$ is stress on face normal to $x_{3}$ in direction $x_{3}$ etc. 
is expected to meet the Coulomb frictional-failure criteria (Eq. 2.16) when fracturing, where $\tau$ is the shear stress, $\sigma_{n}$ the effective normal stress, $\mu$ the coefficient of friction, $S_{n}$ the normal stress, and $P_{f}$ the pore fluid pressure. In a strike-slip regime, the optimal angle for the breaking of new rock is c. $30^{\circ}$ (Anderson, 1951). Sibson (1974) provides a formula for estimating the optimum angle between fault orientation and the orientation of $S_{1}$ for reactivation of the fault $(\gamma)$ that is dependent on the friction coefficient of the rock (Eq. 2.17). $\mu$ is expected to be within the range of $0.6-1.0$ for crustal rock (Byerlee, 1978), which gives a range of $\gamma=22-30^{\circ} \cdot \gamma$ values outside this range can be accounted for by high $P_{f}$ or low $\mu$.

$$
\begin{gathered}
\tau=\mu \sigma_{n}=\mu\left(S_{n}-P_{f}\right) \\
\gamma=\frac{1}{2} \tan ^{-1}(1 / \mu)
\end{gathered}
$$

\subsubsection{Directional statistics and significance tests}

Averages and standard deviations for $\phi$ are calculated using equations for averages found in Davis (1986).

The significance of correlations and null hypotheses throughout this work are quantified using their corresponding $\mathrm{P}$-values and the cut-off for significance $\mathrm{P} \leq 0.05$. The $\mathrm{P}$-value for a dataset indicates the probability that the null hypothesis is true. For correlations, the null hypothesis is that the correlation coefficient is zero. Thus for $\mathrm{P} \leq 0.05$ the null hypothesis can be rejected and the correlation coefficient is non-zero and it is assumed that the correlation between the two variables is significant i.e., not due to chance. For the two-sample statistical tests $\mathrm{P} \leq 0.05$ represents that the two datasets are significantly different.

A two-sample t-test (Eq. 2.18 Peck et al., 2005) compares the means and standard errors of $S_{H \max }$ and $\phi$ and determines the extent to which their confidence intervals overlap in the form of the "t-statistic", where $\bar{x}$ and $S E$ 
are the means and standard errors respectively. The "t-statistic" indicates the degree to which the normal distributions for the two data sets overlap and the sets are considered significantly different if $t \geq 1.96$ (95\% confidence for large N). This test is applicable for axial data as long as the difference between the mean values is less than $90^{\circ}$.

$$
t=\frac{\bar{x}_{1}-\bar{x}_{2}}{\sqrt{S E_{1}^{2}+S E_{2}^{2}}}
$$

The F-value (Eq. 2.19 Unglert et al., 2011) gives an indication of the fit of a number $(n)$ of stress orientation measurements $\left(S_{i}\right)$ with a mean fast direction $(\bar{\phi})$. This test does not include the errors of each measurement as the t-test does, but it is specifically for angular differences.

$$
F=\frac{\sum_{i=1}^{n}\left|\cos \left(\bar{\phi}-S_{i}\right)\right|}{n}
$$




\section{Chapter 3}

\section{Shear-wave splitting}

This chapter presents an analysis of shear-wave splitting measurements obtained with the data from the aforementioned aftershock sequence.

\subsection{The MFAST Package}

The MFAST package (Savage et al., 2010) is a fully automated shear-wave splitting tool that uses three distinct procedures to produce shear-wave splitting results from three component broadband seismograms for which the S-wave arrival times have been picked. We describe these in detail here (summarised from Savage et al. (2010) and the accompanying manual):

1. Filtering of the seismogram in order to find the best signal-to-noise (SNR)-bandwidth product;

2. Application of the Silver and Chan (SC91) shear wave splitting algorithm to perform a grid search of all potential $\phi$ and $\delta t$ pairs;

3. Repeating Step two for a series of different measurement windows and using cluster analysis (Teanby et al., 2004) to determine the most stable solution. 


\section{Filtering}

A series of two-pole Butterworth band-pass filters are applied separately to the waveform, creating 14 filtered versions of the waveform. In order for an event to be considered for processing, the signal to noise ratio (SNR) must be greater than 3 . The noise is taken as the frequency content within the 'noise window', a $3 \mathrm{~s}$ long time window that precedes the S-wave arrival pick by $0.05 \mathrm{~s}$ to allow for mis-picks. This gives an estimate of the noise present in the signal window. The signal is taken as the frequency content within the 'signal window', which is the same length as the noise window but it begins at $0.05 \mathrm{~s}$ before the S-pick. The window must start before the onset of the S-wave and be long enough to include the majority of the S-wave energy, but not so long that it includes too much energy from neighbouring phases. The SNR is calculated in the time domain and is the RMS of the signal divided by the RMS of the noise. The product of the SNR and the filter bandwidth for each filtered waveform is then calculated and used as a test parameter. Using this product as opposed to the SNR itself allows us to weight broader band signals more heavily and makes the results less prone to cycle skipping. The filter with the highest SNR-bandwidth product (Panel a of Figs. 3.1, 3.2 ) is used to analyse S-wave splitting in the next steps.

Figure 3.1: (next page) MFAST plots for 'A' grade measurement a) E,N,Z components of the filtered waveform with the S-pick marked by the black line and the splitting calculation window in grey. b) Particle motion direction ( $p$ and normal $p_{\perp}$ ) components of the waveform before and after splitting correction. Red line shows S-pick and dashed lines indicate the region over which the splitting window moved. c) Estimates of $\delta t, \phi$ for every splitting window used, blue cross marks most stable solution. d) Clustering of values for $\delta t, \phi$. e) Top: Rotated E,N waveforms before and after wave is 'unsplit' Bottom: Particle motion before and after wave is 'unsplit' f) Shows the contour of the errors for the splitting parameters. 


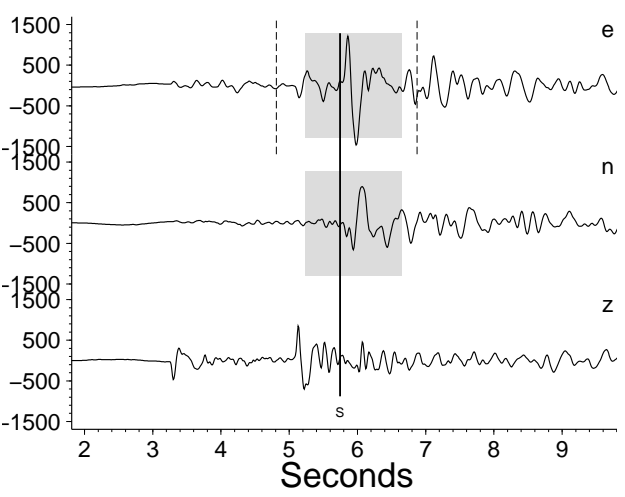

(a)

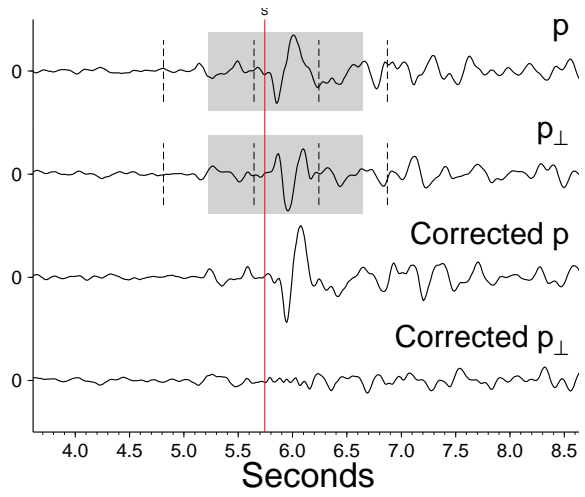

(b)
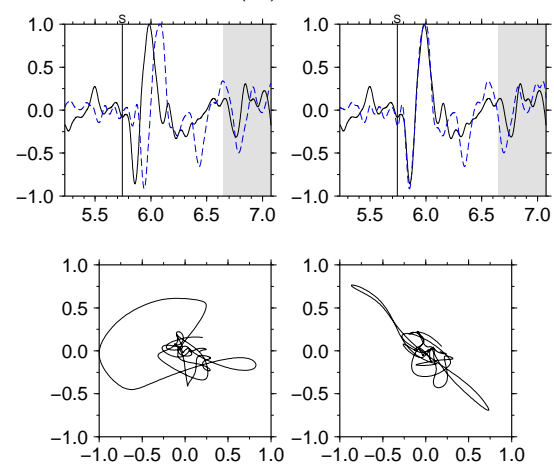

(c)

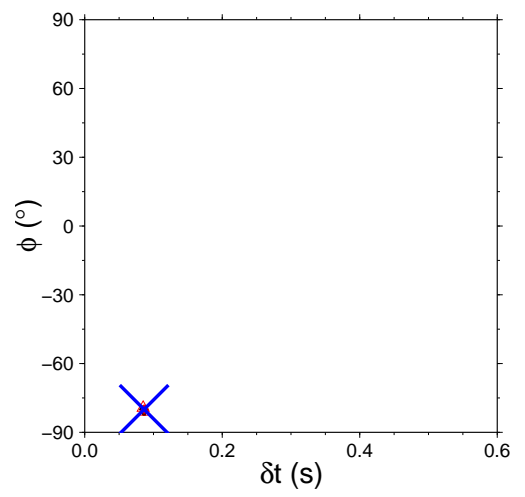

(d)

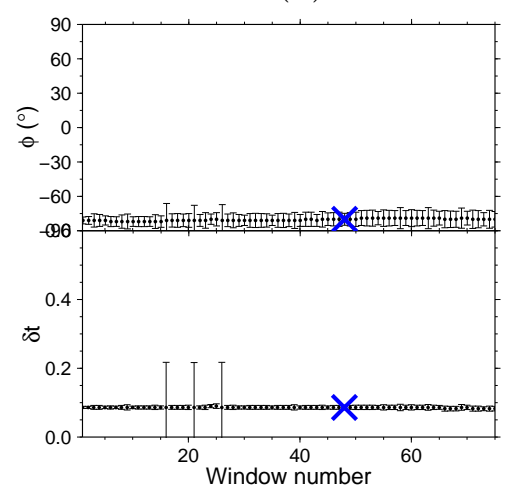

(e)

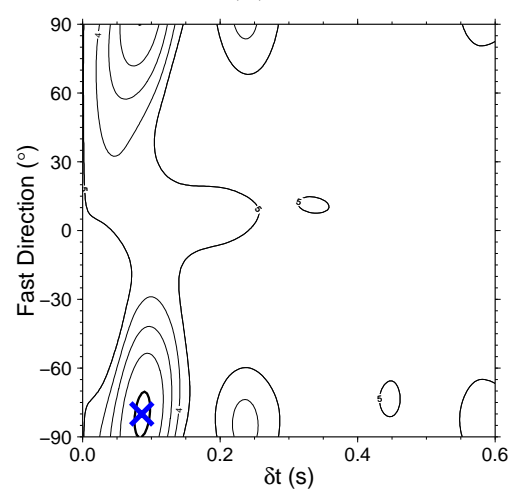

(f) 


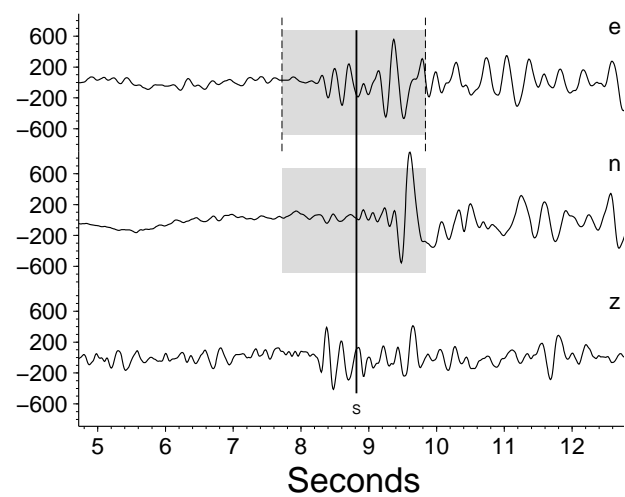

(a)

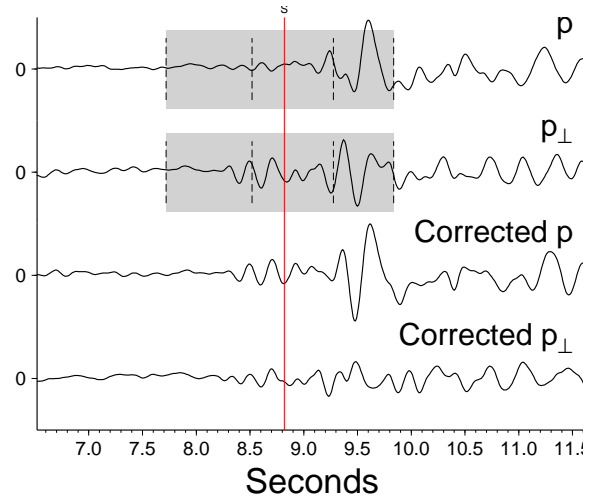

(b)
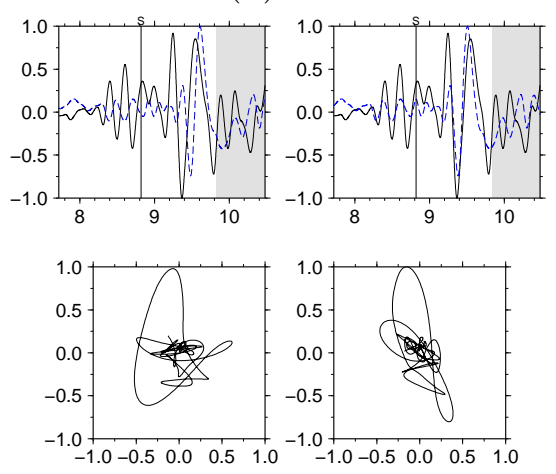

(c)

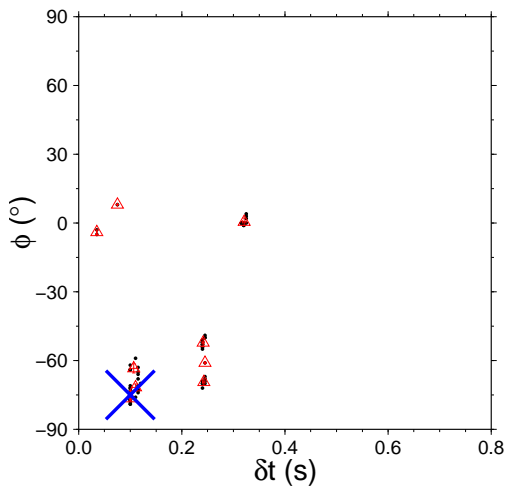

(d)

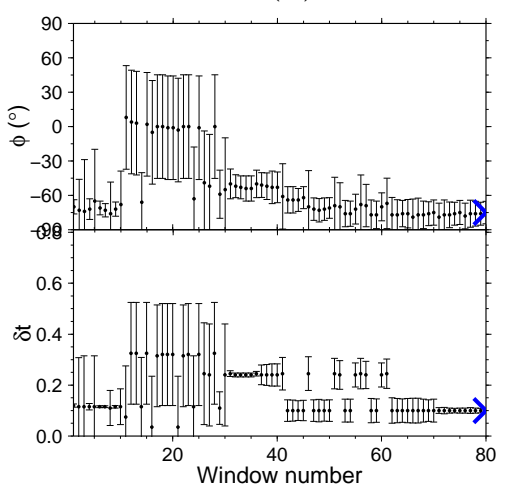

(e)

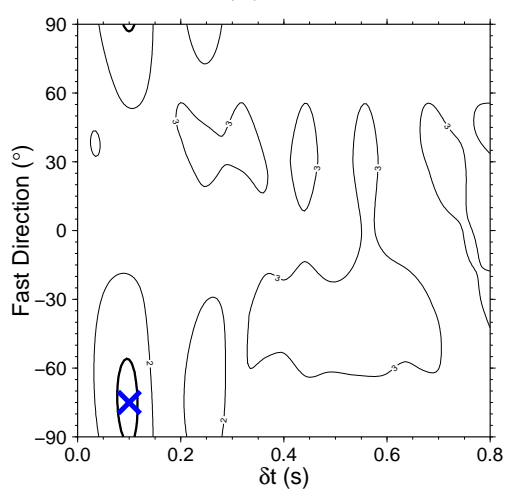

(f)

Figure 3.2: MFAST plots for 'C' grade measurement. See caption of Fig. 3.1 for explanation. 


\section{SC91 Algorithm}

Potential fast direction $(\phi)$ and delay time $(\delta t)$ pairs for the viable events are estimated by performing a grid search using the SC91 algorithm (Silver and Chan 1991) over all possible fast orientations in $1^{\circ}$ increments and delay times from 0.0 to 1.0 seconds in $0.01 \mathrm{~s}$ increments. Each pair of $\phi, \delta t$ is used to un-split the waveform, by rotating the original into the trial fast and slow directions and the slow waveform is shifted forward in time by $\delta t$ (Panels b, e of Figs. 3.1, 3.2). Then the eigenvalues of the co-variance matrix of the corrected waveform are calculated and the pair that has the smallest minimum eigenvalue is chosen (blue cross in Figs. 3.1, 3.2). This is equivalent to choosing the most linear particle motion.

\section{Initial polarisations from splitting measurements}

The initial polarisation $\left(\beta_{S W S}\right)$ is the estimate of the S-wave polarisation before splitting. $\beta_{S W S}$ is calculated from the largest/smallest eigenvectors $\left(b_{1}, b_{2}\right)$ of the covariance matrix. It is analogous to solving a least squares problem, essentially estimating a line of best fit for the particle motion hodogram. The azimuth of the linearised motion yields the difference between $\beta_{S W S}$ and $\phi$ (Fig. 3.3), thus $\beta_{S W S}$ can be determined from $\phi$ as an angle clockwise from North by adding $\phi$ to the difference. The error $\left(\beta_{\text {SW S.ERR }}\right)$ is calculated using the smallest/largest eigenvalues $\left(l_{\min }, l_{\max }\right)$ in Eq. 3.2 .

$$
\begin{gathered}
\beta_{S W S}=\tan ^{-1}\left(b_{1} / b_{2}\right)+\phi \\
\beta_{\text {SWS.ERR }}=\tan ^{-1}\left(l_{\min } / l_{\max }\right)
\end{gathered}
$$

\section{Cluster analysis}

The estimated values can be dependent on the measurement window. The most stable of these pairs are determined using the method of Teanby et al. (2004), which performs measurements for numerous window configurations 
a) b)
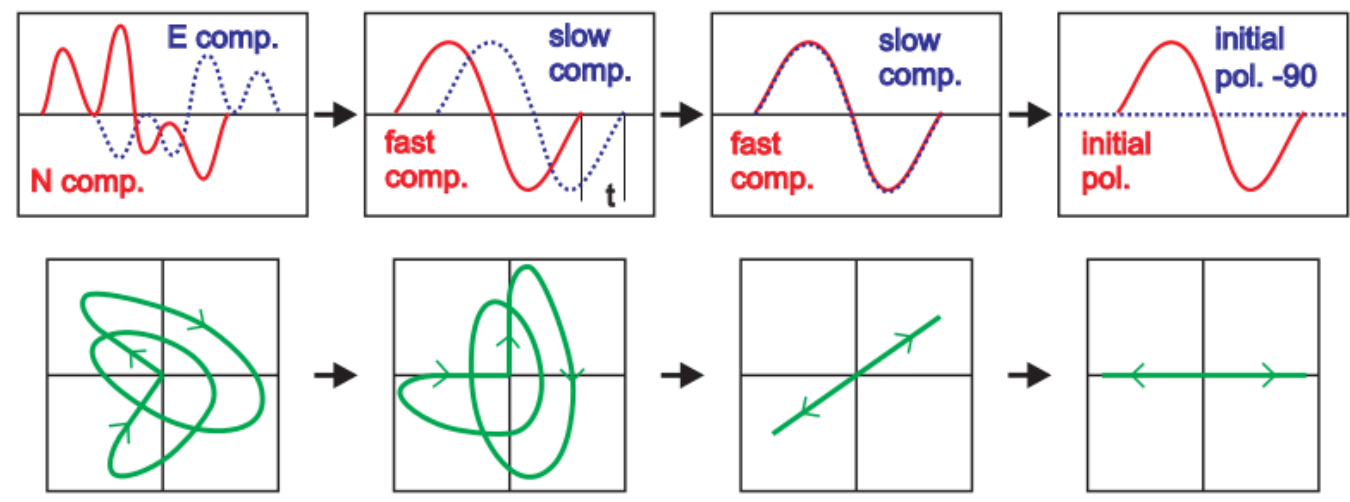

Figure 3.3: Rotation and time-shifting to find $\beta_{S W S}$. a) original E,N component waveforms (Top) and corresponding particle motion (Bottom). b) waveforms rotated to the fast direction. c) waveforms are shifted by $\delta t . \mathrm{d}$ ) waveforms rotated $\beta_{S W S}$ (figure from Gerst, 2003).

and then uses cluster analysis to determine the most stable cluster of measurements and selects the measurement with the smallest error within this cluster as the result (Panels c,d Figs. 3.1,3.2).

\subsubsection{Sources of error/uncertainty}

\section{Cycle-skipping}

Cycle-skipping occurs when the peaks of the fast and slow waveforms are mismatched by an integer number of half-cycles. This potentially results in larger $\delta t$ and $90^{\circ}$ flips in $\phi$. The expected delay times for cycle-skipped measurements $\left(\delta t_{C S}\right)$ can be determined using the dominant frequency of the shear-wave $\left(f_{s}\right)$ and the number of half-cycles $(n)$ :

$$
\delta t_{C S}=\delta t \pm \frac{n}{f_{s}} \quad(n=1,2,3 \ldots)
$$

To avoid cycle skipping, MFAST chooses time windows that include some of the signal before the S-wave onset so the peaks can be matched accurately 
(Fig. 3.4). Also, if there are two or more distinct clusters i.e. two large clusters with a similar number of measurements within them and significantly different splitting results, they are given a lower grade.
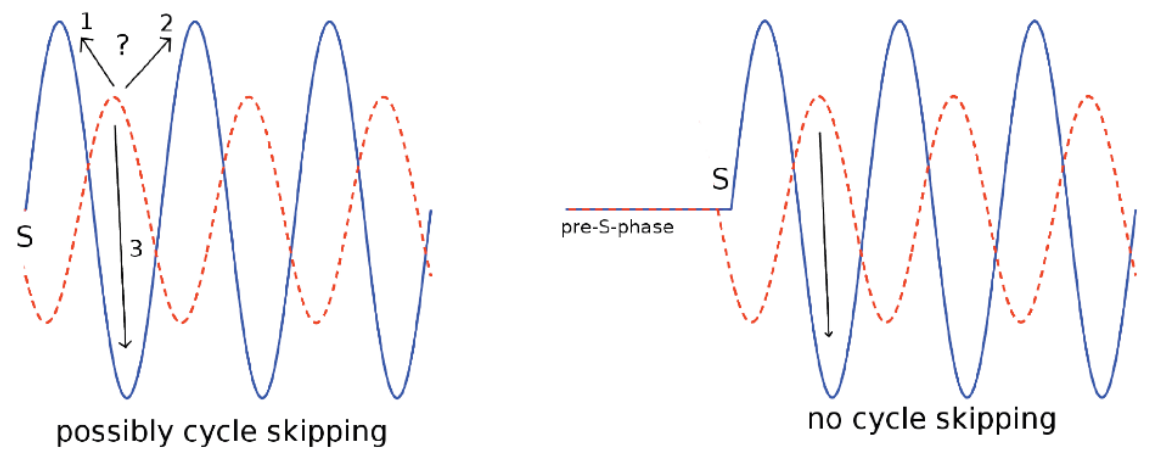

Figure 3.4: Diagram illustrating ambiguity related to cycle skipping (figure from Wessel, 2010). Noise in pre-S-phase, signal in S-phase

\section{Null measurements}

If an incoming wave hits an anisotropic medium with initial polarisation parallel to the fast direction of anisotropy, there is no splitting as the wave passes between the crack/mineral planes (or layers) parallel to them and there is no perpendicular (slow) component. There is also no splitting if the wave hits an anisotropic medium with perpendicular polarisation as the wave cancels out. Therefore, if the difference between $\beta_{S W S}$ and $\phi$ is not between $20^{\circ}$ and $70^{\circ}$, no splitting is anticipated and the result is considered a null. Null measurements are also indicative of isotropic media, thus a large percentage of nulls indicates an isotropic medium, particularly if $\phi$ is variable also. 


\section{Shear-wave window/Angles of incidence}

The shear-wave window is defined by the critical angle $\left(i_{c}\right)$ within which events are not susceptible to $S$-to- $P$ conversion $(N u t t l i, 1961)$, which can affect shear-wave splitting measurements (Booth and Crampin, 1985). It is calculated using the $V_{P} / V_{S}$-ratio (Eq. 3.4) and for the study region is approximately $37^{\circ}$. Events with an angle of incidence greater than $i_{c}$ are left out for the reasons described above. Angles of incidence $i_{t}$ are calculated in MFAST using the TauP tool kit (Crotwell et al., 1998), which uses Snell's Law (Eq. 3.5, $p$ is ray parameter), and a 1D velocity model which was derived from the recent 3D velocity model of New Zealand (Eberhart-Phillips et al., 2010). Straight-line angles of incidence $\left(i_{s}\right)$ are also calculated using the relocated depths/distances with the Pythagorean theorem (Eq. 3.6, $d$ is distance and $z$ is depth). This is used as a further restriction on the data as $i_{t}$ only accounts for the incidence on the layer at the surface, whereas $i_{s}$ gives a rough estimate of its average trajectory across the entire raypath and results with large $i_{s}$ may be affected by horizontal layering (Fig. 3.5). Previous studies have used a straight-line angle of incidence of $45^{\circ}$ (Peng and Ben-Zion, 2004; Cochran et al., 2003) and Gledhill (1991) pointed out that the window increases with depth due increasing velocity. This study uses $i_{s} \leq 60^{\circ}$ as all the earthquakes have $i_{t} \leq i_{c}$ due to low surface velocities and this provides some restriction while still allowing a reasonable amount of data to analyse.

$$
\begin{aligned}
& i_{c}=\sin ^{-1}\left(\frac{V_{S}}{V_{P}}\right) \\
& i_{t}=\sin ^{-1}\left(\frac{p V_{S}}{111}\right) \\
& i_{s}=\sin ^{-1}\left(\frac{d}{z}\right)
\end{aligned}
$$



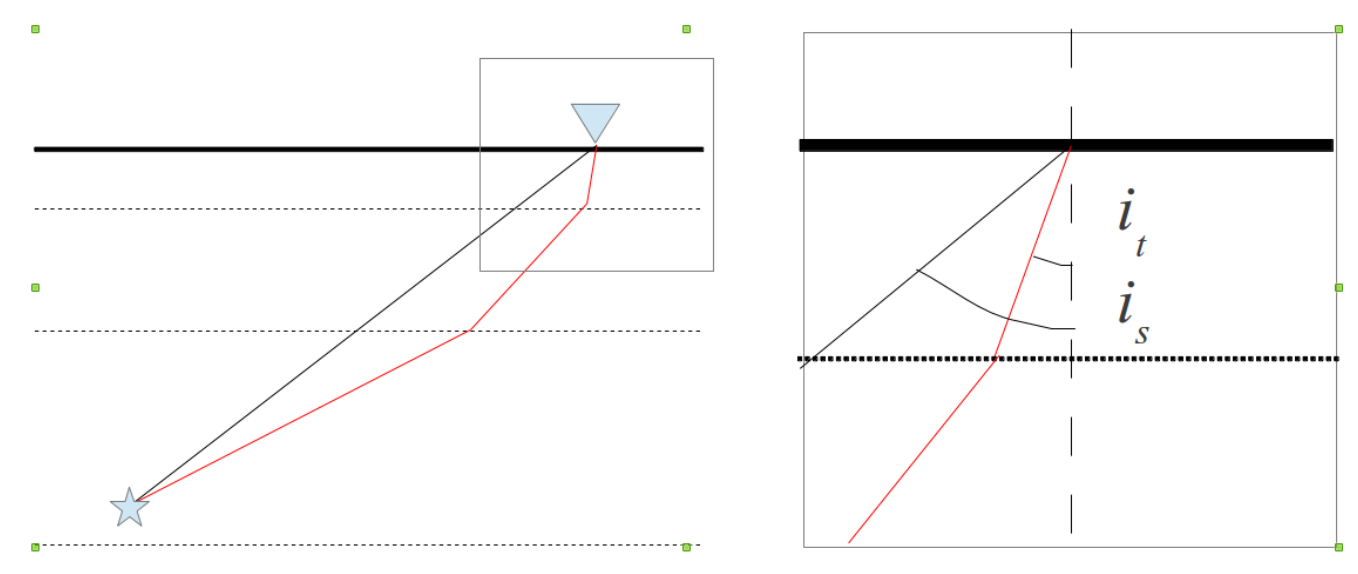

Figure 3.5: Diagram of $i_{t}$ and $i_{s}$, determined by Eqs. 3.5,3.6. Star marks earthquake, triangle marks station, horizontal lines mark boundaries of layers of different velocities.

\section{Grading}

The estimates of $\phi$ and $\delta t$ are automatically graded based on SNR, uncertainty, and distinctiveness of the cluster/s. Lower grades are given to results with more than one distinct cluster in order to limit instances of cycleskipping. A more detailed explanation of this method was given by Savage et al. (2010). Only events with an automatic grade of "B" or higher are used in this study.

\subsubsection{Restriction of $\delta t$ measurements}

The ranges for the grid search used in this study are $\pm 90^{\circ}$ for $\phi$ and $0-1$ $\mathrm{s}$ for $\delta t$. Only results for $\delta t \leq 0.4 \mathrm{~s}$ are considered, as this is the maximum expected value for crustal anisotropy (Savage et al., 2010). This limit appears sufficient as further restriction of $\delta t$ does not reduce scatter of $\phi$. 


\subsection{3 $\delta t$ tomography}

2D $\delta t$ tomography is calculated using the TESSA package (Johnson et al., 2011) to model the anisotropy in the region. The result is a first-order approximation and represents contrasts in $\delta t$ rather than accurate values. A regular grid with $5 \times 5 \mathrm{~km}$ spacing was used as smaller grids did not significantly alter the results but did reduce the resolution of the data. We use all the blocks with $\geq 20$ (for all data) or $\geq 10$ (for $i_{s} \leq 60^{\circ}$ dataset) rays passing through them (this gives a reliable mean for spatial averaging) to find an initial solution to the least squares problem using lsqlin in Matlab ${ }^{\mathrm{TM}}$. lsqlin then converges on a final solution subject to the constraints that: each grid block has anisotropy $0 \mathrm{~s} / \mathrm{km}$ or greater; and $\delta t$ cannot exceed the maximum $\delta t$ for a single block length. TESSA uses the simplification of $\delta t$ being additive and that all the anisotropy is along the ray-path. Only relocated events are used with TESSA, because accurate hypocentres are required to restrict the data by $i_{s} \leq 60^{\circ}$. The consistency of the features of the $\delta t$ tomography are tested using a "jack-knife test", where a percentage of the data is randomly selected and used to create new results for comparison with the results from the full dataset. Here we use a $50 \%$ jack-knife test where the data is randomly divided into two different sets and the results are compared with each other and the full set. Consistency of features is also tested by moving the grid by $\pm 1 \mathrm{~km}$ increments.

The correlation between $\delta t$ and seismicity (earthquake density) was tested for a quadtree grid. The quadtree grid algorithm (previously used by Townend and Zoback, 2001, 2004; Johnson et al., 2011) iteratively divides the study area into a grid according to the event locations. Grid spaces are divided into smaller spaces when they exceed the maximum number of events allowed in a grid space (50 in this case) until no spaces exceed the maximum or the grid spaces reach the minimum size ( $5 \times 5 \mathrm{~km}$ from the $\delta t$ grid described above). The average $\delta t$ in each grid space within the area of statistical significance was plotted against the density of earthquakes for that grid and the significance of the correlation was determined by the P-value. 


\subsubsection{Spatial averaging of $\phi$}

The spatial averaging is also done using the TESSA package (Johnson et al., 2011). It uses the same grid as the $\delta t$ tomography and the method of Audoine et al. (2004) and assigns weights to each $\phi$ node within a given grid block. Rose diagrams (circular histograms) of $\phi$ are plotted in each of the grid blocks and a mean is also plotted if the standard deviation of the data is less than $30^{\circ}$ and the standard error of the mean is less than $10^{\circ}$.

Four different weighting schemes are available. A distance $(d)$ based weighting of $1 / d^{2}$ is used here, as splitting is expected to occur later in the ray-path (Nistala and McMechan, 2005) i.e. the closer a node is to a station, the more likely that it accurately represents the splitting seen there.

\subsubsection{Calculation of $V_{P} / V_{S}$-ratios}

$V_{P} / V_{S}$-ratios were calculated as the ratio of $P$ and $S$ travel times $\left(t_{P}, t_{S}\right)$ on each seismogram, using the method of Nur (1972) (Eq. 3.7). Only high quality $S$-wave manual picks $(1,2)$ were used as the accuracy of the arrival time is less reliable for lower grades. It is assumed that the $P$-wave picks are of uniformly good quality as it is almost always the case that when there is a clear $S$-wave arrival that there is also a clear $P$-wave arrival. Only $V_{P} / V_{S^{-}}$ ratios between 1.5 and 2.0 were considered, as values outside this range are not expected anywhere in New Zealand (Eberhart-Phillips et al., 2010) and would most likely be due to inaccurate arrival time picks. The percentage of values outside this range for all stations was negligible $(\approx 1 \%)$.

$$
\frac{V_{P}}{V_{S}}=\frac{t_{S}}{t_{P}}
$$




\subsection{Results and Discussion}

\subsection{1 $\phi$ on the Canterbury plains}

The majority of the Canterbury aftershock sequence occurred in the uppercrustal seismogenic zone (top $5-25 \mathrm{~km}$ of the crust). Fig. 3.6 shows the rose diagrams (circular histograms) for $\phi$ plotted at all stations. The vast majority of $\phi$ measurements appear parallel/sub-parallel to the maximum horizontal compressive stress $\left(S_{H \max }\right)$ expected from previous studies. Stations along the fault do not give a clear indication of whether the anisotropy is stress or fault controlled. Dar4 and Dar8 are parallel to both, and Dar6 shows a range of E-W and stress parallel measurements. However Dar7 indicates stress-parallel anisotropy.

All events had $i_{c} \leq 37^{\circ}$ and thus were within the shear wave window (see Section 3.1.1). Restricting data by $i_{s} \leq 60^{\circ}$ results in some reduction of scatter of $\phi$. While some stations do exhibit a significant difference in mean fast direction for the two datasets (All data and $i_{s} \leq 60^{\circ}$, see Tables $3.1,3.2$ ), it is of only a few degrees in most cases, except for stations CARD, MCHD, and OXZ. Stations CARD and OXZ appear predominantly aligned with nearby faults in the Southern Alps for $i_{s} \leq 60^{\circ}$ (Fig. 3.6).

MCHD has a mean fast direction ( $\bar{\phi}$, see Table 3.1$)$ that is not comparable with neighbouring stations when considering all data (Fig. 3.6 upper plot). This is due an azimuthal dependence of $\phi$. Fig. 3.7 shows that for station MCHD, events emanating from the fault zone yield predominantly faultparallel $\phi$ at station Dar6 (Fig. 3.7), and those from the West are parallel to $\bar{\phi}$ at station STLD (Fig. 3.8). Thus, the $\phi$ measurements would be representative of anisotropy in their source regions (as seen by Zinke and Zoback (2000) for the Calaveras Fault), suggesting that there is an isotropic volume surrounding MCHD. However, it could also represent incidents of P-SV conversion near the surface, as the majority of $\phi$ measurements are sub-parallel to the back-azimuth. These two possibilities are both valid due to the location of MCHD and are not mutually exclusive. However, isotropy is less 
likely as splitting is probably due to vertical micro-cracks/mineral alignment, thus it should occur nearer the station for shallow earthquakes. 

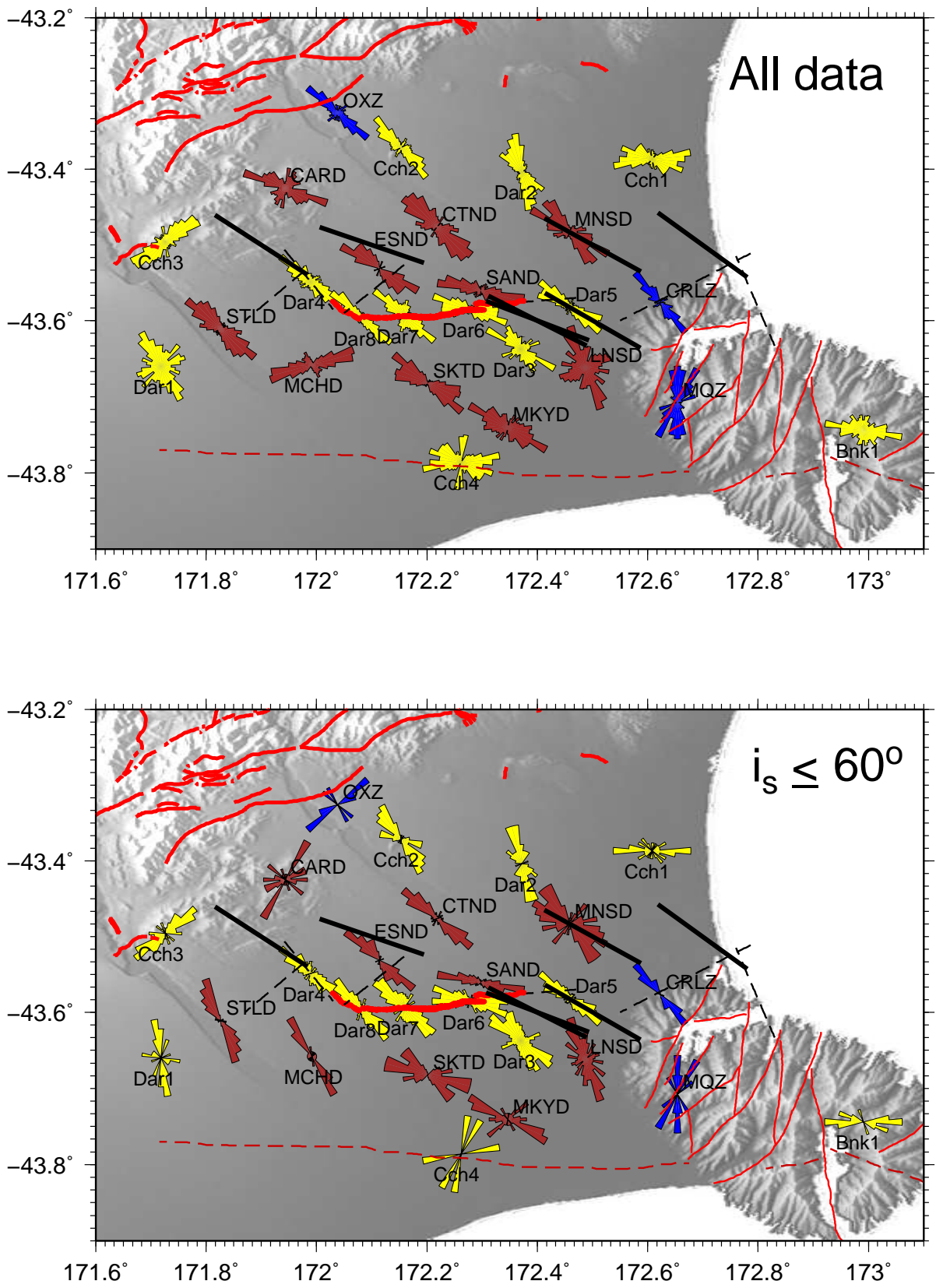

Figure 3.6: Rose diagrams for all $\phi$ and for $\phi$ with $i_{s} \leq 60^{\circ}$ : Universities (yellow) temporary stations ; permanent (blue) and temporary (brown) GeoNet sites. Solid black lines are $S_{H \max }$ estimates from Townend et al. (2012). Solid red lines are faults, with the Greendale fault in the centre from (Quigley et al., 2010). Thin and dashed red lines are active faults and late Cretaceous normal faults respectively (Ring and Hampton, 2012). Dashed black lines are buried faults from (Beavan et al., 2010, 2011). 


\begin{tabular}{|c|c|c|c|c|c|c|c|c|c|}
\hline Station & $\mathrm{N}$ & $\bar{\phi}\left({ }^{\circ}\right)$ & $\operatorname{Stdev}(\phi)$ & $95 \%$ conf. $(\phi)$ & mean $\delta t(\mathrm{~s})$ & $\operatorname{Stdev}(\delta t)$ & $95 \%$ conf. $(\delta t)$ & baz.perp $\%$ & baz.para\% \\
\hline Bnk1 & 341 & 106.6 & 50.2 & 10.1 & 0.165 & 0.086 & 0.009 & 17.3 & 31.1 \\
\hline Cch1 & 492 & 98.1 & 36.3 & 3.8 & 0.126 & 0.078 & 0.007 & 13.0 & 15.0 \\
\hline Cch2 & 304 & 132.1 & 36.9 & 5.1 & 0.153 & 0.082 & 0.009 & 14.1 & 23.7 \\
\hline Cch3 & 278 & 49.5 & 38.6 & 5.7 & 0.122 & 0.087 & 0.010 & 17.3 & 16.5 \\
\hline Cch4 & 538 & 99.2 & 47.2 & 6.7 & 0.183 & 0.109 & 0.009 & 29.0 & 17.8 \\
\hline Dar1 & 432 & 153.2 & 65.1 & 25.8 & 0.135 & 0.076 & 0.007 & 19.7 & 23.8 \\
\hline Dar2 & 451 & 157.4 & 30.8 & 3.1 & 0.125 & 0.089 & 0.008 & 7.8 & 16.4 \\
\hline Dar3 & 393 & 135.7 & 47.5 & 7.9 & 0.136 & 0.110 & 0.011 & 5.6 & 19.3 \\
\hline Dar4 & 584 & 129.0 & 39.0 & 4.1 & 0.153 & 0.096 & 0.008 & 15.1 & 19.5 \\
\hline Dar5 & 501 & 125.2 & 29.8 & 2.8 & 0.153 & 0.084 & 0.008 & 5.0 & 9.4 \\
\hline Dar6 & 641 & 101.1 & 30.6 & 2.6 & 0.119 & 0.079 & 0.006 & 4.5 & 17.3 \\
\hline Dar7 & 625 & 138.5 & 40.7 & 4.3 & 0.136 & 0.080 & 0.006 & 14.1 & 13.4 \\
\hline Dar8 & 558 & 133.5 & 30.7 & 2.8 & 0.151 & 0.081 & 0.007 & 12.5 & 10.4 \\
\hline CARD & 334 & 111.4 & 55.0 & 13.9 & 0.190 & 0.097 & 0.011 & 21.6 & 37.4 \\
\hline CTND & 241 & 133.8 & 33.6 & 4.8 & 0.118 & 0.099 & 0.013 & 4.1 & 12.4 \\
\hline ESND & 116 & 131.7 & 24.5 & 4.5 & 0.095 & 0.066 & 0.012 & 5.2 & 20.7 \\
\hline LNSD & 342 & 151.9 & 61.1 & 21.2 & 0.137 & 0.089 & 0.010 & 9.6 & 12.0 \\
\hline MCHD & 442 & 81.2 & 36.9 & 4.2 & 0.135 & 0.081 & 0.008 & 2.3 & 60.9 \\
\hline MKYD & 329 & 115.9 & 42.0 & 6.3 & 0.134 & 0.097 & 0.011 & 21.6 & 16.7 \\
\hline MNSD & 432 & 126.1 & 35.2 & 3.9 & 0.119 & 0.076 & 0.007 & 9.5 & 14.1 \\
\hline SAND & 416 & 104.1 & 32.4 & 3.5 & 0.132 & 0.091 & 0.009 & 4.1 & 11.1 \\
\hline SKTD & 457 & 117.6 & 26.8 & 2.5 & 0.118 & 0.073 & 0.007 & 17.3 & 10.5 \\
\hline STLD & 580 & 131.4 & 34.0 & 3.2 & 0.123 & 0.083 & 0.007 & 17.4 & 19.5 \\
\hline CRLZ & 204 & 135.3 & 32.5 & 5.0 & 0.187 & 0.080 & 0.011 & 6.9 & 8.3 \\
\hline MQZ & 374 & 24.3 & 43.0 & 6.3 & 0.115 & 0.081 & 0.008 & 35.6 & 7.8 \\
\hline OXZ & 275 & 128.3 & 39.8 & 6.2 & 0.176 & 0.104 & 0.013 & 12.0 & 40.0 \\
\hline
\end{tabular}

Table 3.1: Data for all angles of incidence. Mean values of $\phi$ and $\delta t$ for all stations and percentages of events within $\pm 20^{\circ}$ of being parallel (baz.para\%) or perpendicular (baz.perp\%) to $\phi$. N is number of measurements. Stdev is standard deviation. 95\% confidence interval taken as twice the standard error. 


\begin{tabular}{|c|c|c|c|c|c|c|c|c|c|}
\hline Station & $\mathrm{N}$ & $\bar{\phi}\left(^{\circ}\right)$ & $\operatorname{Stdev}(\phi)$ & $95 \%$ conf. $(\phi)$ & mean $\delta t(\mathrm{~s})$ & $\operatorname{Stdev}(\delta t)$ & $95 \%$ conf. $(\delta t)$ & baz.perp $\%$ & baz.para\% \\
\hline Bnk1 & 10 & 98.8 & 21.2 & 13.2 & 0.110 & 0.101 & 0.064 & 30.0 & 20.0 \\
\hline Cch1 & 22 & 93.2 & 37.7 & 19.6 & 0.143 & 0.090 & 0.039 & 40.9 & 13.6 \\
\hline Cch2 & 48 & 130.0 & 28.3 & 8.4 & 0.176 & 0.097 & 0.028 & 31.3 & 6.3 \\
\hline Cch3 & 37 & 51.0 & 33.9 & 12.5 & 0.140 & 0.113 & 0.037 & 29.7 & 18.9 \\
\hline Cch4 & 3 & 31.3 & 35.5 & 47.4 & 0.233 & 0.134 & 0.155 & 33.3 & 0.0 \\
\hline Dar1 & 17 & 162.1 & 37.2 & 21.6 & 0.084 & 0.046 & 0.022 & 17.6 & 17.6 \\
\hline Dar2 & 33 & 162.9 & 30.4 & 11.2 & 0.126 & 0.083 & 0.029 & 12.1 & 36.4 \\
\hline Dar3 & 201 & 138.8 & 41.5 & 7.9 & 0.134 & 0.118 & 0.017 & 21.9 & 22.4 \\
\hline Dar4 & 91 & 132.4 & 35.2 & 8.5 & 0.165 & 0.115 & 0.024 & 15.4 & 27.5 \\
\hline Dar5 & 268 & 126.1 & 32.2 & 4.3 & 0.174 & 0.104 & 0.013 & 10.8 & 28.7 \\
\hline Dar6 & 339 & 99.8 & 31.4 & 3.6 & 0.135 & 0.099 & 0.011 & 8.8 & 36.6 \\
\hline Dar7 & 138 & 139.3 & 39.7 & 8.7 & 0.149 & 0.093 & 0.016 & 23.2 & 20.3 \\
\hline Dar8 & 88 & 137.9 & 31.3 & 7.1 & 0.195 & 0.110 & 0.024 & 30.7 & 11.4 \\
\hline CARD & 37 & 64.0 & 45.2 & 22.6 & 0.268 & 0.152 & 0.050 & 32.4 & 24.3 \\
\hline CTND & 92 & 131.4 & 29.4 & 6.4 & 0.110 & 0.103 & 0.022 & 23.9 & 21.7 \\
\hline ESND & 37 & 139.7 & 21.5 & 7.0 & 0.081 & 0.065 & 0.021 & 10.8 & 32.4 \\
\hline LNSD & 182 & 158.9 & 44.9 & 10.1 & 0.107 & 0.070 & 0.010 & 18.7 & 34.1 \\
\hline MCHD & 28 & 140.7 & 33.3 & 14.0 & 0.081 & 0.057 & 0.022 & 10.7 & 32.1 \\
\hline MKYD & 36 & 101.2 & 41.9 & 19.1 & 0.202 & 0.154 & 0.051 & 41.7 & 11.1 \\
\hline MNSD & 136 & 121.6 & 40.4 & 9.1 & 0.119 & 0.090 & 0.015 & 23.5 & 14.7 \\
\hline SAND & 267 & 102.9 & 26.8 & 3.3 & 0.108 & 0.078 & 0.010 & 9.4 & 40.4 \\
\hline SKTD & 98 & 108.3 & 27.9 & 5.8 & 0.104 & 0.064 & 0.013 & 17.3 & 5.1 \\
\hline STLD & 54 & 146.7 & 19.6 & 5.3 & 0.082 & 0.044 & 0.012 & 9.3 & 7.4 \\
\hline CRLZ & 27 & 141.0 & 12.6 & 4.8 & 0.163 & 0.062 & 0.024 & 3.7 & 7.4 \\
\hline MQZ & 8 & 8.3 & 27.1 & 19.5 & 0.110 & 0.056 & 0.039 & 0.0 & 0.0 \\
\hline OXZ & 6 & 64.4 & 42.1 & 47.2 & 0.105 & 0.063 & 0.051 & 33.3 & 16.7 \\
\hline
\end{tabular}

Table 3.2: Data for angles of incidence $i_{s} \leq 60^{\circ}$. Mean values of $\phi$ and $\delta t$ for all stations and percentages of events within $\pm 20^{\circ}$ of being parallel (baz.para\%) or perpendicular (baz.perp\%) to $\phi$. N is number of measurements. Stdev is standard deviation. $95 \%$ confidence interval taken as twice the standard error. 

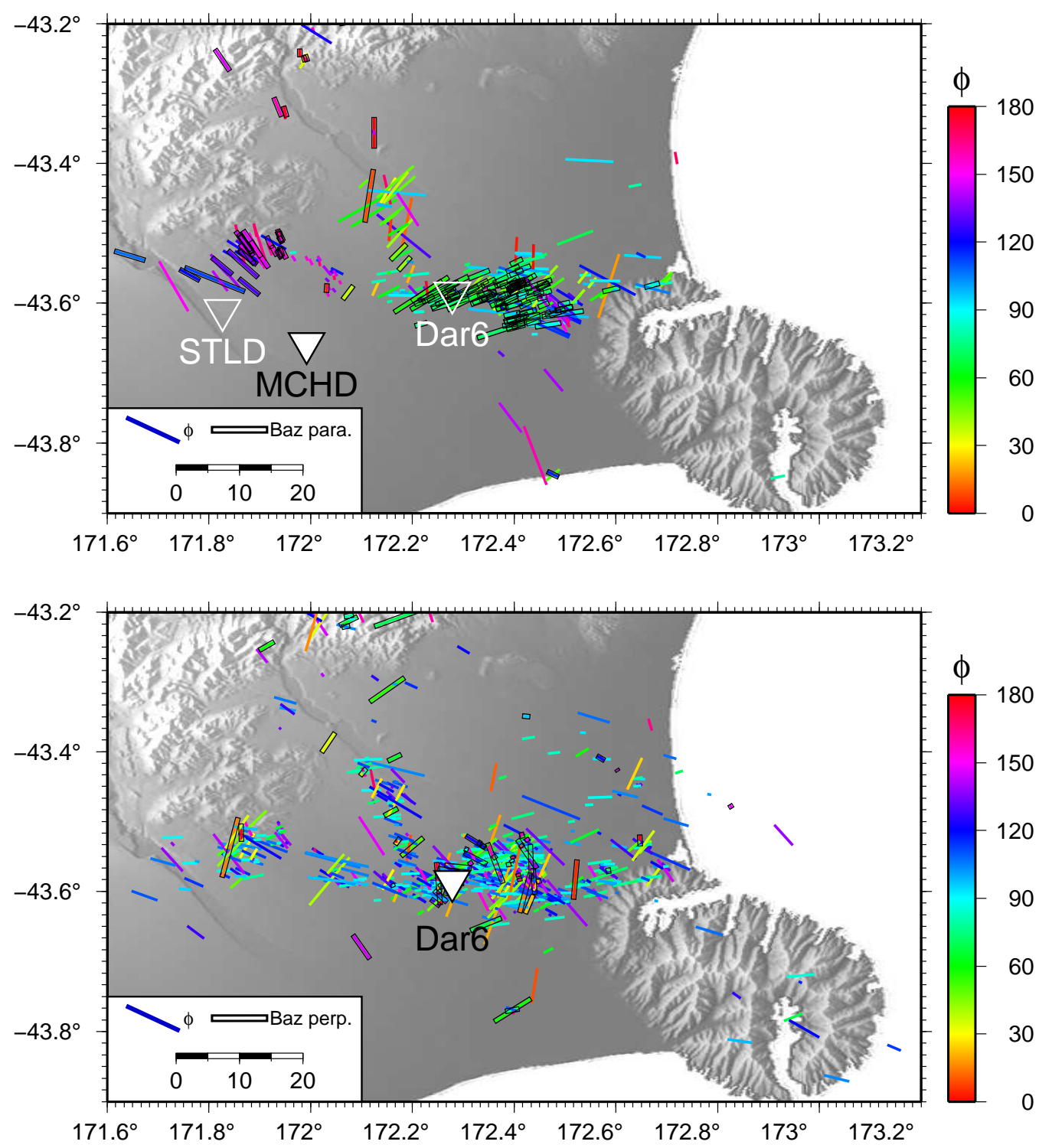

Figure 3.7: $\phi$ plotted at event location for station MCHD (upper) and Dar6 (lower). Length of vectors represents $\delta t$, max length is $0.4 \mathrm{~s}$ (length of vectors in the key). Triangles are station locations. Vectors with a black outline are either within $\pm 20^{\circ}$ of being parallel (Baz para) or perpendicular (Baz perp) to back azimuth (see key). 

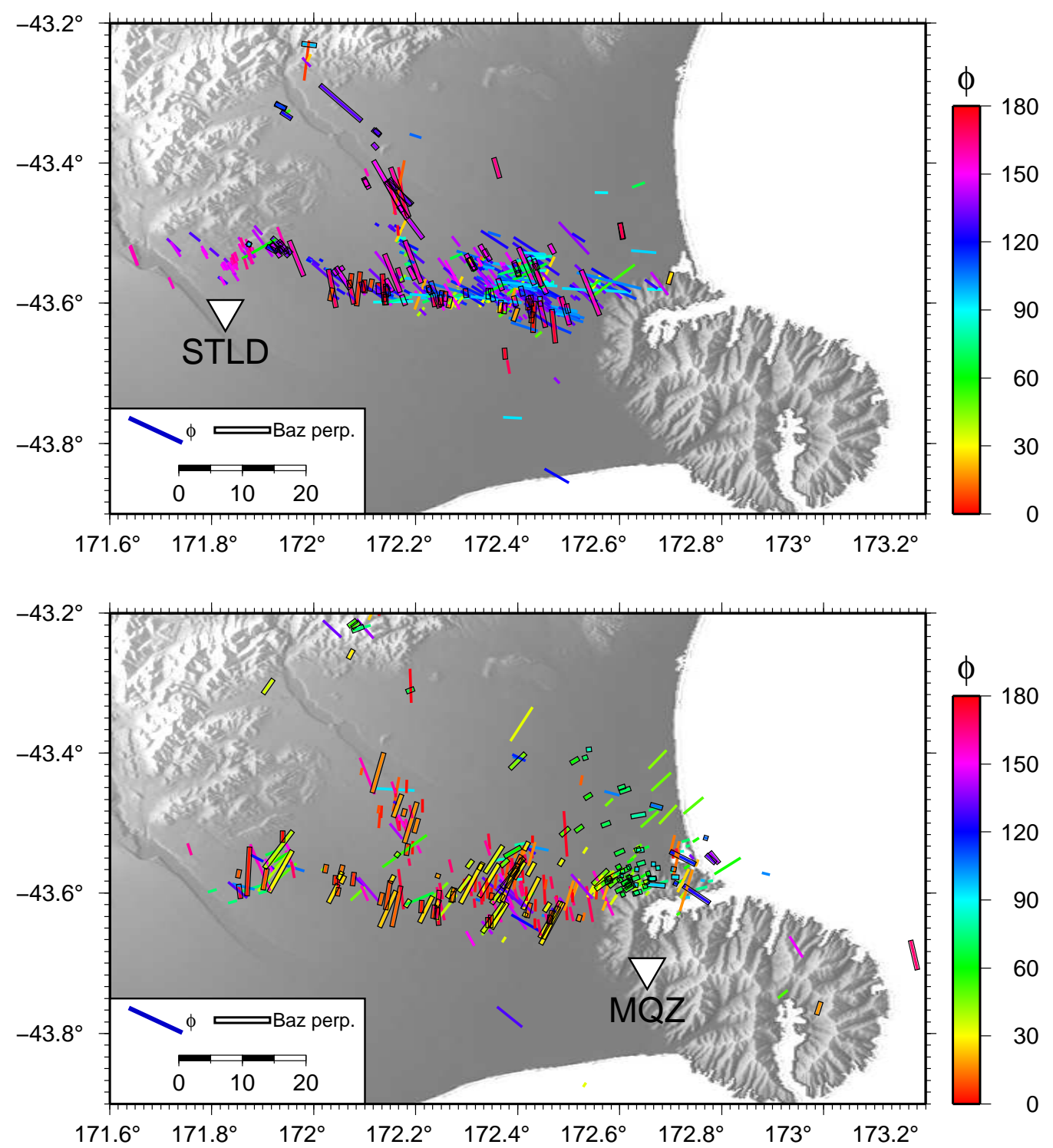

Figure 3.8: $\phi$ plotted at event location for station STLD (upper) and MQZ (lower). Length of vectors represents $\delta t$, max length is $0.4 \mathrm{~s}$ (length of vectors in the key). Triangles are station locations. Vectors with a black outline are either within $\pm 20^{\circ}$ of being parallel (Baz para) or perpendicular (Baz perp) to back azimuth (see key). 
$\bar{\phi}$ for most stations in both groups are between $81.2^{\circ}-157^{\circ}$ (Fig. 3.6), suggesting either alignment with the regional stress field $\left(115^{\circ}\right.$, see Introduction) or the E-W strike of the fault. The two exceptions are stations Cch3 and MQZ. Anisotropy at station Cch3 is sub-parallel to the strike of a nearby unnamed fault. When events recorded at station MQZ are mapped at their epicentres (Fig. 3.8), a significant percentage of $\phi$ (c. 36\%, see Table 3.1) are approximately perpendicular to the azimuth of the raypath, which suggests the presence of transverse isotropy. There is a layer of inter-bedded basaltic lava flows and breccia at this site (Forsyth et al., 2008), but it is shallow (c. $1 \mathrm{~km}$ ) and close to the station and thus unlikely account for such anisotropy. The small range of back-azimuth allows for the possibility that $\phi$ is aligning with one or more of the faults on Banks Peninsula (Fig. 3.6) similar to the other station on the peninsula (Bnk1). Station Cch4 also exhibits a similar circular pattern (Fig. 3.9), but due to its location the measurements perpendicular to the back azimuth are also parallel to the fault strike both of the Greendale fault and the normal fault which it sits atop, which implies fault induced anisotropy as well as potential $S_{H \max }$-parallel anisotropy. Cch1 (not shown) exhibits a pattern similar to Cch4 and though there are no mapped $\mathrm{E}-\mathrm{W}$ faults in its vicinity, it is possible that the predominantly E-W offshore faults mapped by Barnes (2011) extend onshore and are causing the same mix of E-W fault and stress induced anisotropy as seen at Cch4.

\section{Depth extent of anisotropy}

Many previous studies (Savage et al., 1990; Gledhill, 1991; Zhang and Schwartz, 1994) found that nearby stations showed different $\phi$ and no correlation of $\delta t$ with hypocentral distance, suggesting near-surface anisotropy. The data for Canterbury show little variation in $\phi$ between stations near enough to one another to be useful for any constraining of the depth of anisotropy, as the events occur mainly at shallow depths. Standard deviation of $\phi$ for nearly all stations is greater than $30^{\circ}$ (Table 3.1), which implies more than one mechanism is causing the anisotropy (Peng and Ben-Zion, 2004) or that 

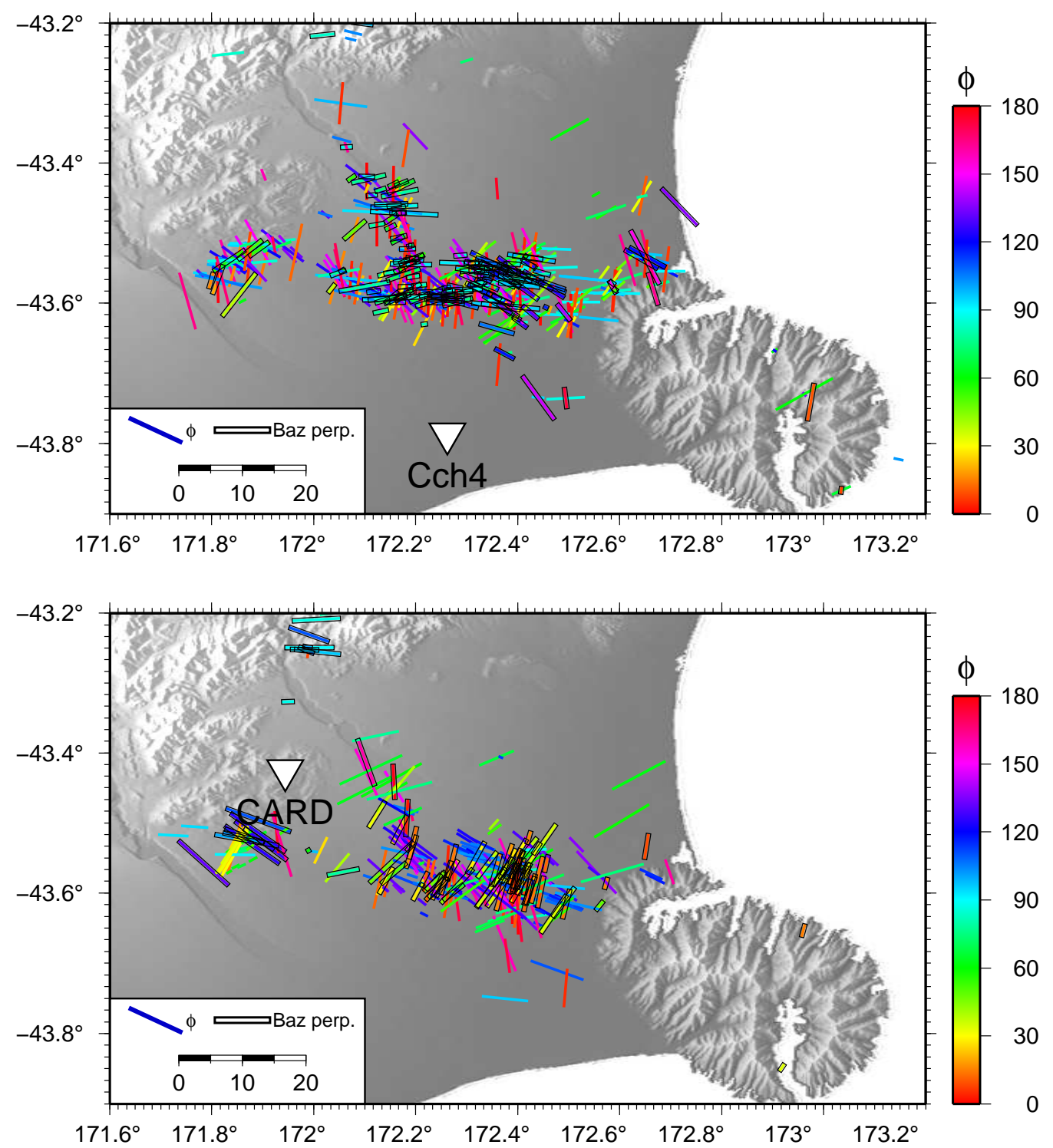

Figure 3.9: $\phi$ plotted at event location for station Cch4 (upper) and CARD (lower). Length of vectors represents $\delta t$, max length is $0.4 \mathrm{~s}$ (length of vectors in the key). Triangles are station locations. Vectors with a black outline are either within $\pm 20^{\circ}$ of being parallel (Baz para) or perpendicular (Baz perp) to back azimuth (see key). 
there is significant scattering of $\phi$, either of which preclude any overwhelming near-station effects.

\section{$\beta_{S W S}$ dependent anisotropy at station CARD}

Plotting the density of $\delta t$ vs. $\phi$ parameters for all of the events detected at station CARD reveals four distinct concentrations (Fig. 3.10). These concentrations are divided into different groups (blue, green, red, and yellow) and plotted for other parameter comparisons to look for any patterns (Fig. 3.11). With the exception of the yellow group, they are all located near the fault zone and thus have similar event-station paths (Fig. 3.12). The red, blue and green groups are separated by delay time and $\phi$ differs by $0^{\circ}$ or $90^{\circ}$, both of which are potential indicators of cycle skipping (see Section 3.1.1). However, cycle skipping requires discrete shifts in delay time that are dependent on the frequency of the waveform (Eq. 3.3) and the majority of dominant shear wave frequency $\left(f_{s}\right)$ values generated from MFAST are too low (c. $\left.3 \mathrm{~Hz}\right)$ to account for the $\delta t$ shift of c. $0.1 \mathrm{~s}$.

Larger values of $\delta t$ for the green and blue groups are associated with $\beta_{S W S}$ c. $150^{\circ}$, and smaller ones for red and yellow with $\beta_{S W S}$ c. $60^{\circ}$ (Fig. 3.11). This could indicate that the events in the blue and green groups are splitting further from the station and the red and yellow are splitting closer to the station. Ultimately these results suggest that the anisotropy near the station is heterogeneous and that when a wave splits may depend on it initial polarisation.

\section{Vertical re-splitting}

If splitting results are caused by two anisotropic layers of vertical symmetry rather than one, this can be determined by plotting $\phi$ vs. $\beta_{S W S}$ (Fig. 3.13) and looking for repeating patterns every $90^{\circ}$ and for concentrations of nulls at the discontinuities (Silver and Savage, 1994; Rümpker and Silver, 1998). For short-period events (Period $/ \delta t \leq 1 \mathrm{~s}), \phi$ represents the fast direction of the upper layer and $\beta_{S W S}$ that of the lower. For longer period waves, 

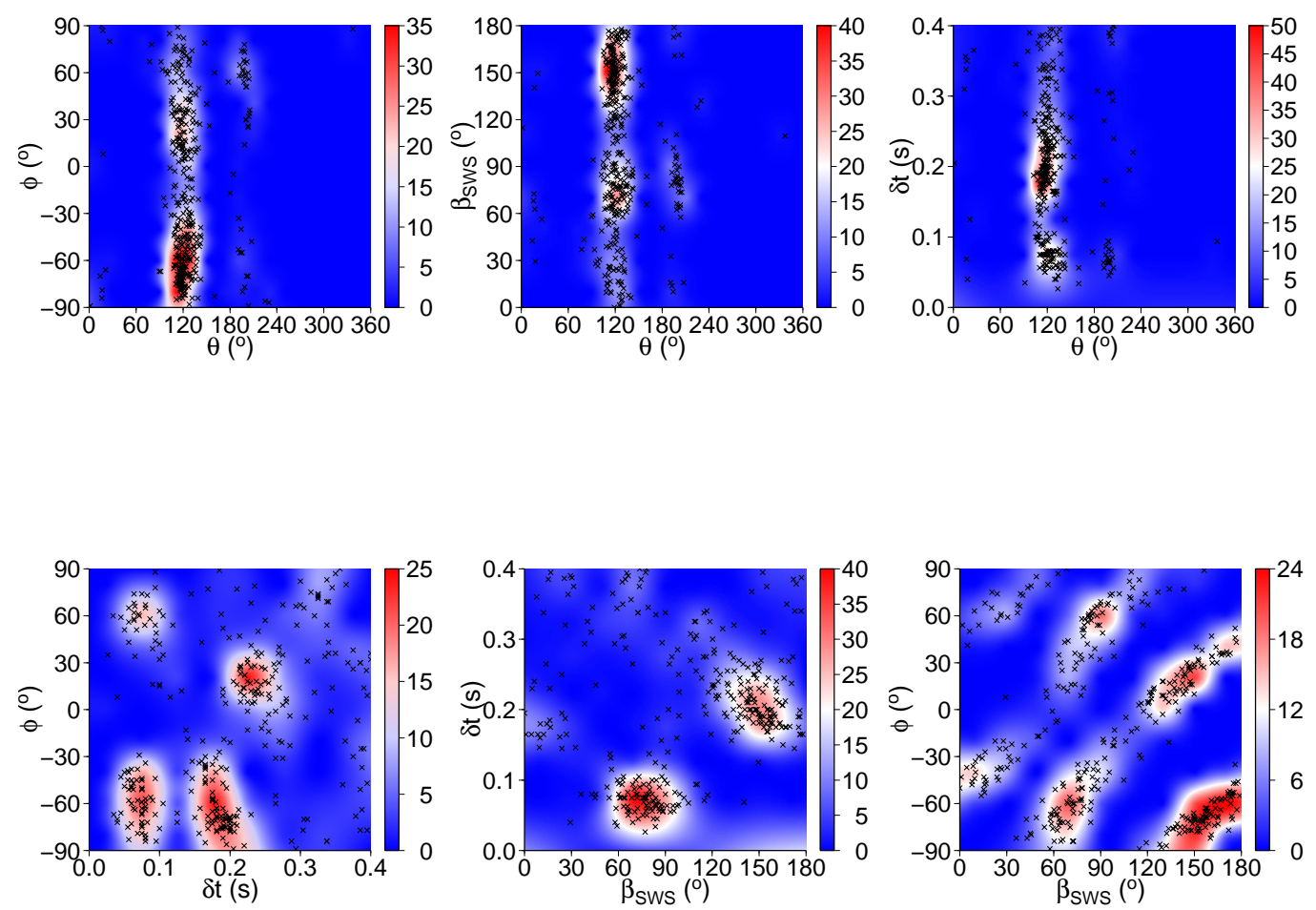

Figure 3.10: Correlation of SWS and earthquake parameters for station CARD. Red/blue scale represents density of event parameters marked by black crosses. $\theta$ is back-azimuth, $\beta_{S W S}$ is incoming polarisation, $\delta t$ is delay time and $\phi$ is fast direction of anisotropy. 

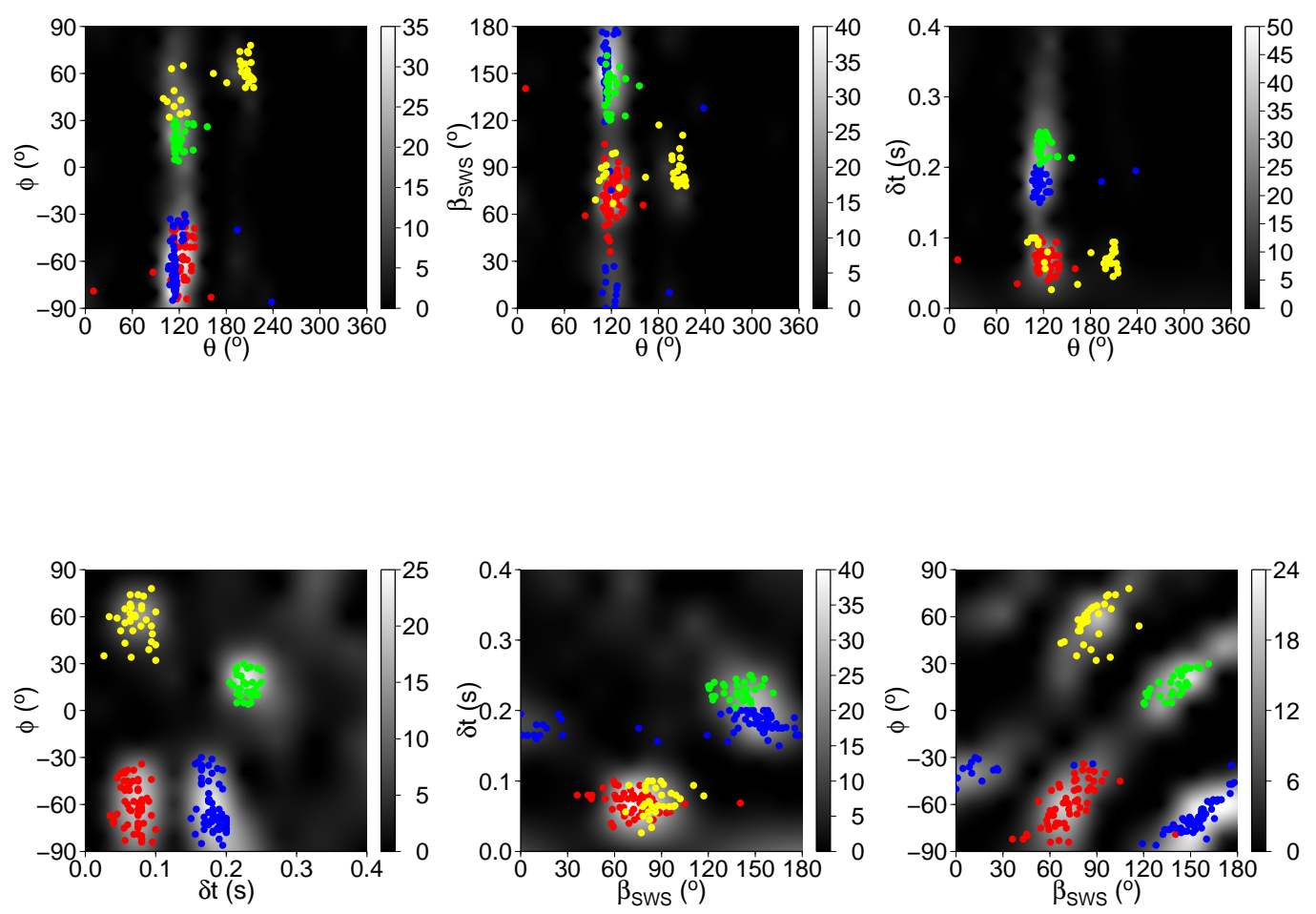

Figure 3.11: Correlation of SWS and earthquake parameters for station CARD. Black/white contour represents density of data points and is the same as that in Fig. 3.10. The four sets of coloured points are the measurements within the four high density regions seen in the bottom left $\delta t$ vs. $\phi$ plot. $\theta$ is back-azimuth, $\beta_{S W S}$ is incoming polarisation, $\delta t$ is delay time and $\phi$ is fast direction of anisotropy. 


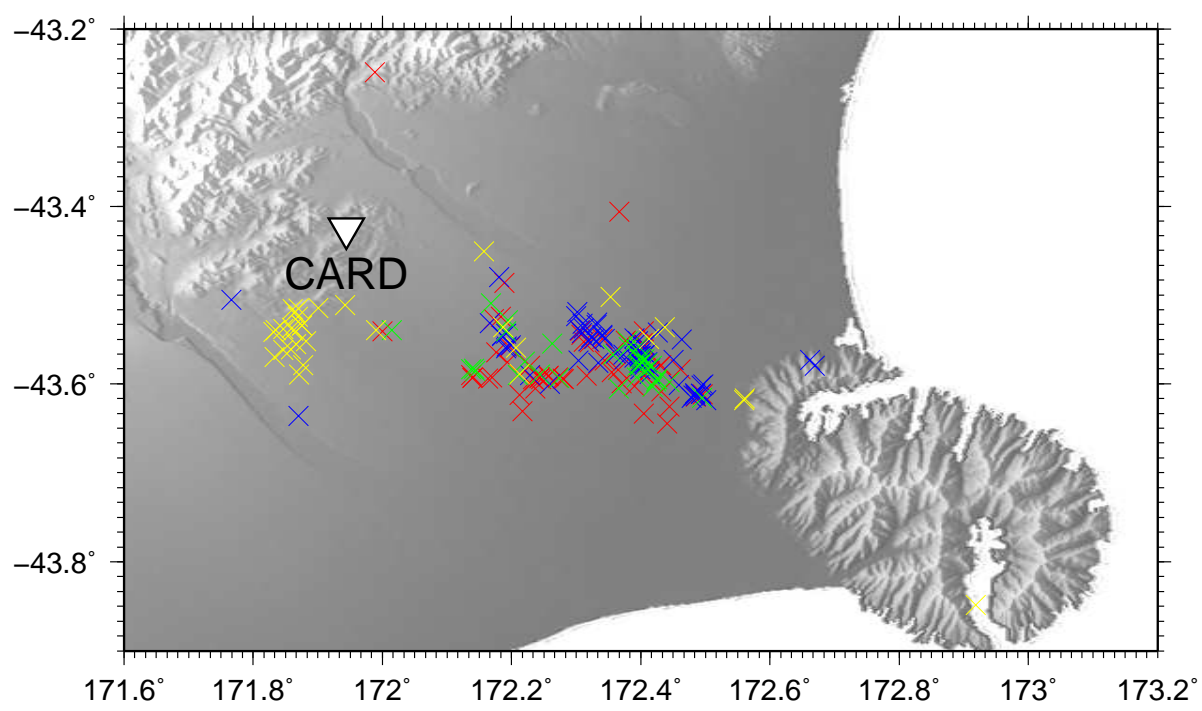

Figure 3.12: Locations for events used in comparison of splitting parameters in Fig. 3.11

(period $/ \delta t \geq 5), \phi$ represents an apparent fast direction that can be used to calculate the fast directions of the two layers using equations from Silver and Savage (1994). All events are assumed to be short-period as the majority of the results have Period $/ \delta t \leq 1$ and $\delta t$ in this equation refers to the entire delay-time rather than that of the top layer, which is what was measured and will thus give values higher than expected. No relationships were found for any stations in the dataset to suggest more than one layer of azimuthal splitting (examples shown in Fig. 3.13). Mean $\beta_{S W S}$ showed large standard deviation (Table. 3.3), indicating no consistent splitting occurring before the wave splitting to $\phi$. This was confirmed by examining plots of $\beta_{S W S}$ orientations at their epicentres (not shown) as done for $\phi$ in earlier figures. 

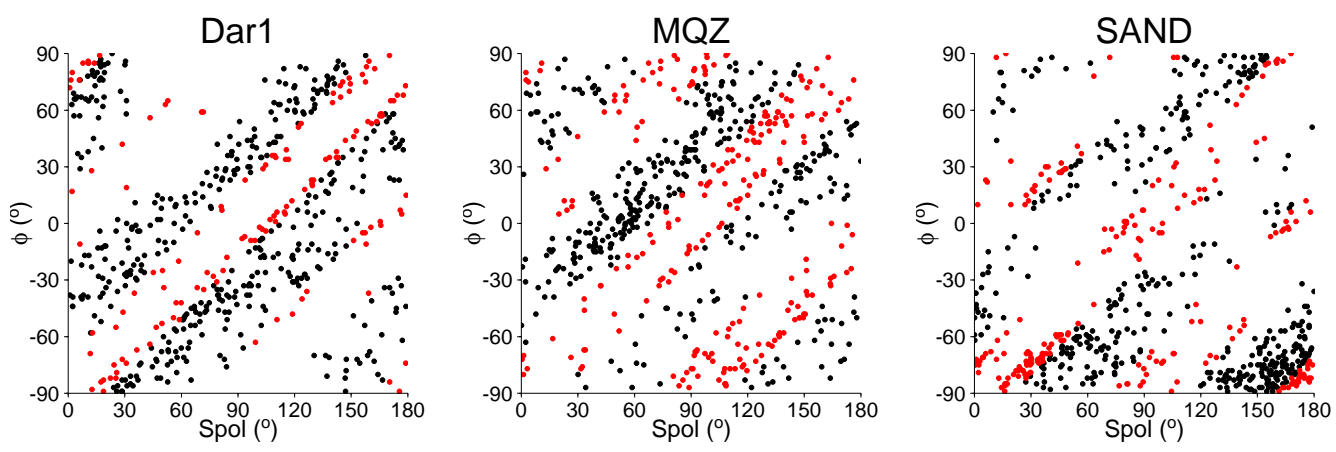

Figure 3.13: $\phi$ vs. $\beta_{S W S}$ for several stations. Good splitting measurements marked in black, null measurements marked in red. The banding of red and black datapoints is due to the method for determining a null result (i.e. $\left.20<\left|\phi-\beta_{S W S}\right|<70\right)$.

\subsubsection{Delay time tomography and spatial averaging}

$\delta t$ tomography for all data and data with $i_{s}<60^{\circ}$ were estimated (Figs. 3.14, 3.15) using the method described above. Ray coverage within the grid (Fig. 3.14a), the re-created checkerboard data (Fig. 3.14c) and the region of resolution $>5.5$ (the same used by Johnson et al., 2011) are used to define the region of statistical significance (the dark area in Figs. 3.14e, 3.15e). Both data sets show higher anisotropy at either end of the Darfield fault and lower anisotropy at the discontinuity near station Dar6. The higher anisotropy could be due to increased crack density caused by stress increases at the ends of the fault/s after the Darfield earthquake. The lower anisotropy could be due to complex faulting at the discontinuity which would effectively make the rock more isotropic. Anisotropy appears to be located predominantly near regions of denser seismicity. While the $\delta t$ tomography shows anisotropy predominantly near greater seismicity (Figs. 3.14, 3.15), significance testing of the quadtree comparison of average $\delta t$ with seismicity (Fig. 3.18) showed that the hypothesis that the correlation was random could not be rejected, as the $\mathrm{P}$-value was above the critical threshold $(\mathrm{P}>0.05)$. This indicates that while they may be related, there are other effects to be considered and in- 
creasing seismicity does not necessarily result in increasing anisotropy. The observation is limited by the fact that the estimates of $\delta t$ from the tomography are only a first order approximation. While the overall distribution of $\delta t$ remains consistent, the results do change noticeably when the grid is moved $\pm 1 \mathrm{~km}$ as well as for the $50 \%$ jack-knife testing (Figs. 3.16, 3.17), making it difficult to constrain the location of the anisotropy.

Spatial averaging of $\phi$ using all data (Fig. 3.14f) approximately matches the orientations seen when the data is plotted at the stations where they were measured (Fig. 3.6). Decreased scatter for the $i_{s}<60^{\circ}$ averaging (Fig. 3.15f) implies that scattering is occurring closer to the source when the raypath is more horizontal. Variations in $\bar{\phi}$ for the two sets of spatial averages occur nearer the edges of the grid where there are less instances of intersecting rays and thus are attributed to the differing ray coverages. 


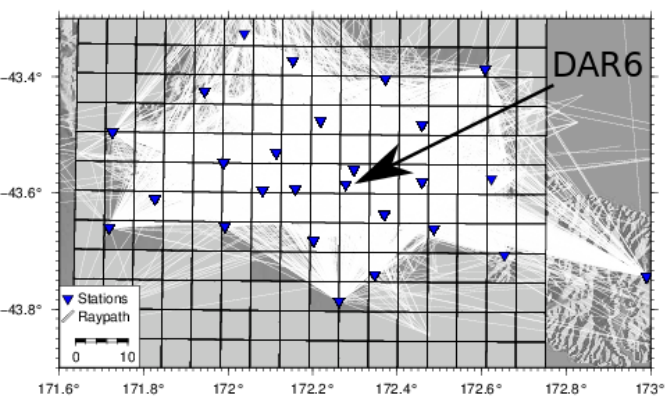

(a) Event-station paths

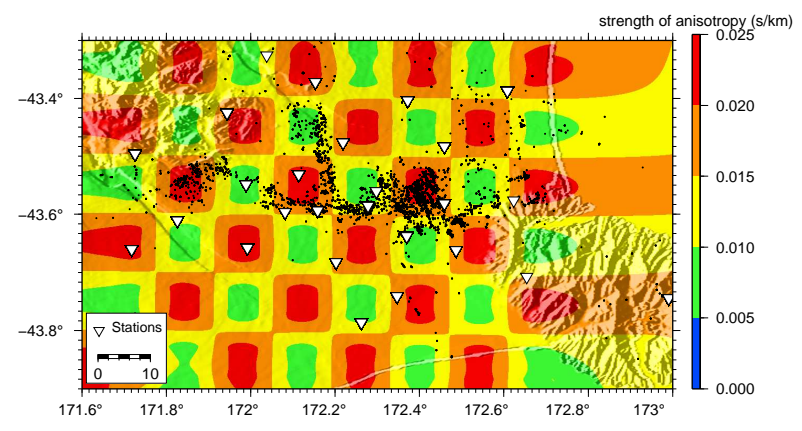

(b) Input checkerboard

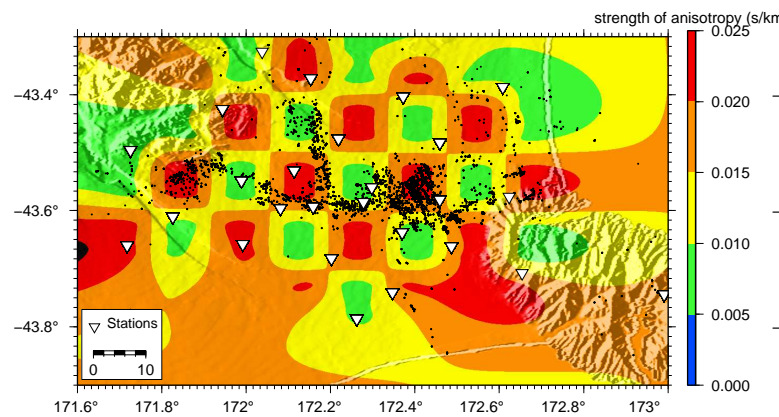

(c) Output checkerboard

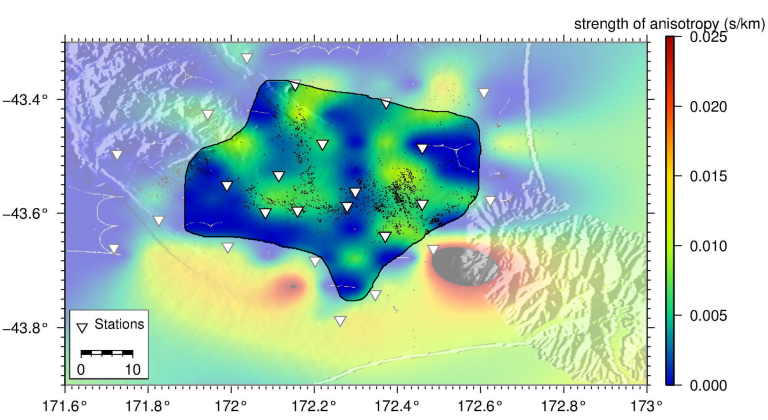

(e) $\delta t$ tomography data

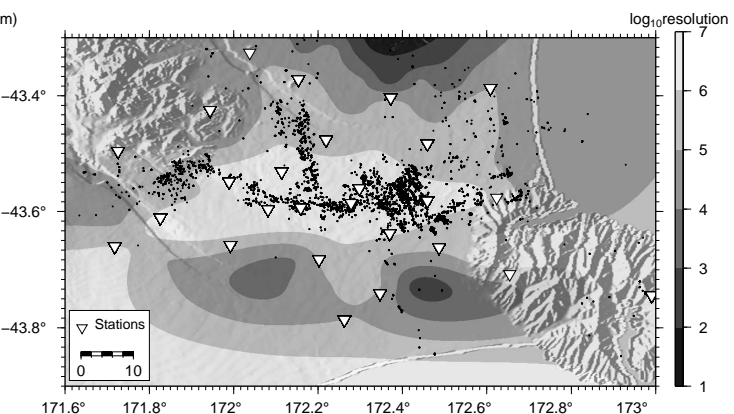

(d) Data resolution

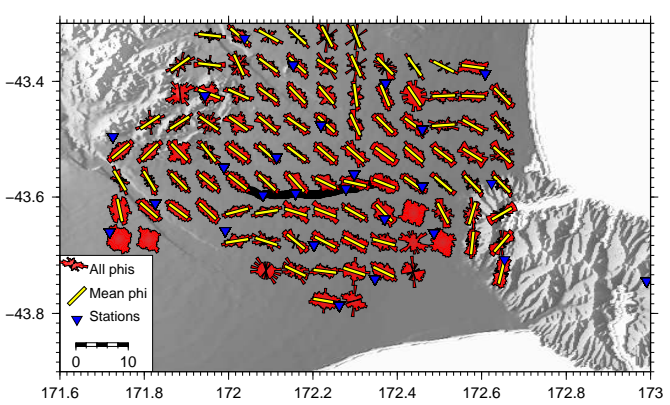

(f) Spatial averages of $\phi$

Figure 3.14: $\delta t$ tomography and spatial averaging data using all SWS estimates (9493 event-station pairs). (a) all event-station paths and grid used in inversion, (b) input checkerboard (c) re-creation of checkerboard using data, (d) resolution of data (e) $\delta t$ tomography with highlighted area of statistical significance, and (f) spatial averaging of $\phi$. Black points represent seismicity, white/blue triangles are station locations. Greendale fault shown in black for spatial averaging of $\phi$. 


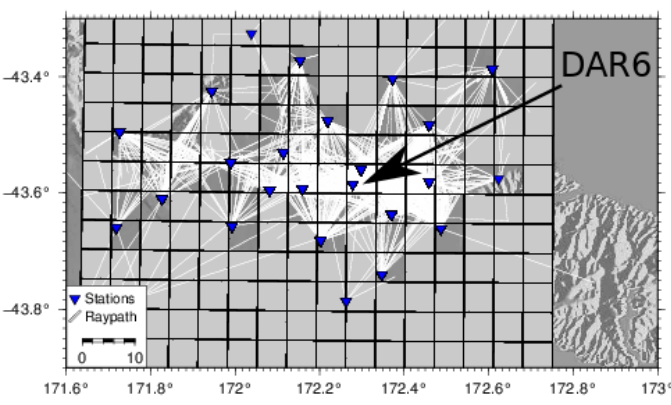

(a) Event-station paths

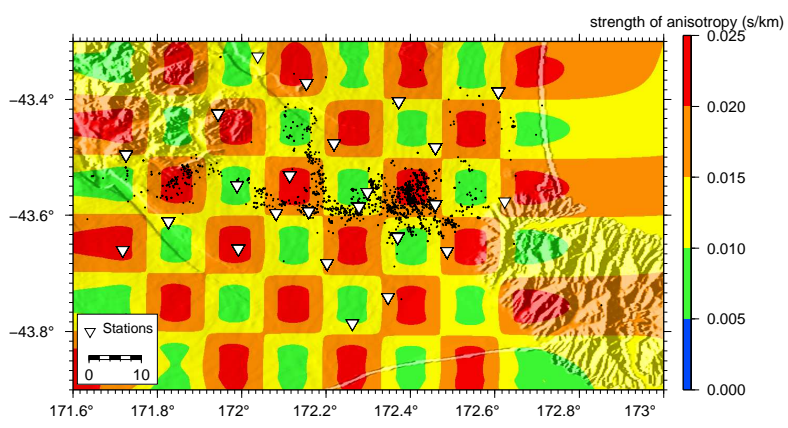

(b) Input checkerboard

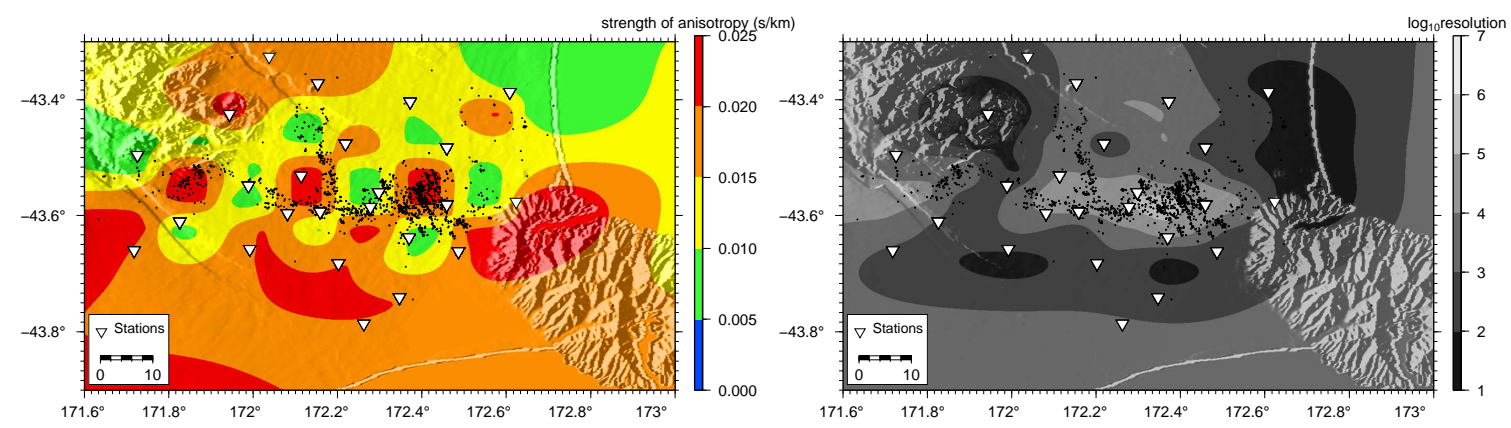

(c) Output checkerboard

(d) Data resolution

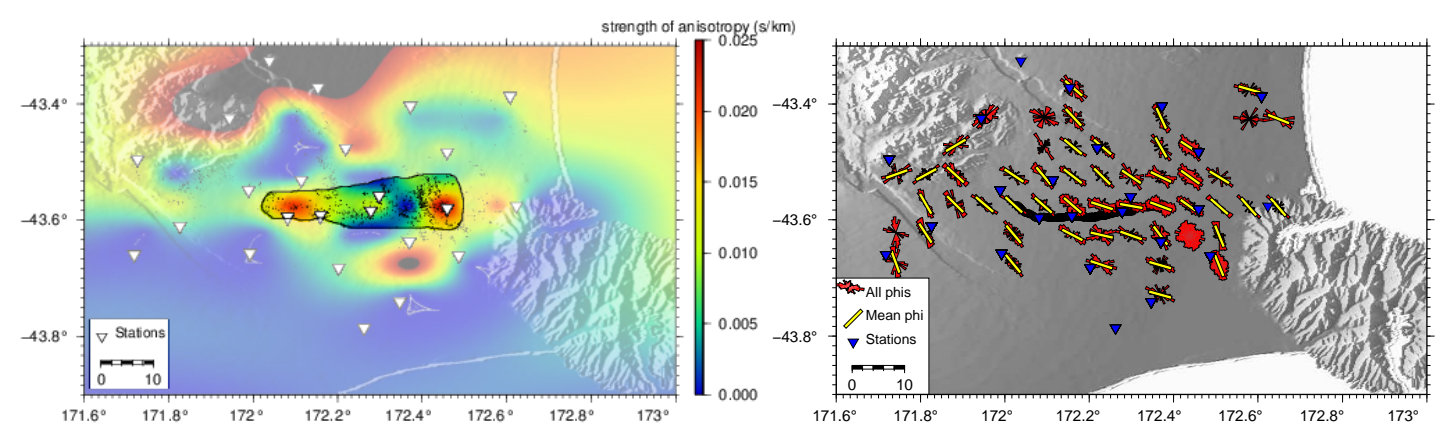

(e) $\delta t$ tomography data

(f) Spatial averages of $\phi$

Figure 3.15: $\delta t$ tomography and spatial averaging data using SWS estimates with $i_{s}<60^{\circ}$ (2278 event-station pairs). (a) all event-station paths and grid used in inversion, (b) input checkerboard (c) re-creation of checkerboard using data, (d) resolution of data (e) $\delta t$ tomography with highlighted area of statistical significance, and (f) spatial averaging of $\phi$ Black points represent seismicity, white/blue triangles are station locations. Greendale fault shown in black for spatial averaging of $\phi$. 


\begin{tabular}{|c|c|c|c|c|}
\hline Station & $\mathrm{N}$ & $\operatorname{mean} \beta_{S W S}\left(^{\circ}\right)$ & stdev $\beta_{S W S}$ & $95 \%$ conf. $\beta_{S W S}$ \\
\hline Bnk1 & 341 & 9.5 & 48.7 & 9.2 \\
\hline Cch1 & 492 & 134.8 & 46.4 & 6.7 \\
\hline Cch2 & 304 & 156.3 & 66.9 & 35.4 \\
\hline Cch3 & 278 & 114.2 & 59.2 & 20.5 \\
\hline Cch4 & 538 & 49.6 & 57.8 & 13.3 \\
\hline Dar1 & 432 & 74.5 & 71.8 & 45 \\
\hline Dar2 & 451 & 104.2 & 45.9 & 6.8 \\
\hline Dar3 & 393 & 106.2 & 58.3 & 16.2 \\
\hline Dar4 & 584 & 160.6 & 55.5 & 10.9 \\
\hline Dar5 & 501 & 132.9 & 69.5 & 34.3 \\
\hline Dar6 & 641 & 82.2 & 55.9 & 10.6 \\
\hline Dar7 & 625 & 33.5 & 66.5 & 24.0 \\
\hline Dar8 & 558 & 170.3 & 58.6 & 13.9 \\
\hline CARD & 334 & 116.5 & 54.1 & 13.1 \\
\hline CTND & 241 & 137.2 & 57.1 & 19.0 \\
\hline ESND & 116 & 178.4 & 41.9 & 10.6 \\
\hline LNSD & 342 & 91.2 & 46.9 & 8.2 \\
\hline MCHD & 442 & 129.3 & 42.5 & 5.6 \\
\hline MKYD & 329 & 106.3 & 75.4 & 71.2 \\
\hline MNSD & 432 & 137.6 & 62.5 & 20.9 \\
\hline SAND & 416 & 151.3 & 54.0 & 11.7 \\
\hline SKTD & 457 & 128.1 & 46.0 & 6.7 \\
\hline STLD & 580 & 171.2 & 49.4 & 7.3 \\
\hline CRLZ & 204 & 26.2 & 45.7 & 9.9 \\
\hline MQZ & 374 & 66.0 & 55.0 & 13.1 \\
\hline OXZ & 275 & 50.4 & 47.3 & 9.4 \\
\hline
\end{tabular}

Table 3.3: Mean values of $\beta_{S W S}$ for all stations. $\mathrm{N}$ is number of measurements. stdev $\beta_{S W S}$ is standard deviation of $\beta_{S W S} .95 \%$ confidence interval taken as twice the standard error. 

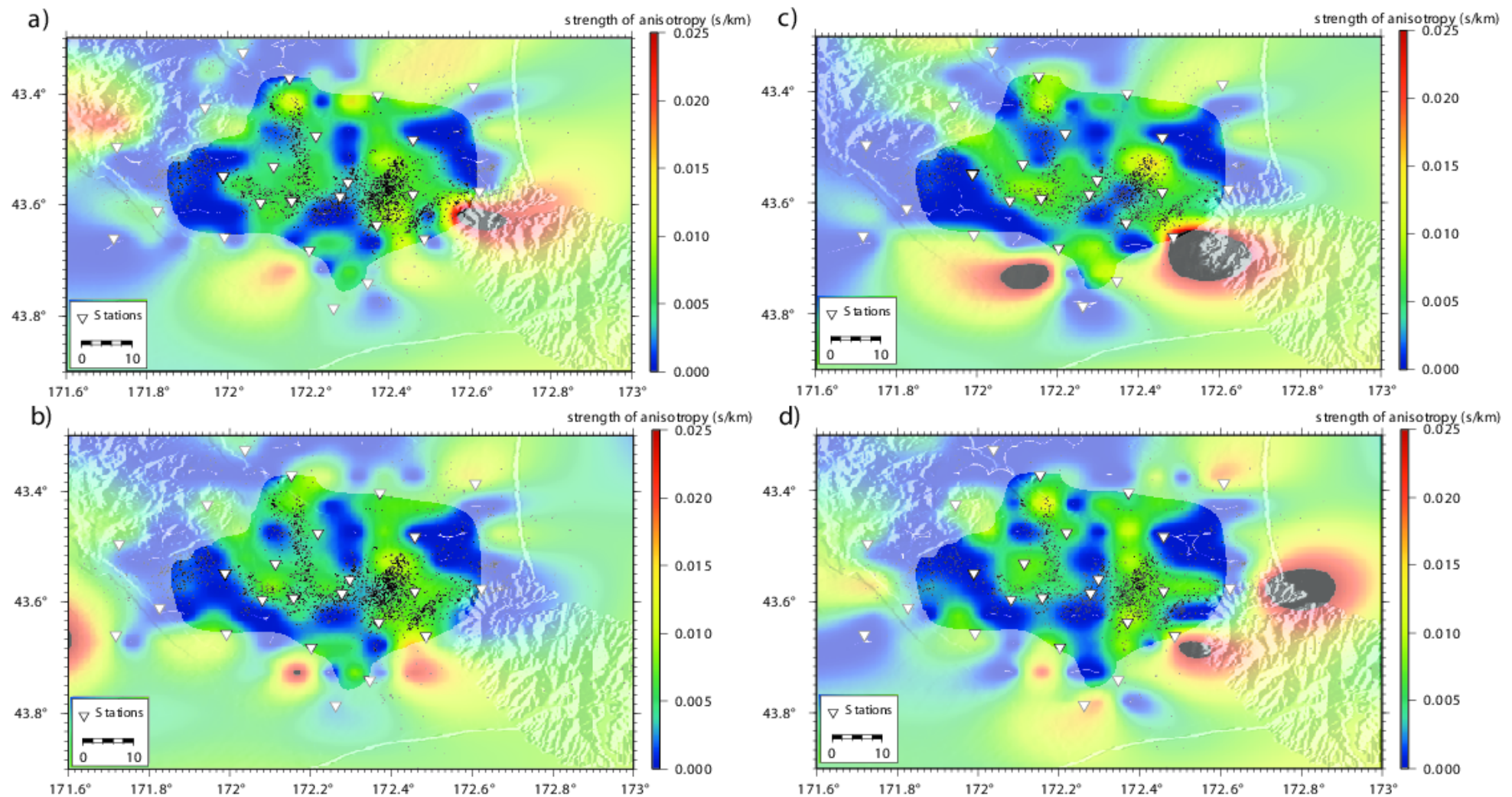

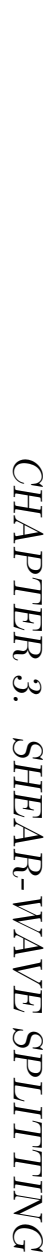

Figure 3.16: $\delta t$ tomography for all events with: a) Grid moved 1 km East, b) Grid moved $1 \mathrm{~km}$ North, c) $50 \%$ jack-knife data, d) other $50 \%$ of data 

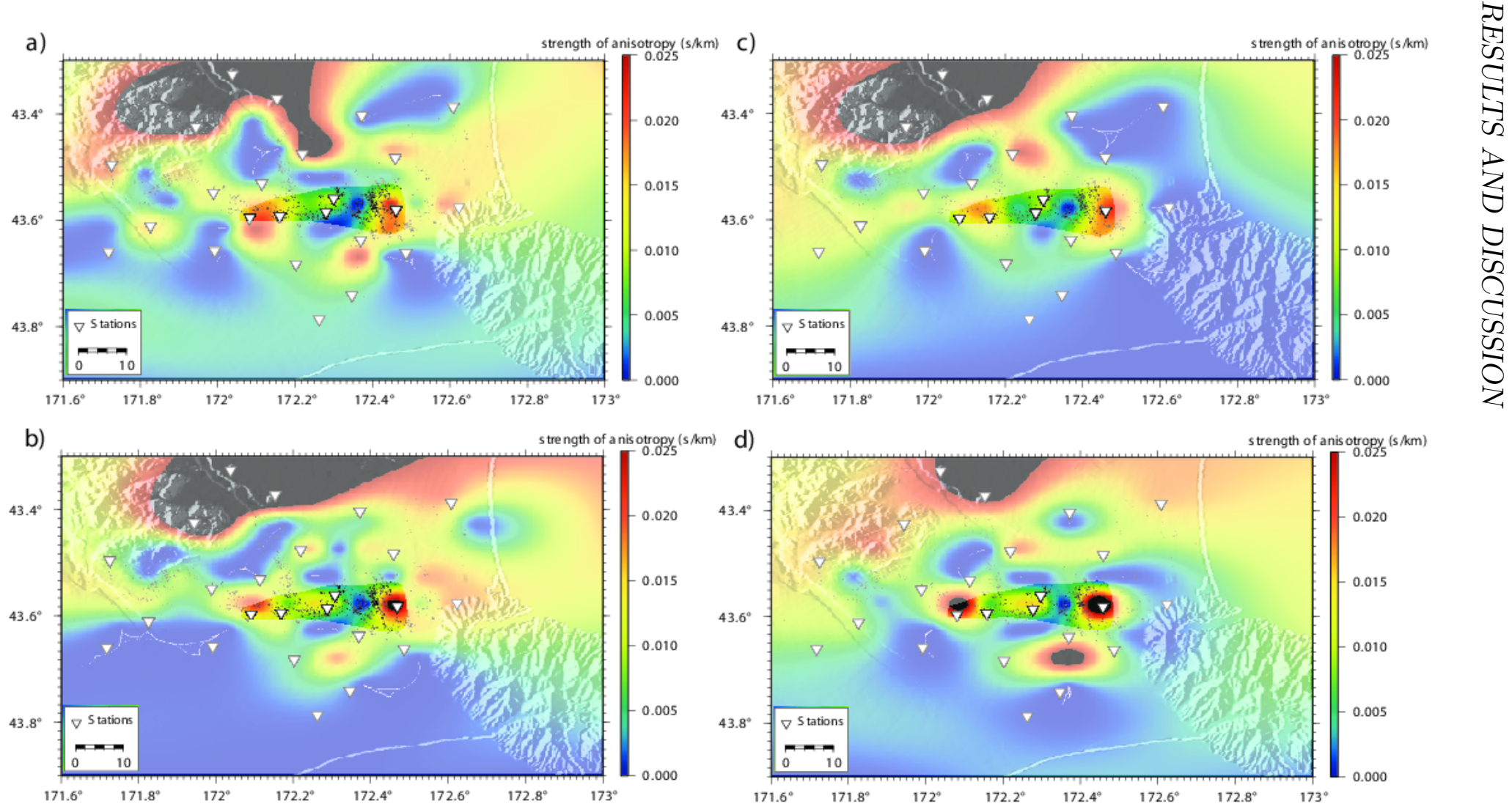

Figure 3.17: $\delta t$ tomography for events within $i_{s}<60^{\circ}$ with: a) Grid moved $1 \mathrm{~km}$ East, b) Grid moved $1 \mathrm{~km}$ North, c) $50 \%$ jack-knife data, d) other $50 \%$ of data 

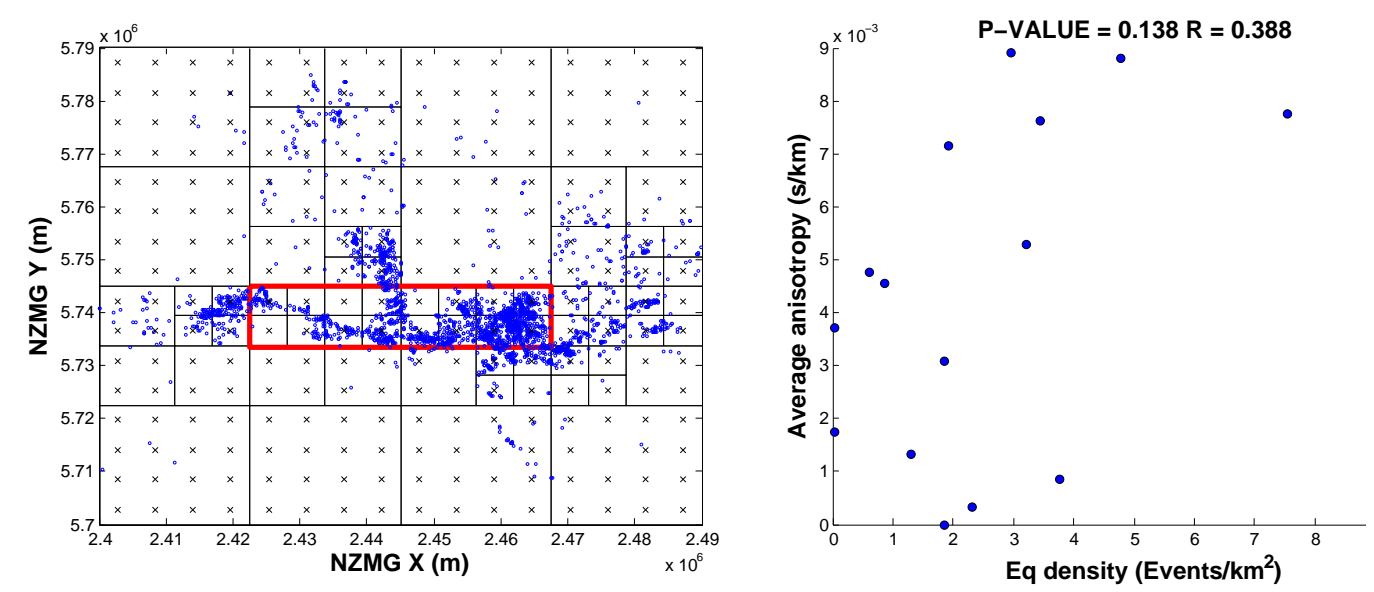

(a) Quadtree grid with seismicity $\quad$ (b) Correlation of avg. $\delta t$ vs. Eq. density

Figure 3.18: Comparison of average $\delta t$ from tomography and earthquake density for all data (Fig. 3.14) Left: Quadtree grid defined by seismicity (blue points), grid outline is same as seen in Fig. 3.14a, axes are coordinates in New Zealand map grid (NZMG), min. grid size is $5 \times 5 \mathrm{~km}$, grid spaces divided when $\mathrm{n} \geq 50$, crosses mark $\delta t$ nodes that are to be averaged and used in correlation, Red rectangle denotes grid spaces that correspond to the region of statistical significance, which are the only results used in this comparison. Right: Correlation of average $\delta t$ vs. earthquake density for all data, plot points represent grid blocks in plot on left.

\section{3 $V_{P} / V_{S}$-ratio and $V_{P} / V_{S}$-ratio vs. $\delta t$}

Correlations of $V_{P} / V_{S}$-ratio, splitting parameters, and locations were calculated for all stations and tested for significance (See tables in Appendix B). Many stations (Fig. 3.19) show a significant correlation or anti-correlation between $V_{P} / V_{S}$-ratio and $\delta t$ (normalised by raypath). Correlation between $V_{P} / V_{S}$-ratio and $\delta t$ is expected when there is spatial or temporal variation 
in crack density as isotropic crack density will not result in variation of $\delta t$ or $V_{P} / V_{S}$-ratio Unglert et al. (2011). $\delta t$ tomography indicates this is true for the Canterbury plains. Correlation and anti-correlation of $V_{P} / V_{S}$-ratio and $\delta t$ are expected to represent the presence of liquid or gas respectively. Liquid (most likely water which is near-incompressible), is expected to inhibit $\mathrm{S}$-wave travel times more so than $\mathrm{P}$-wave travel times, thus increasing the $V_{P} / V_{S}$-ratio (e.g. Reyners et al., 2006). Gas, due to its compressibility, will inhibit the $\mathrm{P}$-wave propagation more than the S-wave propagation, thus decreasing the $V_{P} / V_{S}$-ratios (e.g. Chiarabba and Moretti, 2005).

The stations with correlations all have $\bar{\phi}$ comparable to $S_{H \max }$. Thus, the correlations of $V_{P} / V_{S}$-ratio and $\delta t$ are consistent with the hypothesis of $U n$ glert et al. (2011), who proposed the correlation or anti-correlation of $\delta t$ with $V_{P} / V_{S}$-ratio as an indicator of stress-induced anisotropy.

However, not all stations with $\bar{\phi}$ comparable to $S_{H \max }$ show this correlation. This could be due to a lack of spatial variation in crack density along the event-station raypaths or to structural features. The positive correlations for stations Dar6, Dar7 and Dar8 suggest fluid-filled cracks along the Darfield fault.

The average $V_{P} / V_{S}$-ratios for each station (Fig. 3.19) are mostly consistent with the previous estimates for $V_{P} / V_{S}$ from Eberhart-Phillips et al. (2010), but with comparatively lower $V_{P} / V_{S}$ along the middle of the Greendale fault and near station CRLZ (Fig. 3.19). This difference is most likely due to the higher resolution of the data for the Canterbury region in this thesis. While the low $V_{P} / V_{S}$-ratios in these areas indicate the increased presence of gas due to increased porosity/crack density, the positive correlations between $V_{P} / V_{S}$-ratio and $\delta t$ could indicate the presence of liquids. Thus, it is unclear from these data whether the cracks near the faults are predominantly gasor fluid-filled. 


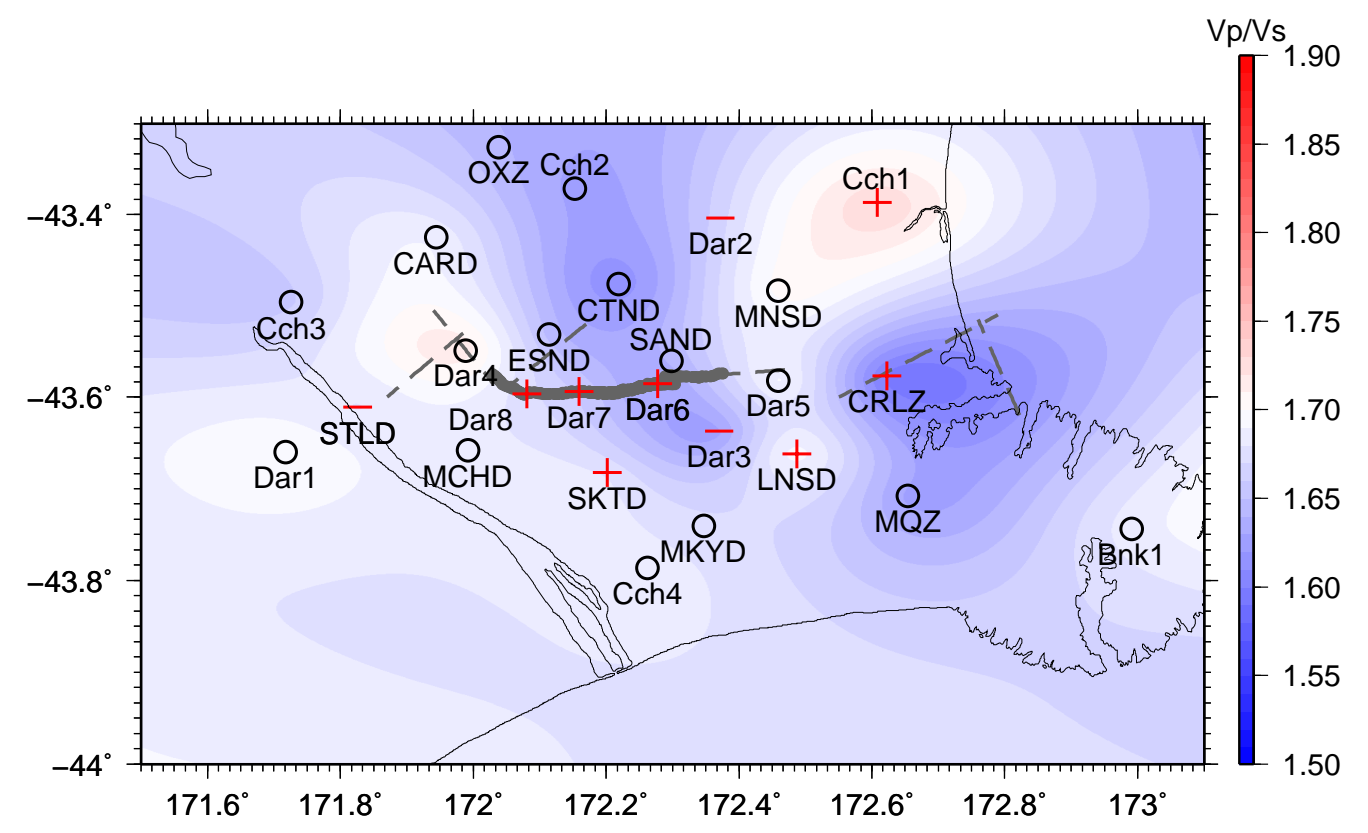

Figure 3.19: Map of average $V_{P} / V_{S}$-ratio for each station. Grey line demarcates Darfield fault trace from Quigley et al. (2010). Dashed grey lines are inferred buried faults (Beavan et al., 2010, 2011). Symbols for each station signify significant positive correlation between $V_{P} / V_{S}$-ratio and $\delta t(+)$, significant negative correlation (-), and no correlation (o). Significance of correlation taken from tables in Appendix B. Contour is estimated by GMT (Generic Mapping Tools, Wessel and Smith, 1995) as variation between average station values.

\subsection{Conclusions}

Seismic anisotropy on the Canterbury Plains appears to be controlled predominantly by stress, with some structural anisotropy due to fracture alignment at the fault. Measurements at stations further from the alluvial gravels of the plains (Bnk1, Cch3, MQZ) are believed to be dominated by structure-controlled anisotropy. Spatial averaging of $\phi$ indicates that scattering of $\phi$ may be due to heterogeneities encountered by the wave early in the 
raypath. This is supported by the results found for station CARD which show dependence of $\phi$ on the initial polarisation $\left(\beta_{S W S}\right)$. These hypotheses will be further tested by comparison with the initial polarisations from focal mechanisms and stress estimates calculated in the following chapter. 


\section{Chapter 4}

\section{Focal mechanisms and stress inversion}

\subsection{Method}

Focal mechanisms and stress inversions for this study are calculated using the same process as that used by Townend et al. (2012), which is described below. This approach enables error estimates from the location to propagate through to the focal mechanism and stress estimates.

\subsubsection{Earthquake relocations with NonLinLoc}

While high-quality relocations for the data set already exist (Syracuse et al., 2012), in order to utilise the probabilistic method of focal mechanism determination of Walsh et al. (2009) it is necessary to have some estimate of the uncertainty for take-off angle/azimuth for each event-station pair, which is currently unavailable for these results. Thus, locations for the data are estimated using NonLinLoc (Lomax (2007) based on method of Tarantola and Valette (1982)), which does so by using a well constrained 1D velocity model (Eberhart-Phillips et al., 2010) and $P$ and $S$ arrival times to calculate and search 3D travel-time (and take-off angle) grids for the maximum likelihood 
hypocenter. This method is the same used by Walsh et al. (2009), because it provides location uncertainty in the form of a probability density function (PDF) for each event.

\subsubsection{Focal mechanism estimation}

Whereas other probabilistic methods of focal mechanism estimation assume that hypocentres have no error i.e. can be mapped as a single point with no uncertainty (Fig. 2.5), the method of Walsh et al. (2009) maps the PDF for each hypocenter/station pair (in this case from NonLinLoc), treats the hypocenter probabilistically (Fig. 4.1), and also accounts for other potential sources of uncertainty (e.g. P-wave travel-time error, probability of an incorrectly wired seismometer). It finds the maximum a priori (MAP) set of focal mechanism parameters $(\xi, \delta, \lambda)$ via a grid search. The uncertainty of the focal mechanism can be represented by the concentration parameter $(\kappa)$. This is found by fitting the data to a Matrix-Fisher distribution under the assumption that the error for the focal mechanism parameters is equal (see Walsh et al. (2009) for full explanation).

\subsubsection{Stress inversion of focal mechanism}

The Wallace-Bott hypothesis (Wallace, 1951; Bott, 1959) states that a faultplane will slip in the direction of the maximum resolved shear stress. Using this assumption, the stress tensor for a small volume of rock can be estimated from one or more focal mechanism generated within it. McKenzie (1969) shows that a single focal mechanism produces a poorly constrained estimate of the stress tensor, thus it is necessary to use a method that uses multiple focal mechanisms to provide greater constraint. The algorithm of Arnold and Townend (2007) is a Bayesian method that uses multiple focal mechanisms and their accompanying uncertainty $(\kappa)$ to estimate the principal axes of the stress tensor $\left(S_{1}, S_{2}, S_{3}\right)$ and the stress ratio $(\nu)$ that are most compatible with the nodal planes for the focal mechanisms used. It also estimates the 


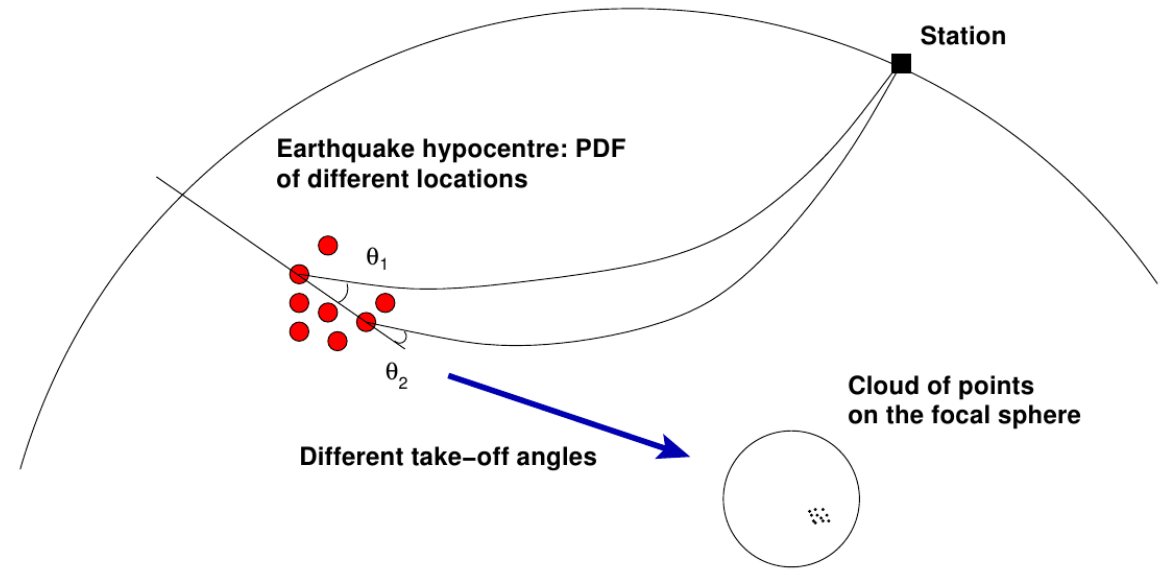

Figure 4.1: PDF for hypocentres projected onto focal sphere for a single station, from Walsh et al. (2009).

maximum horizontal compressive stress $\left(S_{H \max }\right)$ using the transformation of Lund and Townend (2007).

Generating an optimal stress estimate requires both a sufficient number of focal mechanisms for the stress parameters to be stable and that they are close together so it is more probable that they represent the same stress tensor. Therefore, grouping of the focal mechanisms is determined using the "k-means" algorithm (Hartigan, 1975), which groups the earthquakes into a set number $(k)$ of clusters based on their locations such that an earthquake within a given cluster is closer to the centroid of that cluster than any other, and where $k$ is determined according to the desired average number of earthquakes in each cluster. $k=32$ is used here (following the rule of thumb from Townend and Zoback, 2004), as it provides good resolution and stable stress estimates.

The algorithm is run 1000 times from different starting points and the solution (set of centroids) with the minimum sum of hypocenter-centroid distances is used (Fig. 4.2). 


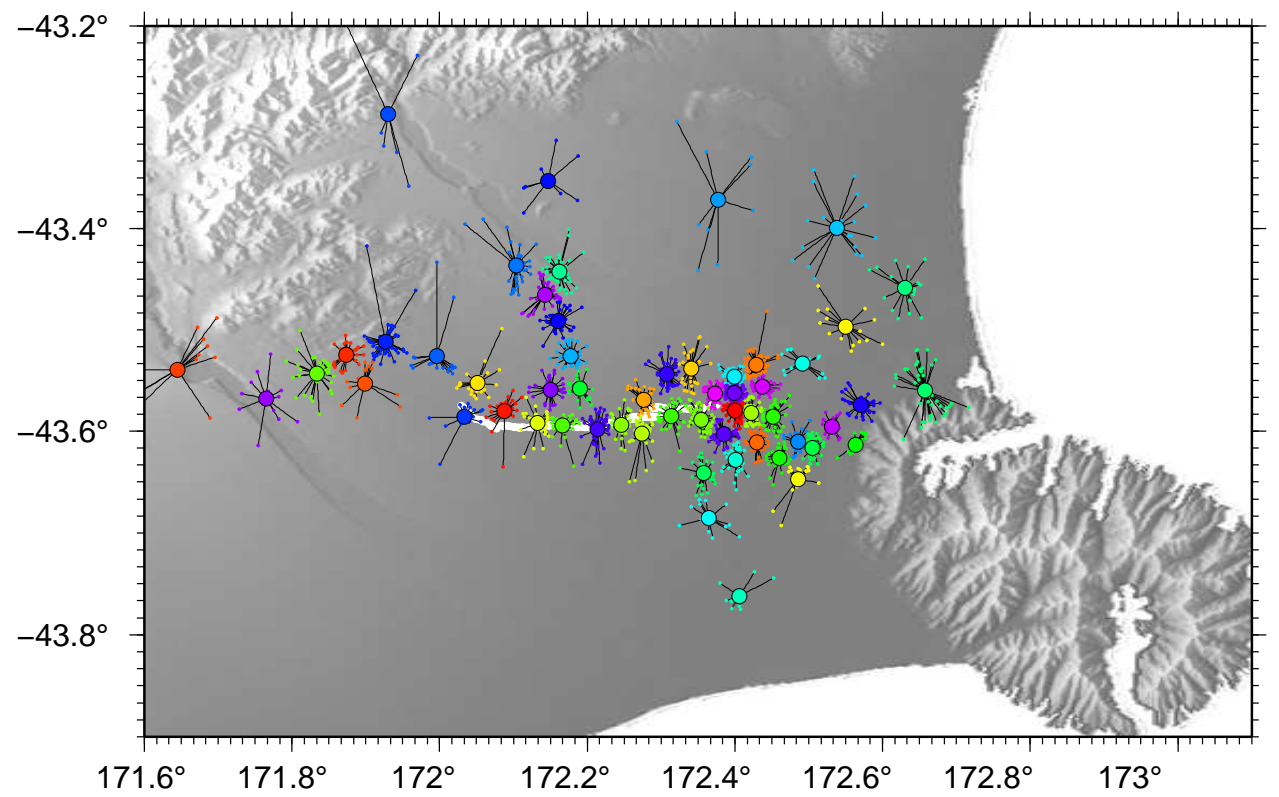

Figure 4.2: Clusters of focal mechanisms as determined by the k-means algorithm for data selected according to the method in the following section. Large circles represent cluster centroids, linked small circles represent focal mechanism locations. The number of events in each cluster ranges from 6-83 (see Table 4.1). White line is Darfield fault trace.

\subsubsection{Selection of events for stress inversion}

Events used in the stress inversions were selected according to several criteria. Firstly, only events with ten or more first motions and a high $(\geq 8)$ NonLinLoc quality rating were used. The NonLinLoc quality rating quantifies the variation in travel time gradients, with less variation indicating higher quality (Lomax , 2007). All events were manually inspected and events that showed PDFs spanning the range of take-off angles or had poor coverage of the focal sphere (Fig. 4.3) were not used. Events located at depths shallower than $3.5 \mathrm{~km}$ or within $0.3 \mathrm{~km}$ of the boundaries in the velocity model were 
not used as the majority showed PDFs spanning the range of take-off angles. This left a dataset of exactly 2000 events for stress inversion.

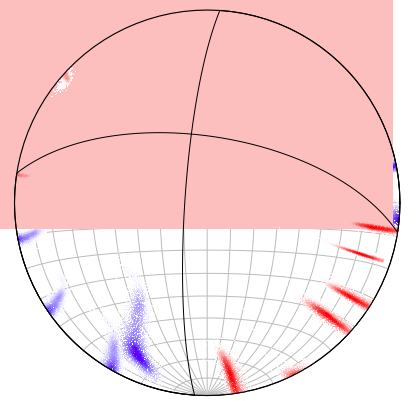

(a)

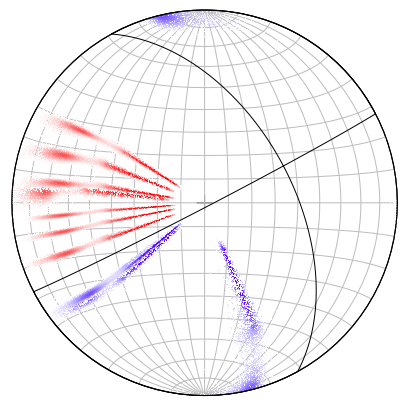

(b)

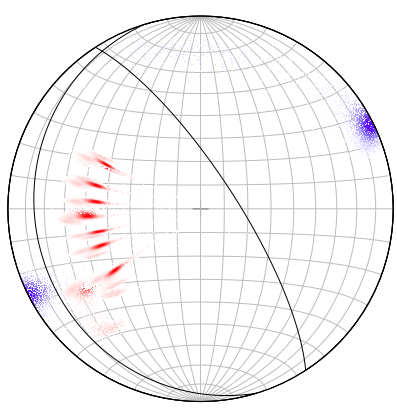

(c)

Figure 4.3: Comparison of reliable and unreliable focal mechanisms generated from this dataset using the method of Walsh et al. (2009). (a) shows a reliable focal mechanism with good coverage of focal sphere. (b) shows an unreliable focal mechanism with PDFs spanning the range of take-off angles. (c) shows an unreliable focal mechanism with poor coverage of the focal sphere. Blue denotes compressive first motion PDF, red dilatational.

\subsection{Results and Discussion}

\subsubsection{Focal Mechanisms}

Over $50 \%$ of the rakes for the events are within the ranges of $\pm 20^{\circ}, 160^{\circ}$ to $180^{\circ}$, and $-160^{\circ}$ to $-180^{\circ}$ (Figs. 4.4, 4.5), indicating that most of the events were strike-slip. $\kappa$ values indicate an uncertainty of $25-30^{\circ}$ ( 1 std. dev.) for all focal mechanisms.

\subsection{2 $\beta_{F M}$ and $\beta_{S W S}$ comparison}

The comparison of the two estimates of the initial polarisation from focal mechanisms $\left(\beta_{F M}\right)$ and shear wave splitting $\left(\beta_{S W S}\right)$ show no agreement for 


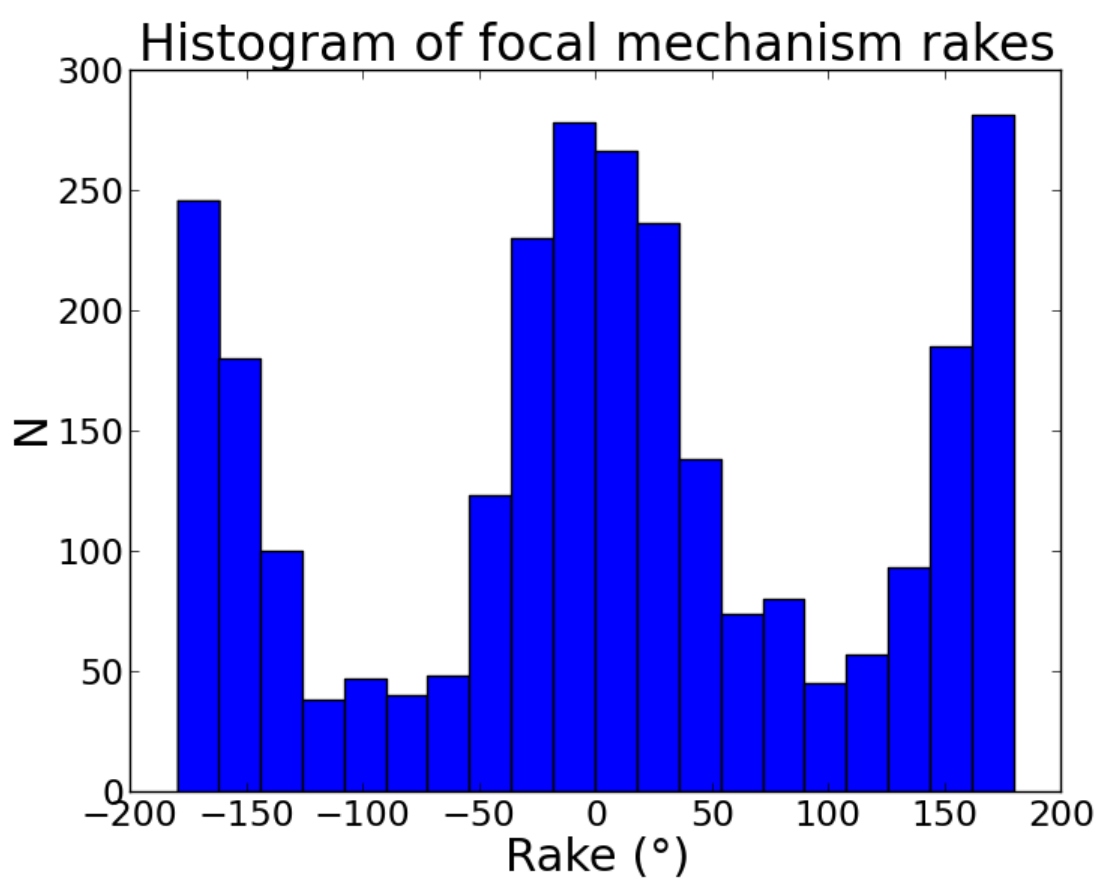

Figure 4.4: Histogram of focal mechanism rake

most stations as the distribution of the angular difference of the two estimates generally exhibit a uniform distribution (Fig. 4.7). Where the distribution is non-uniform e.g. Cch1, the most common value is near zero, indicating some degree of agreement for the two values. These results are expected as previous studies have not found significant agreement between these two values (e.g. Audoine, 2002; Balfour, 2004). In both cases it was assumed that the disagreement was due to re-splitting of the waves. 


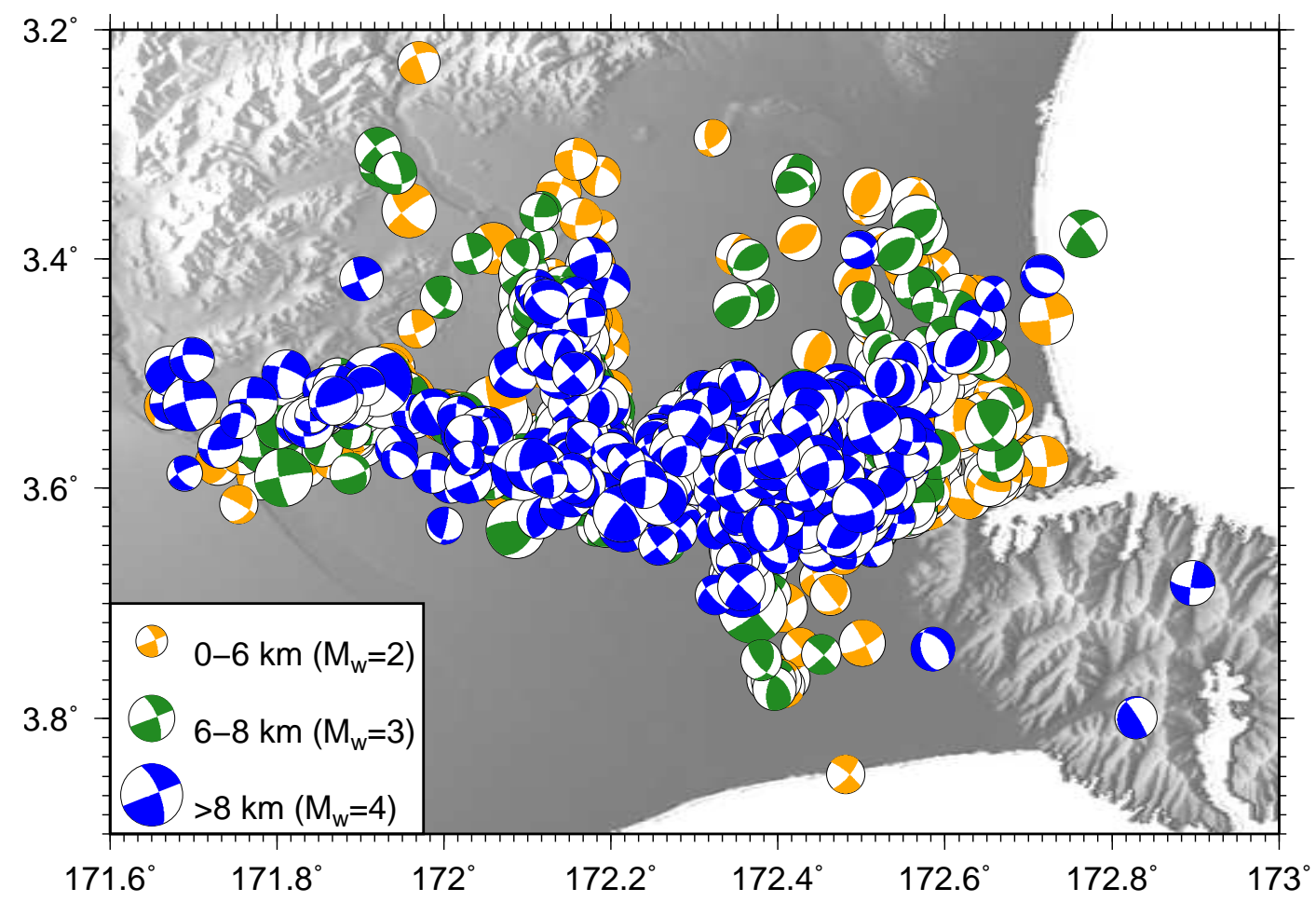

Figure 4.5: All focal mechanisms used in stress inversion study. Size indicates magnitude and colour indicates depth range.

\subsubsection{Stress inversion}

The stress inversion provided a detailed estimate of the stress field (Fig. 4.8) which shows very little variation of $S_{H \max }$ (Table. 4.1) and a mean orientation of $S_{H \max }=116 \pm 18^{\circ}$ (95\% conf.). This is consistent with the work of Townend et al. (2012). $S_{H \max }$ approximates $S_{1}$ for many of the results (Figs. 4.9-4.12) and $S_{2}$ is predominantly vertical/sub-vertical consistent with the expected strike-slip regime.

Beavan et al. (2010) inferred a blind thrust fault (HF in Fig. 4.8) at the western end of the fault trace from GPS data. This observation is supported by field observations of stretched fences and cracking of roads by Quigley 
et al. (2010). Clusters 39 and 54 (Fig 4.9, region 1 in Fig. 4.8) are ambiguous as to whether $S_{2}$ or $S_{3}$ is vertical and thus suggests the region is either a strike-slip or thrust regime. However, the other clusters $(5,14,52)$ indicate a strike-slip regime. $S_{H \max }$ orientation for these clusters is more N-S than those on the plains. This could be due to changing topography, as changes in overburden can alter the stress field and thus cause a rotation (Fialko et al., 2005; Boese et al., 2012).

To the north-east of the Greendale fault is a group of clusters that indicate a thrust regime (Fig. 4.10, region 2 in Fig. 4.8). Clusters 20 and 22 clearly indicate thrust, whereas clusters 25, 29 and 46 show similar 'girdling' of $S_{2}$ and $S_{3}$ as seen for clusters 39 and 54, indicating thrust or strike-slip.

At the Greendale fault, $S_{H \max }$ at the eastern and western ends are highly consistent with average value of $S_{H \max }=116 \pm 18^{\circ}$ (Fig. 4.8). $S_{H \max }$ along the middle of the fault trace is less consistent (Fig. 4.11, region 3 in Fig. 4.8) with several clusters $(9,38,43,44)$ showing $S_{H \max }$ sub-parallel to the fault strike, and sharp variations between neighbouring estimates e.g. cluster 41 between clusters 9 and 43. There are several hypotheses that could explain this variation.

It is possible that the fault produces a stress heterogeneity large enough to rotate the regional stress field $\left(Z\right.$ oback, 1992), though if $S_{H \max }$ was oriented parallel to the fault before the Darfield earthquake it would have been severely misoriented for reactivation (Sibson, 1985). The stress could have rotated after the Darfield earthquake from an optimal reactivation angle to a fault-parallel orientation. This cannot be verified as there is a dearth of pre-mainshock seismicity, but it is possible to assess the implications of such a rotation. Hardebeck and Hauksson (2001) derived a relationship between the ratio of the stress drop and the half of the differential stress $\left(\frac{\Delta \tau}{\tau}\right.$, where $\tau$ is half the differential stress $\left.\left(S_{1}-S_{3}\right) / 2\right)$ and the angle of rotation of $S_{H \max }$ $(\Delta a)$ for rotations near a fault (Eq. $4.1, ' a$ ' is pre-rotation angle between 
$S_{H \max }$ and fault strike).

$$
\Delta a=\tan ^{-1}\left(\frac{1-\frac{\Delta \tau}{\tau} \sin 2 a-\sqrt{\left(\frac{\Delta \tau}{\tau}\right)^{2}+1-2 \frac{\Delta \tau}{\tau} \sin 2 a}}{\frac{\Delta \tau}{\tau} \cos 2 a}\right)
$$

Using an assumed rotation of $\Delta a=25^{\circ}$ (from regional $S_{\text {Hmax }}$ to fault parallel) yields a ratio of stress drop to differential stress of 0.4 , suggesting that $40 \%$ of the stress on the fault was released after the earthquake. Alternately, post-seismic rotation could be related to a change in the loading states of the fault segments (Bohnhoff et al., 2006).

While the earthquakes used for the stress inversion are tightly clustered $(\leq 5$ $\mathrm{km}$, Fig 4.2) it is possible that the stress field in the fault zone is not uniform as assumed in the inversion. Therefore, the variation of stress orientation could represent heterogeneity of the stress field at the fault rather than a systematic rotation.

The remaining stress inversions indicate are highly consistent and indicate a strike-slip regime (Fig. 4.12).

\section{D mapping of stress inversion}

In order to investigate any change in stress orientation with depth, as well as using an alternative grouping method to k-means, events were grouped using a 3D $4 \times 4 \times 4 \mathrm{~km}$ grid. The resulting stress inversions showed similar results to the $2 \mathrm{D}$ inversion, the only exception being a significant variation (no overlap of confidence intervals) at the fault jog (Fig. 4.13), with the deeper estimate being parallel to the average $S_{\text {Hmax }}$ and the shallow one more fault-parallel. As it is the only example of a change and is located at a region of complex faulting, this variation probably represents heterogeneity of the stress field at the jog rather than any systematic variation of stress with depth. 
Bnk1

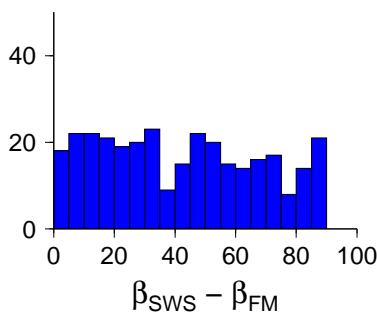

Cch3

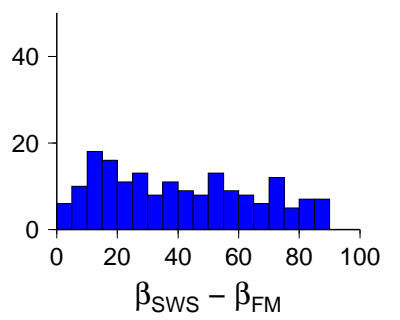

Dar2

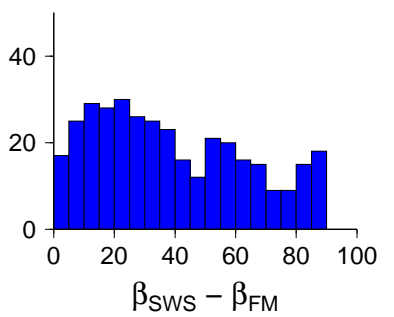

Dar5

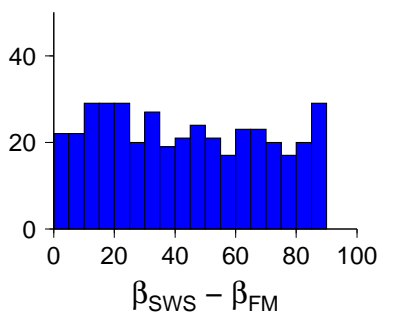

Dar8

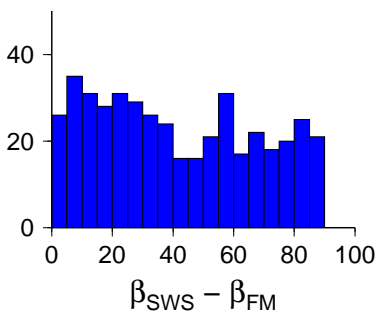

Cch1

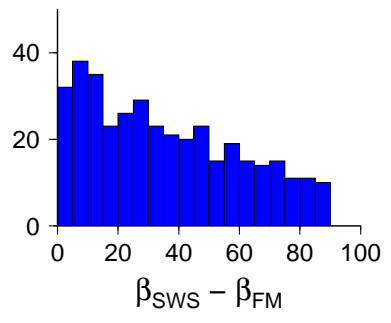

Cch4

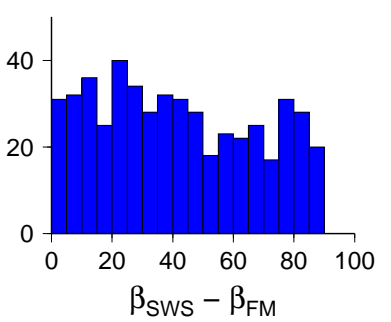

Dar3

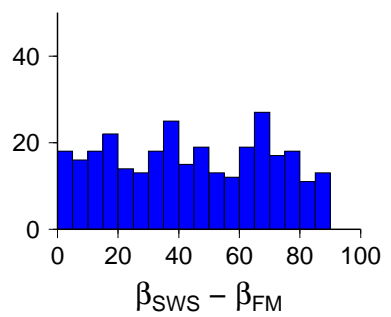

Dar6

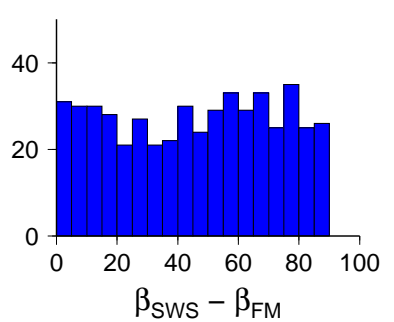

CARD

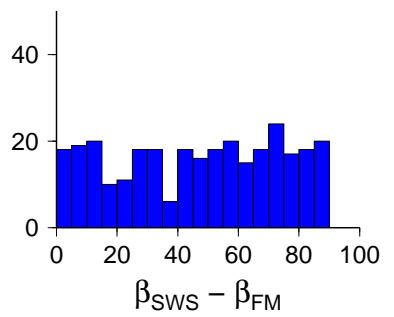

Cch2

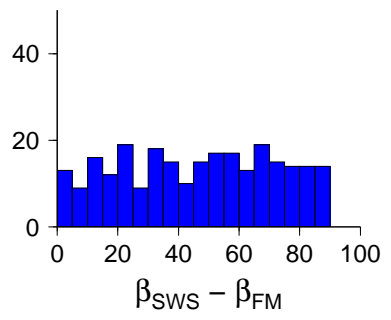

Dar1

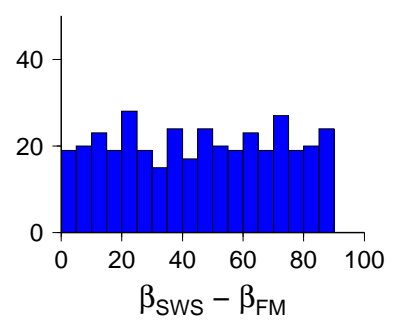

Dar4

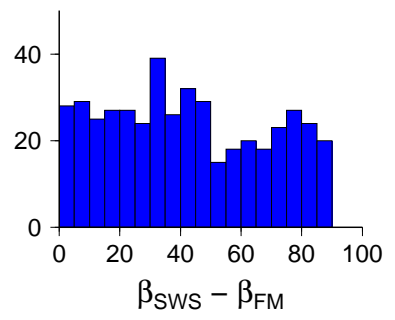

Dar7

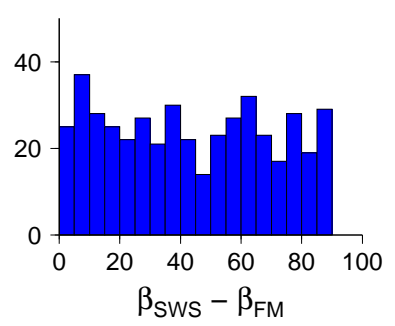

CTND

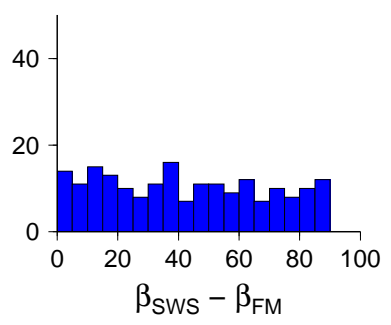

Figure 4.6: Histograms of angular difference between $\beta_{F M}$ and $\beta_{S W S}$ for all stations 

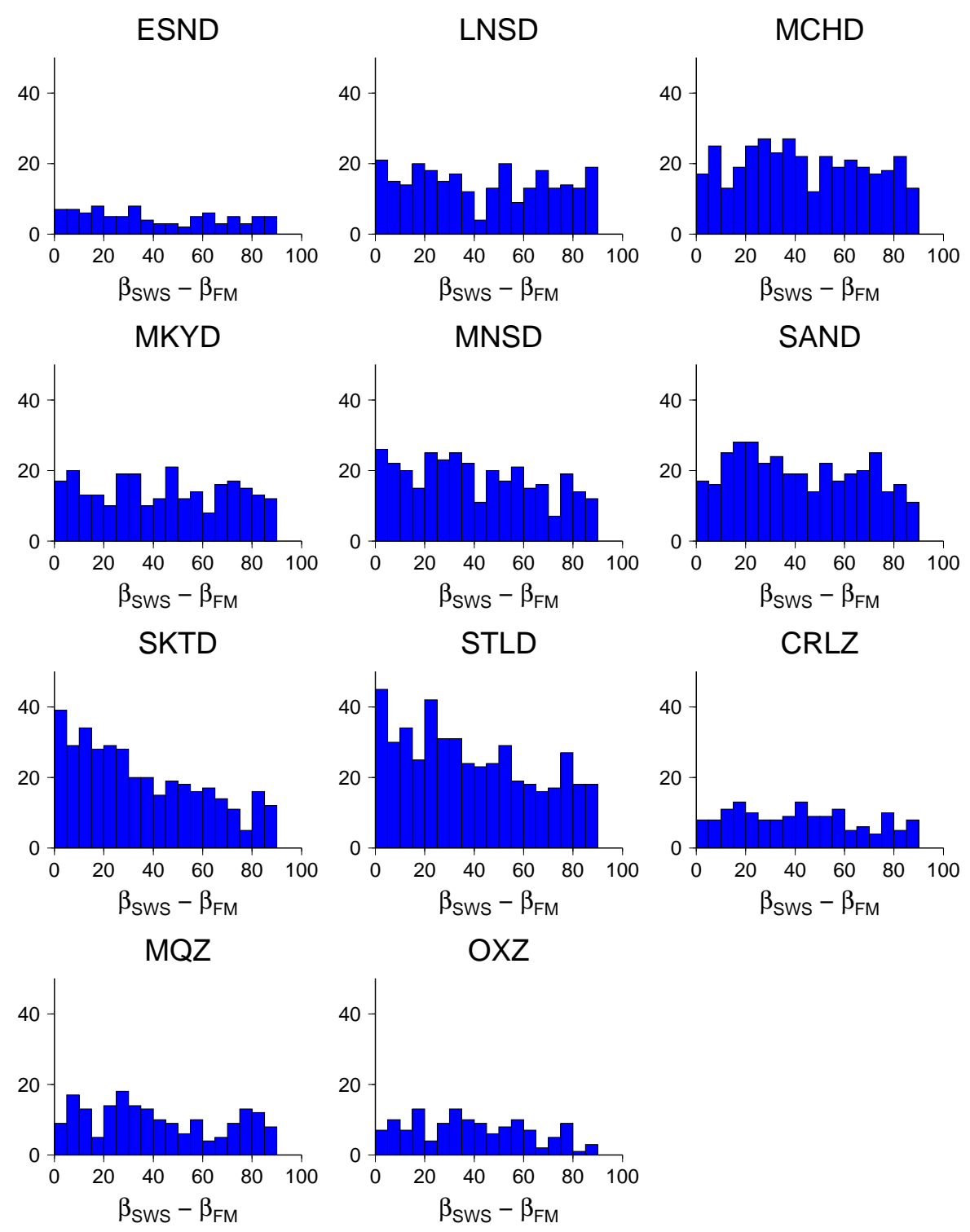

Figure 4.7: Histograms of angular difference between $\beta_{F M}$ and $\beta_{S W S}$ for all stations (cont.) 

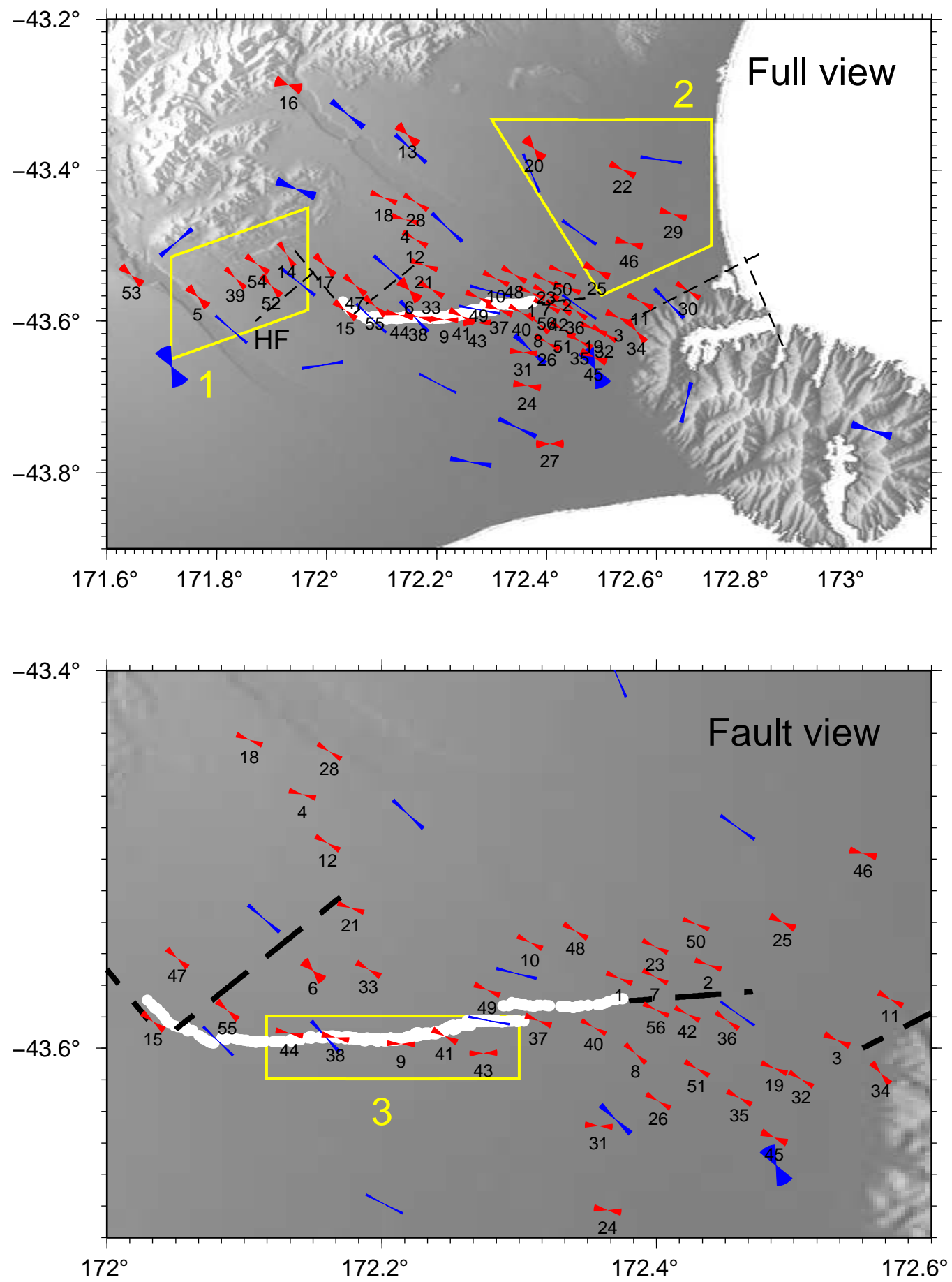

Figure 4.8: $S_{H \max }$ comparison with $\bar{\phi}$. Red bow-ties represent $S_{H \max }$ orientation with $90 \%$ confidence interval shown by width of bow-tie. Blue bow-ties represent $\bar{\phi}$, with $95 \%$ confidence shown by width of bow-tie. Greendale fault in white. Dashed lines are inferred faults from Beavan et al. (2010, 2011) Numbers represent cluster number. HF denotes inferred fault at Hororata. Yellow boxes denote regions of interest discussed in text. Numbers are cluster numbers (Fig. 4.9-4.12, Table 4.1). 


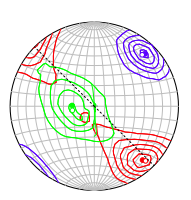

5

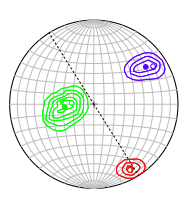

14

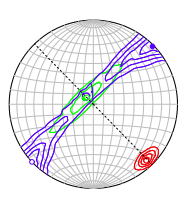

39

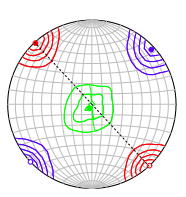

52

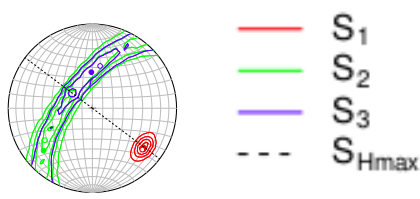

54

Figure 4.9: Principal stress directions for clusters at western end of fault (region 1 in Fig. 4.8) near thrust fault inferred by Beavan et al. (2010), stereonet is horizontal plane i.e. vertical stresses plotted at centre.

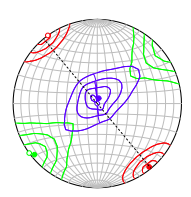

20

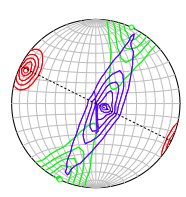

22

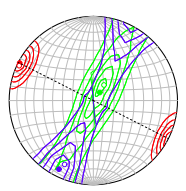

25

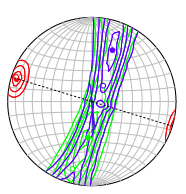

29

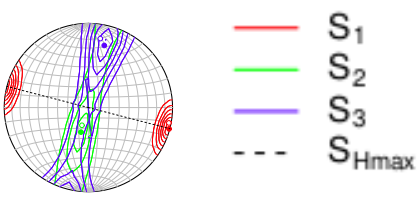

46

Figure 4.10: Principal stress directions for clusters to the north-east of the fault (region 2 in Fig. 4.8), stereonet is horizontal plane i.e. vertical stresses plotted at centre.

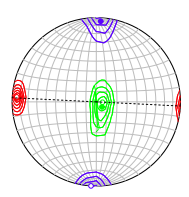

9

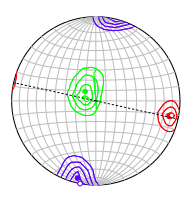

38

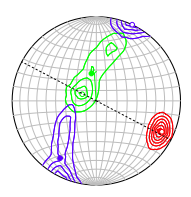

41

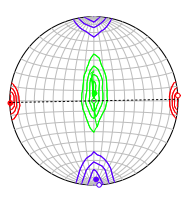

43

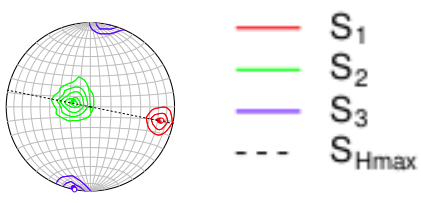

44

Figure 4.11: Principal stress directions for clusters along middle section of Greendale fault (region 3 in Fig. 4.8), stereonet is horizontal plane i.e. vertical stresses plotted at centre. 

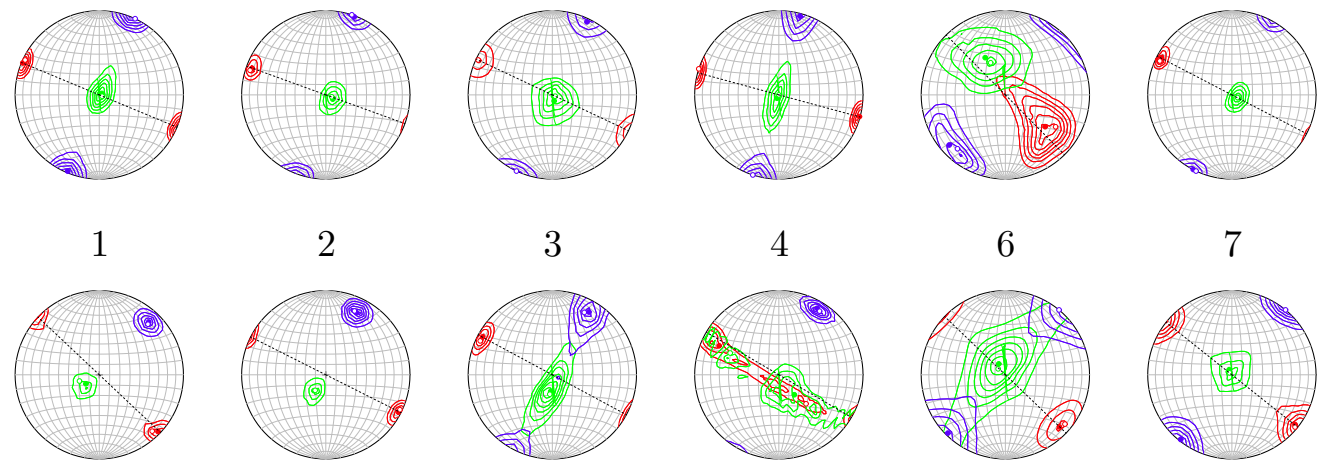

7

8

10

11

12

13
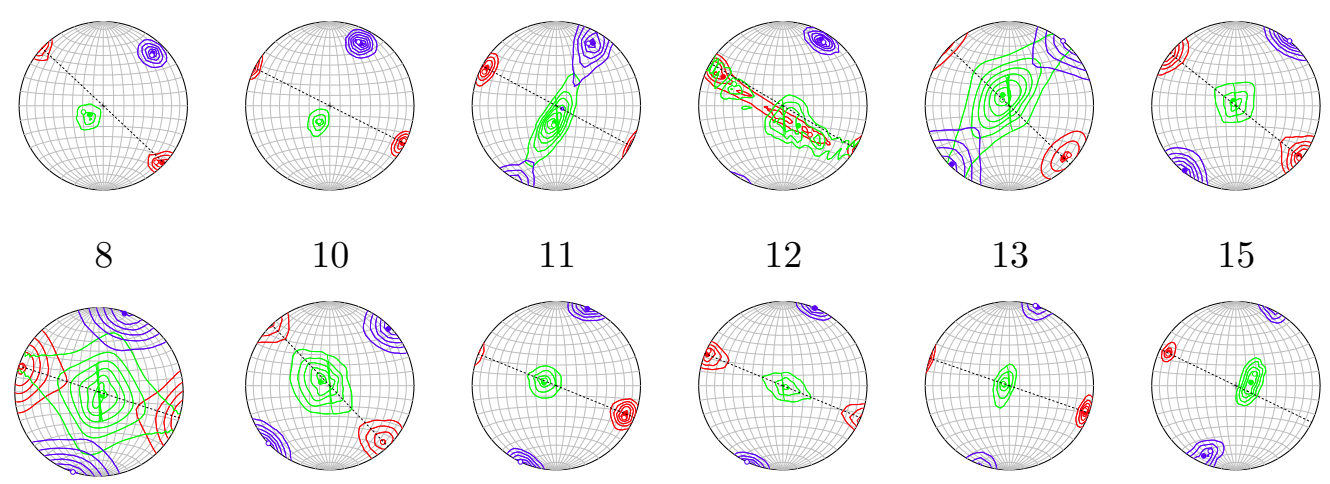

15

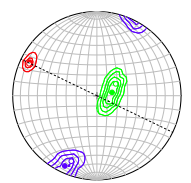

18

19

21

23
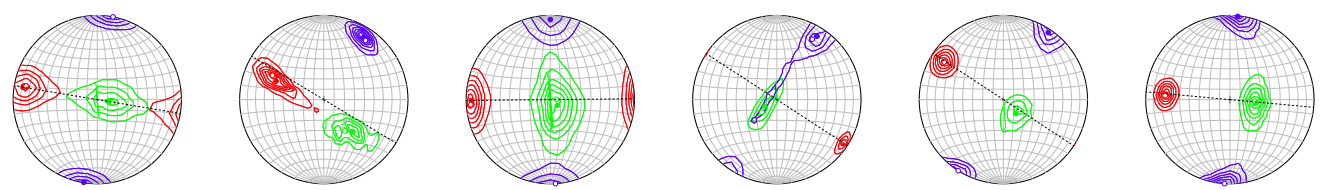

24
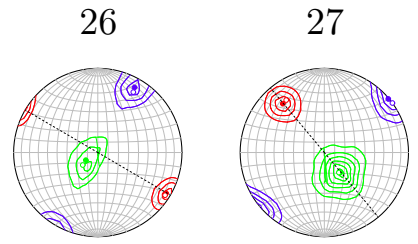

28

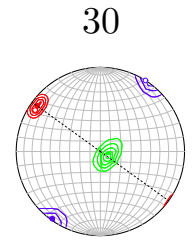

31

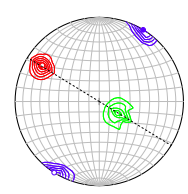

33

34
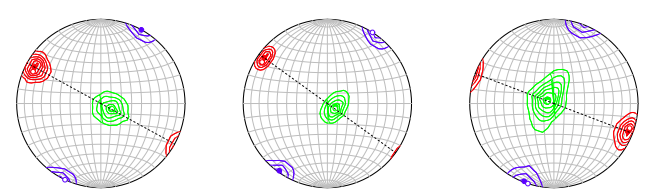

32

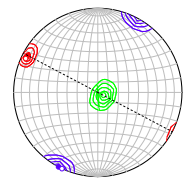

35

36

37
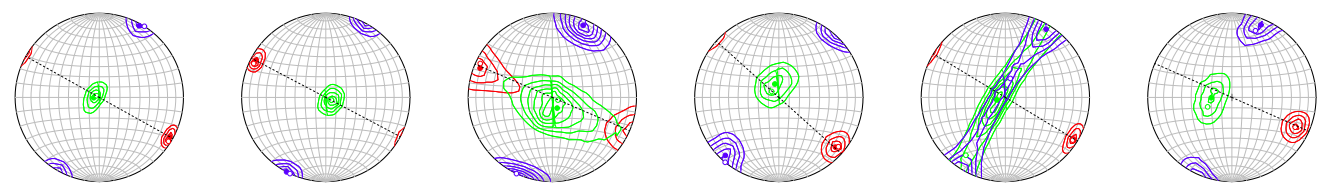

40

42

45

47

48

49
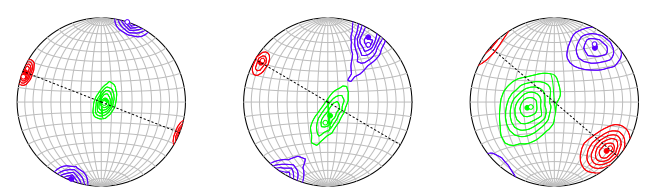

53

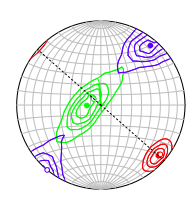

55

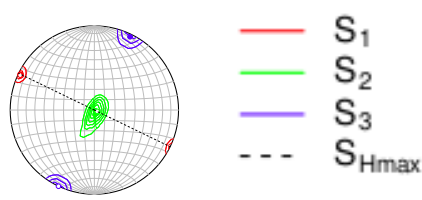

50

51

56

Figure 4.12: Principal stress directions for clusters not previously illustrated, stereonet is horizontal plane i.e. vertical stresses plotted at centre. 


\begin{tabular}{|c|c|c|c|c|c|c|c|c|c|}
\hline Cluster & $\mathrm{N}$ & $\bar{S}_{H \max }$ & $90 \%$ conf. & $\nu$ & Cluster & $\mathrm{N}$ & $\bar{S}_{H \max }$ & $90 \%$ conf. & $\nu$ \\
\hline 1 & 41 & 115.2 & 15.0 & 0.60 & 29 & 20 & 108.0 & 15.5 & 1.00 \\
\hline 2 & 45 & 108.0 & 10.2 & 0.60 & 30 & 42 & 122.4 & 11.6 & 0.50 \\
\hline 3 & 20 & 115.2 & 14.6 & 0.40 & 31 & 33 & 93.6 & 11.7 & 0.70 \\
\hline 4 & 37 & 108.0 & 15.2 & 0.80 & 32 & 62 & 122.4 & 12.7 & 0.40 \\
\hline 5 & 13 & 133.7 & 18.0 & 0.20 & 33 & 26 & 121.7 & 15.5 & 0.60 \\
\hline 6 & 29 & 127.5 & 15.3 & 0.50 & 34 & 21 & 144.0 & 19.5 & 0.40 \\
\hline 7 & 77 & 115.2 & 9.0 & 0.50 & 35 & 37 & 115.2 & 9.0 & 0.30 \\
\hline 8 & 51 & 134.5 & 13.2 & 0.20 & 36 & 50 & 122.4 & 8.4 & 0.60 \\
\hline 9 & 44 & 93.6 & 13.1 & 0.70 & 37 & 36 & 108.0 & 10.6 & 0.60 \\
\hline 10 & 52 & 114.7 & 9.9 & 0.50 & 38 & 38 & 100.8 & 11.5 & 0.60 \\
\hline 11 & 31 & 115.6 & 10.8 & 0.80 & 39 & 52 & 136.8 & 13.3 & 0.90 \\
\hline 12 & 41 & 122.6 & 15.0 & 0.00 & 40 & 83 & 122.4 & 14.4 & 0.60 \\
\hline 13 & 8 & 129.6 & 17.1 & 0.80 & 41 & 42 & 115.2 & 11.8 & 0.40 \\
\hline 14 & 47 & 149.7 & 14.6 & 0.60 & 42 & 60 & 115.2 & 9.0 & 0.50 \\
\hline 15 & 18 & 129.6 & 16.0 & 0.50 & 43 & 42 & 86.4 & 11.2 & 0.60 \\
\hline 16 & 6 & 108.0 & 25.0 & 0.40 & 44 & 33 & 100.8 & 12.6 & 0.40 \\
\hline 17 & 17 & 136.8 & 16.5 & 0.30 & 45 & 16 & 115.2 & 18.9 & 0.30 \\
\hline 18 & 36 & 115.2 & 15.7 & 0.40 & 46 & 17 & 100.7 & 12.1 & 0.90 \\
\hline 19 & 40 & 115.2 & 15.0 & 0.20 & 47 & 29 & 129.6 & 11.4 & 0.60 \\
\hline 20 & 9 & 144.0 & 27.6 & 0.80 & 48 & 30 & 122.4 & 14.4 & 1.00 \\
\hline 21 & 42 & 108.0 & 11.3 & 0.70 & 49 & 29 & 113.5 & 13.6 & 0.70 \\
\hline 22 & 19 & 115.2 & 14.3 & 0.80 & 50 & 73 & 108.0 & 7.8 & 0.60 \\
\hline 23 & 58 & 114.1 & 10.0 & 0.70 & 51 & 38 & 122.9 & 15.0 & 0.80 \\
\hline 24 & 15 & 100.8 & 17.1 & 0.30 & 52 & 18 & 136.8 & 15.8 & 0.50 \\
\hline 25 & 13 & 115.1 & 14.9 & 0.90 & 53 & 12 & 127.7 & 15.5 & 0.60 \\
\hline 26 & 41 & 123.7 & 15.0 & 0.20 & 54 & 39 & 128.2 & 15.3 & 0.90 \\
\hline 27 & 10 & 86.4 & 15.4 & 0.60 & 55 & 25 & 129.6 & 12.8 & 0.80 \\
\hline 28 & 48 & 122.2 & 11.1 & 0.90 & 56 & 74 & 115.2 & 10.4 & 0.60 \\
\hline
\end{tabular}

Table 4.1: Mean values of $S_{H \max }$ estimates of stress ratio $\nu . \mathrm{N}$ is number of focal mechanisms used to calculate stresses in each cluster. 


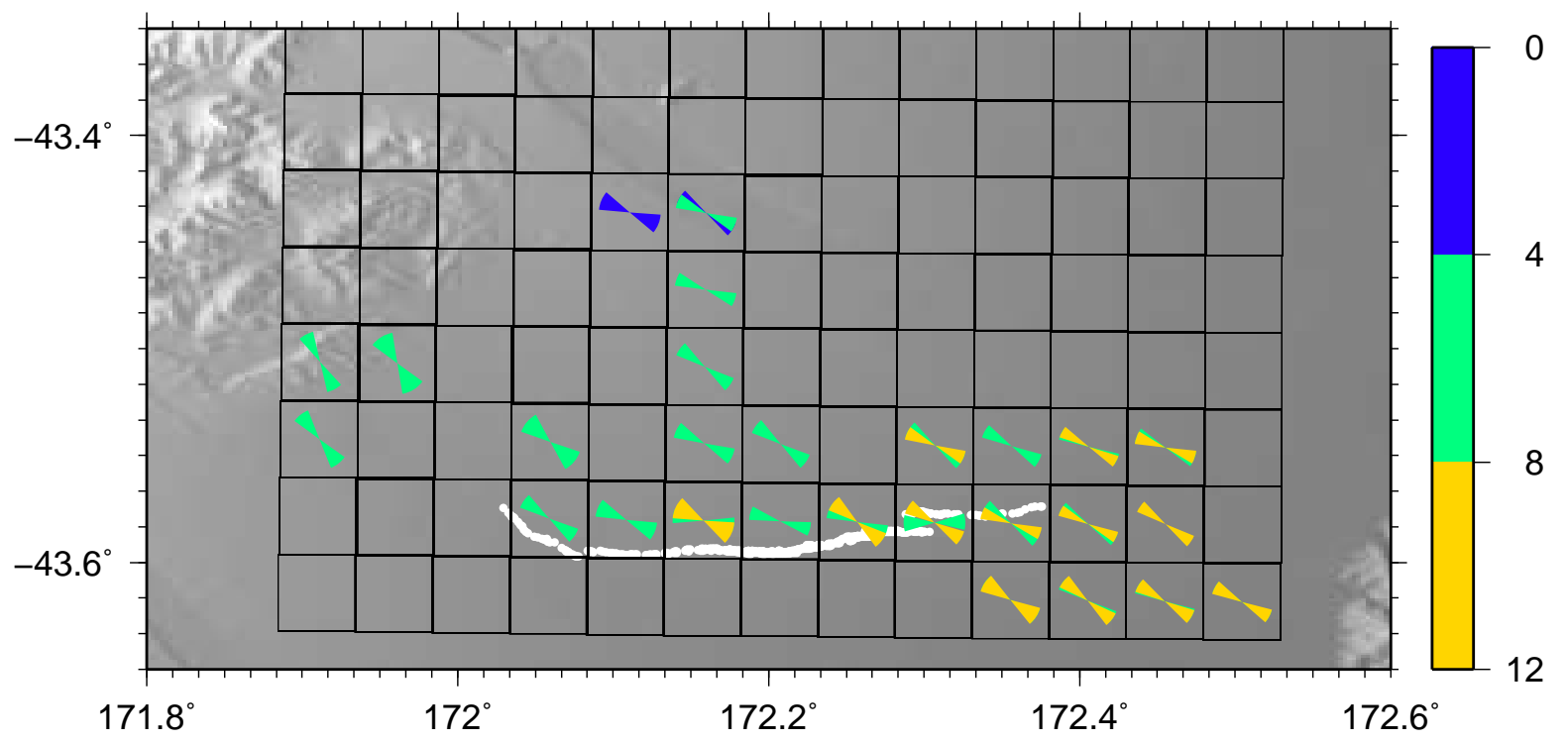

Figure 4.13: 3D stress inversion with $4 \times 4 \times 4 \mathrm{~km}$ regular grid (black lines). Bars represent $S_{H \max }$ and colour represents depth. Only stress estimates with ten or more focal mechanisms are used. Darfield fault in white. 


\subsection{Comparison of SWS and Stress estimates}

The mean values for $\phi$ are compared to the nearest $S_{H \max }$ estimate using a two-sample t-test (Tables. 4.2) for which the two measurements are considered significantly different if $t \geq 1.96$. Excluding the stations for which no alignment with $S_{H \max }$ is expected (Cch3, MCHD, MQZ), the majority of $\bar{\phi}$ match their nearest $S_{H \max }$ estimates (Table. 4.2), consistent with the assertion from Chapter 3 that SWS is predominantly controlled by stress. While some stations that are expected to show agreement between $\bar{\phi}$ and $S_{\text {Hmax }}$ (Dar3, Dar4, MNSD, SKTD) do not show this for the nearest stress estimates, they do have high average F-values (Tables. 4.3) when all $S_{H \max }$ values within $10 \mathrm{~km}$ of the stations are compared with $\bar{\phi}$, suggesting that anisotropy is also stress-induced for these stations. For station Dar7, $\bar{\phi}$ does not compare well with $S_{H \max }$ or with the fault strike, which suggests that $\bar{\phi}$ is indicative of anisotropy further from the fault.

Overall, $\phi$ and $S_{H \max }$ appear well matched, with $\bar{\phi}$ for stations Dar1 and STLD matching the rotation of $S_{H \max }$ at the Southern Alps (clusters 5, 14, $39,52,53,54)$ and station Dar2 matching the rotation of cluster 20 (Fig. 4.8). 


\begin{tabular}{ccccccc}
\hline Station & Cluster & $\bar{\phi}$ & $\mathrm{SE}_{\phi}$ & $S_{H \max }$ & $\mathrm{SE}_{S_{H \max }}$ & t-value (*different) $^{*}$ d \\
\hline Bank1 & 30 & 106.9 & 5.1 & 122.4 & 7.1 & 1.776 \\
Cch1 & 22 & 97.8 & 2.1 & 115.2 & 8.7 & 1.939 \\
Cch2 & 13 & 132.1 & 2.6 & 129.6 & 10.4 & 0.229 \\
Cch3 & 5 & 49.7 & 3.1 & 133.7 & 11.0 & $7.365^{*}$ \\
Cch4 & 24 & 99.7 & 3.2 & 100.8 & 10.4 & 0.103 \\
Dar1 & 5 & 153.2 & 12.5 & 133.7 & 11.0 & 1.169 \\
Dar2 & 20 & 157.1 & 1.6 & 144.0 & 16.8 & 0.774 \\
Dar3 & 31 & 133.4 & 3.8 & 93.6 & 7.1 & $4.921^{*}$ \\
Dar4 & 14 & 128.7 & 2.1 & 149.7 & 8.9 & $2.294^{*}$ \\
Dar5 & 36 & 125.3 & 1.5 & 122.4 & 5.1 & 0.545 \\
Dar6 & 49 & 100.5 & 1.4 & 113.5 & 8.3 & 1.548 \\
Dar7 & 38 & 138.2 & 2.6 & 100.8 & 7.0 & $4.988^{*}$ \\
Dar8 & 55 & 134.2 & 1.5 & 129.6 & 7.8 & 0.583 \\
CARD & 14 & 111.9 & 5.9 & 149.7 & 8.9 & $3.539^{*}$ \\
CTND & 12 & 133.1 & 2.6 & 122.6 & 9.2 & 1.104 \\
ESND & 6 & 131.0 & 2.5 & 127.5 & 9.3 & 0.363 \\
LNSD & 45 & 153.0 & 12.2 & 115.2 & 11.5 & $2.256^{*}$ \\
MCHD & 15 & 81.3 & 2.1 & 129.6 & 9.8 & $4.836^{*}$ \\
MKYD & 24 & 115.2 & 3.3 & 100.8 & 10.4 & 1.318 \\
MNSD & 50 & 125.3 & 2.1 & 108.0 & 4.7 & $3.332^{*}$ \\
SAND & 10 & 104.0 & 1.8 & 114.7 & 6.1 & 1.701 \\
SKTD & 9 & 117.2 & 1.3 & 93.6 & 8.0 & $0.914^{*}$ \\
STLD & 39 & 131.1 & 1.6 & 136.8 & 8.1 & 1.674 \\
CRLZ & 30 & 135.0 & 2.6 & 122.4 & 7.1 & 0.020 \\
MQZ & 34 & 13.7 & 2.7 & 144.0 & 11.9 & \\
OXZ & 13 & 129.4 & 4.2 & 129.6 & 10.4 & \\
\hline & & & & & & \\
\hline
\end{tabular}

Table 4.2: Comparison of $\bar{\phi}$ of each station with the nearest $S_{H \max }$ estimate using two-sample t-test. SE is standard error. Significance determined by whether there is a $\geq 95 \%$ chance the orientations are different (marked by asterisks). 


\begin{tabular}{ccccc}
\hline Station & $\mathrm{N}$ & $\bar{S}_{\text {Hmax }}$ & $\bar{\phi}$ & F-value \\
\hline Cch1 & 2 & 111.6 & 97.8 & 0.94 \\
Cch2 & 4 & 118.8 & 132.1 & 0.93 \\
Cch3 & 2 & 130.7 & 49.7 & 0.03 \\
Dar2 & 1 & 144.0 & 157.1 & 0.95 \\
Dar3 & 14 & 115.6 & 133.4 & 0.88 \\
Dar4 & 5 & 136.2 & 128.7 & 0.97 \\
Dar5 & 17 & 117.2 & 125.3 & 0.97 \\
Dar6 & 11 & 109.7 & 100.5 & 0.93 \\
Dar7 & 8 & 112.1 & 138.2 & 0.78 \\
Dar8 & 6 & 119.7 & 134.2 & 0.89 \\
CARD & 1 & 149.7 & 111.9 & 0.62 \\
CTND & 5 & 116.5 & 133.1 & 0.91 \\
ESND & 11 & 117.6 & 131.0 & 0.91 \\
LNSD & 9 & 121.8 & 153.0 & 0.72 \\
MCHD & 1 & 129.6 & 81.3 & 0.44 \\
MKYD & 2 & 93.6 & 115.2 & 0.85 \\
MNSD & 6 & 110.2 & 125.3 & 0.93 \\
SAND & 10 & 112.6 & 104.0 & 0.93 \\
SKTD & 3 & 103.2 & 117.2 & 0.92 \\
STLD & 4 & 133.9 & 131.1 & 0.99 \\
CRLZ & 4 & 124.3 & 135.0 & 0.93 \\
\hline
\end{tabular}

Table 4.3: Comparison of $\bar{\phi}$ of each station with $S_{H \max }$ estimates within a $10 \mathrm{~km}$ radius using the F-value (See Section 2.3.1). N is number of $S_{H \max }$ estimates within $10 \mathrm{~km}$. F-value of 0.95 or higher indicates average angular difference of $20^{\circ}$ or less. 


\subsection{Conclusions}

The orientations of the principal stresses from the inversions are consistent with a strike-slip regime. Estimates further afield at the western end of the fault and to the north and east of the fault suggest that these may be thrust regimes. The orientation of $S_{H \max }$ is very consistent $\left(S_{H \max }=116 \pm 18^{\circ}\right)$ across the Canterbury plains, except near the fault where there are several fault-parallel estimates. While the cause of this variation is not clear, it does indicate that there was heterogeneity of stress at the fault following the earthquake. Comparison of the shear-wave splitting parameters with those estimated from focal mechanisms revealed that compressive stress has a significant effect on the state of seismic anisotropy on the Canterbury Plains. The comparison of $\beta_{F M}$ and $\beta_{S W S}$ supports the hypothesis that there are other factors e.g. scattering, that have inconsistent effects on the polarisation of the waves before splitting. 


\section{Chapter 5}

\section{Conclusions}

The estimates of tectonic stress for the Canterbury plains indicate a highly consistent direction of maximum stress and a predominantly strike-slip regime, with an average of $S_{H \max }=116 \pm 18^{\circ}$, except in the area near the fault where $S_{H \max }$ exhibits heterogeneity with several possible causes. This variation means that no inferences about the strength of the fault can be made from these data. Further from the fault there is potential evidence for thrust regimes to the west and north/east of the fault.

The orientation of $S_{H \max }$ in the crust beneath the Canterbury plains is well represented by the shear-wave splitting measurements at stations across the plains, with the exception of those near the Darfield fault which are ambiguous (either stress or structure induced anisotropy, and station MCHD whose results are either a result of isotropy near the station or P-SV conversion. The comparison of shear wave splitting parameters and the two initial polarisation estimates illustrates that while there is a consistent overall pattern for $\phi$, there is significant scattering of both $\phi$ and the initial polarisation, and also that $\phi$ can be dependent on the initial polarisation as shown by results at station CARD.

Shear wave splitting results for stations at the Southern Alps (Cch3) and Banks Peninsula (MQZ, Bnk1) show disagreement with the stress estimates, implying structure-controlled anisotropy in these regions and potentially a 
relation between the geological setting (e.g. sedimentary basin, mountain range) and the dominant type of anisotropy.

\section{Further work}

\section{Spatial dependence of $\phi$}

This study provides some evidence for variations in $\phi$ due to the raypath. This could be further investigated by examining earthquake clusters e.g. using the clusters determined by the k-means algorithm for the stress inversions, to reveal any variations due to distance/azimuth. Dar7 would be an ideal station for this as it intersects two branches of seismicity.

\section{Ambiguity of stress at the fault}

Estimating the principal axes of stress from focal mechanisms uses the assumption that the region containing the focal mechanisms has a uniform stress field. However, it is never certain that this is the case. The only way to get a reliable estimate of the stress orientations along the fault would be to drill a borehole. The location of station Dar7 would be ideal as $\phi$ at this station does not compare well with the fault trace or the neighbouring $S_{H \max }$ estimates.

\section{Rotation after Christchurch earthquake?}

The results from this study provide a detailed picture of the state of stress and seismic anisotropy on the Canterbury Plains after a large earthquake. Unfortunately, no such analysis of the stress state prior to the Darfield earthquake is possible. However, it does provide a detailed pre-mainshock dataset for similar work that could be done with data from after the 22 February 2011 earthquake. 


\section{References}

Aki, K., and P. G. Richards (1980), Quantitative seismology theory and methods, W.H. Freeman and Co., San Fransisco.

Anderson, E. M. (1951), The Dynamics of Faulting, Blackwell Publishing.

Anderson, H., and T. Webb (1989), The rupture process of the 1987 Edgecumbe earthquake, New Zealand, New Zealand Journal of Geology and Geophysics, 32, 43-52.

Arnold, R., and J. Townend (2007), A Bayesian approach to estimating tectonic stress from seismological data, Geophysical Journal International, $170(3), 1336-1356$.

Audoine, E., M. K. Savage, and K. Gledhill (2004), Anisotropic structure under a back arc spreading region, the Taupo Volcanic Zone, New Zealand, Journal of Geophysical Research, 109, B11,305, doi:10.1029/2003JB002932.

Audoine, E. L. (2002), Upper mantle and crustal seismic anisotropy across the Pacific-Australian plate boundary, New Zealand, Ph.D. thesis, Victoria University of Wellington, New Zealand.

Babǔska, V., and M. Cara (1991), Seismic Anisotropy in the Earth, Kluwer Academic Publishers.

Balfour, N. (2004), Stress and crustal anisotropy in Marlborough, New Zealand: Evidence for low fault strength and structure controlled 
anisotropy , Master's thesis, Victoria University of Wellington, New Zealand.

Balfour, N. J., M. K. Savage, and J. Townend (2005), Stress and crustal anisotropy in Marlborough, New Zealand: evidence for low fault strength and structure controlled anisotropy., Geophysical Journal International, 163, 1077-1086, doi:10.1111/j.1365-246X.2005.02783.x.

Barnes, P. (2011), In brief: Finding faults - NIWA probes Pegasus Bay, Tech. rep., NIWA, http://www.niwa.co.nz/general/water-atmosphere/wateratmosphere-3-november-2011/in-brief-finding-faults-niwa-probes-pegasusbay.

Beavan, J., S. Samsonov, M. Motagh, L. Wallace, and S. Ellis (2010), The Darfield (Canterbury) earthquake: Geodetic observations and preliminary source model, Bulletin of the New Zealand Society for Earthquake Engineering, 43(4), 228-235.

Beavan, J., M. Motagh, E. J. Fielding, N. Donnelly, and D. Collett (2011), Fault slip models of the 2010-2011 Canterbury, New Zealand, earthquakes from geodetic data and observations of postseismic ground deformation, New Zealand Journal of Geology and Geophysics, 55(3), 207-221.

Boese, C. M., J. Townend, E. Smith, and T. Stern (2012), Microseismicity and stress in the vicinity of the Alpine Fault, central Southern Alps, New Zealand, Journal of Geophysical Research, 11\%, doi:10.1029/2011JB008460.

Bohnhoff, M., H. Grosser, and G. Dresen (2006), Strain partitioning and stress rotation at the North Anatolian fault zone from aftershock focal mechanisms of the 1999 Izmit M w $=7.4$ earthquake, Geophysical Journal International, 166, 373-385, doi:10.1111/j.1365-246X.2006.03027.x.

Booth, D. C., and S. Crampin (1985), Shear-wave polarizations on a curved 
wavefront at an isotropic free surface, Geophysical Journal of the Royal Astronomical Society, doi:10.1111/j.1365-246X.1985.tb05154.x.

Bott, M. (1959), The mechanics of oblique slip faulting, Geology Magazine, pp. 109-117.

Byerlee, J. (1978), Friction of Rocks, Pure and Applied Geophysics, 116, 615-626.

Chiarabba, C., and M. Moretti (2005), An insight into the unrest phenomena at the Campi Flegrei caldera from $V_{P}$ and $V_{P} / V_{S}$ tomography, Terra Nova, 18(6), 373-379, doi:10.1111/j.1365-3121.2006.00701.x.

Cochran, E. S., J. E. Vidale, and Y. G. Li (2003), Near-fault anisotropy following the Hector Mine earthquake, Journal of Geophysics, 108, doi:10.1029/2002JB002352.

Cook, R. A., R. A. Wood, and H. J. Campbell (1989), The Chatham Rise, An exploration frontier, Tech. rep., New Zealand Geological Survey.

Crampin, S. (1985), Evaluation of anisotropy by shear-wave splitting, Geophysics, 50, 142-152.

Crampin, S. (1994), The fracture criticality of crustal rocks, Geophysical Journal International, 118, 491-496.

Crampin, S. (1999), Calculable fluid-rock interactions, Journal of the Geological Society of London, 156(3), 501-514.

Crampin, S., and J. H. Lovell (1991), A decade of shear-wave splitting in the Earth's crust:what does it mean? What use can we make of it? What should we do next?, International Journal of Geophysics, 107, 387-407.

Crotwell, H. P., T. J. Owens, and J. Ristema (1998), The TauP ToolKit: Flexible Seismic Travel-Time and Raypath Utilities, Seismological Research Letters, $70(2), 154-160$. 
Cubrinovski, M., et al. (2010), Geotechnical reconnaissance of the 2010 Darfield (Canterbury) earthquake, Bulletin of the New Zealand Society for Earthquake Engineering, 43(4), 243-320.

Davis, J. (1986), Statistics and data analysis in Geology, John Wiley and sons.

Downes, G., and M. Yetton (2012), Pre-2010 historical seismicity near Christchurch, New Zealand: the 1869 Mw 4.7-4.9 Christchurch and 1870 Mw 5.6 -5.8 Lake Ellesmere earthquakes, New Zealand Journal of Geology and Geophysics, 55(3), 199-205.

Eberhart-Phillips, D., M. Reyners, M. Chadwick, and S. Ellis (2010), Establishing a versatile 3-D seismic model for New Zealand, Seismological Research Letters, 81-6, doi:10.1785/gssrl.81.6.992.

Fialko, Y., L. Rivera, and H. Kanamori (2005), Estimate of differential stress in the upper crust from variations in topography and strike along the San Andreas fault , Geophysical Journal International, 160, 527-532.

Forsyth, P. J., D. J. Barrell, and R. Jongens (2008), Geology of the Christchurch area, Tech. rep., Institute of Geological and Nuclear Sciences Lower Hutt, New Zealand. GNS Science.

Fry, B., and M. C. Gerstenberger (2011), Large apparent stresses from the Canterbury earthquakes of 2010 and 2011, Seismological Research Letters, 82(6), 833-838.

Gerst, A. (2003), Temporal changes in seismic anisotropy as a new eruption forecasting toll?, Master's thesis, Victoria University of Wellington, New Zealand.

Ghisetti, F. C., and R. H. Sibson (2012), Compressional reactivation of E-W inherited normal faults in the area of the 2010-2011 Canterbury earthquake 
sequence, New Zealand Journal of Geology and Geophysics, 55(3), 177184.

Gledhill, K. (1991), Evidence for shallow pervasive seismic anisotropy in the Wellington Region, New Zealand, Journal of Geophysical Research, 96, 21,503-21,516.

Gledhill, K., J. Ristau, M. Reyners, B. Fry, and C. Holden (2011), The Darfield (Canterbury, New Zealand) Mw 7.1 Earthquake of September 2010: A Preliminary Seismological Report, Tech. rep., Institute of Geological and Nuclear Sciences Lower Hutt, New Zealand. GNS Science.

Hardebeck, J. L., and E. Hauksson (2001), Crustal stress field in southern California and its implications for fault mechanics, Journal of Geophysical Research, 106, 21,859-21,882.

Hartigan, J. A. (1975), Clustering algorithms, Wiley, New York.

Hasegawa, A., K. Yoshida, and T. Okada (2011), Nearly complete stress drop in the 2011 Mw 9.0 off the Pacific coast of Tohoku Earthquake, Earth Planets Space, 63, 703-707.

Holt, R. A. (2011), Shear wave splitting on the Canterbury Plains: The Nature of the Greendale Fault, post-grad diploma thesis, Victoria University of Wellington, New Zealand.

Johnson, J. H., M. K. Savage, and J. Townend (2011), Distinguishing between Stress-induced and Structural Anisotropy at Mount Ruapehu Volcano, New Zealand., Journal of Gepohysical Research, 116(B12303), doi:10.1029/2011JB008308.

Jongens, R., D. J. A. Barrel, J. K. Campbell, and J. R. Pettinga (2012), Faulting and folding beneath the Canterbury Plains identified prior to the 2010 emergence of the Greendale Fault, New Zealand Journal of Geology and Geophysics, 55(3), 169-176. 
Kaneshima, S. (1990), Origin of Crustal Anisotropy: Shear wave splitting studies in Japan, Journal of Gepohysical Research, 95(B7), 11,121-11,133.

Leitner, B., D. Eberhart-Phillips, H. Anderson, and J. Nabelek (2001), A focused look at the Alpine Fault, New Zealand: seismicity, focal mechanisms and stress observations, Journal of Gepohysical Research, 106, 2193-2220.

Lomax, A. (2007), The NonLinLoc Software Guide, http://alomax.free.fr/nlloc/.

Lund, B., and J. Townend (2007), Calculating horizontal stress orientations with full or partial knowledge of the tectonic stress tensor, Geophysical Journal International, 170(3), 1328-1335.

McKenzie, D. P. (1969), The relation between fault plane solutions for earthquakes and the directions of the principal stresses, Bulletin of the Seismological Society of America, 59(2), 591-601.

Nistala, S., and G. A. McMechan (2005), 3D Modeling of fracture-induced shear-wave splitting in the Southern California basin, Bulletin of the Seismological Society of America, 95 (3), 1090-1100.

Nur, A. (1972), Dilatancy, pore fluids, and premonitory variations of $t_{S} /$ $t_{P}$ travel times, Bulletin of the Seismological Society of America, 62(5), $1217-1222$.

Nuttli, O. (1961), The effect of the Earth's surface on the S wave particle motion, Bulletin of the Seismological Society of America, 51(2), 237-246.

Okaya, D., N. Christensen, D. Stanley, and T. Stern (1995), Crustal Anisotropy in southern California from local earthquake data, New Zealand Journal of Geology and Geophysics, 38, 579-583.

Paulssen, H. (2004), Crustal anisotropy in southern California from local earthquake data, Geophysical Research Letters, 31(L01601), doi:10.1029/2003GL018654. 
Peck, R., C. Olsen, and J. Devore (2005), Introduction to statistics and data Analysis, Brooks and Cole.

Peng, Z., and Y. Ben-Zion (2004), Systematic analysis of crustal anisotropy along the Karadere-Düzce branch of the north Anatolian fault, Geophysical Journal International, 159, 253-274.

Quigley, M., et al. (2010), Surface rupture of the Greendale fault during the Mw 7.1 Darfield (Canterbury) earthquake, New Zealand: Initial findings, Bulletin of the New Zealand Society for Earthquake Engineering, 43, 236242 .

Quigley, M., et al. (2012), Surface rupture during the $2010 \mathrm{M}_{w} 7.1$ Darfield (Canterbury) earthquake: Implications for fault rupture dynamics and seismic-hazard analysis , Geology, 40(1), 55-58, doi:10.1130/G32528.1.

Reyners, M., D. Eberhart-Phillips, G. Stuart, and Y. Nishimura (2006), Imaging subduction from the trench to $300 \mathrm{~km}$ depth beneath the central North Island, New Zealand, with $V_{P}$ and $V_{P} / V_{S}$, Geophysical Journal International, 165, 565-583, doi:10.1111/j.1365-246X.2006.02897.x.

Rice, J. R. (1992), Fault Stress States, Pore Pressure Distributions, and the Weakness of the San Andreas Fault, EVANS, B. and WONG, T.F. (eds) Fault Mechanics and Transport Properties of Rocks. Academic Press, New York, pp. 475-503.

Ring, U., and S. Hampton (2012), Faulting in Banks Peninsula: tectonic setting and structural controls for late Miocene intraplate volcanism, New Zealand, Journal of the Geological Society of London, 169, 773-785.

Rümpker, G., and P. G. Silver (1998), Apparent shear-wave splitting parameters in the presence of vertically varying anisotropy., Geophysical Journal International, 135, 790-800, doi:10.1046/j.1365-246X.1998.00660.x. 
Savage, M. K. (1999), Seismic anisotropy and mantle deformation: What have we learned from shear-wave splitting?, Reviews of Geophysics, 37, 65-106.

Savage, M. K., W. A. Peppin, and U. R. Vetter (1990), Shear Wave Anisotropy and Stress Direction in and Near Long Valley Caldera, California, 1979-1988, Tech. rep., Seismological Laboratory, Mackay School of Mines, University of Nevada, Reno.

Savage, M. K., A. Wessel, N. A. Teanby, and A. W. Hurst (2010), Automatic measurement of shear wave splitting and applications to time varying anisotropy at Mount Ruapehu volcano, New Zealand, Journal Of Geophysical Research, 115(B12,321), doi:10.1029/2010JB007722.

Sibson, R., F. Ghisetti, and J. Ristau (2011), Stress control of an evolving strike-slip fault system during the 2010-2011 Canterbury, New Zealand, earthquake sequence, Seismological Research Letters, 82, 824-832.

Sibson, R. H. (1974), Frictional constraints on thrust, wrench and normal faults, Nature, 249, 593-603.

Sibson, R. H. (1985), A note on fault reactivation, Journal of Structural Geology, 7(6), 751-754.

Silver, P. G., and M. K. Savage (1994), The interpretation of shear-wave splitting parameters in the presence of two anisotropic layers, Geophysical Journal International, 119, 949-963.

Stein, S., and M. Wysession (2003), An introduction to seismology, earthquakes and earth structure, Blackwell Publishing.

Syracuse, E. M., R. A. Holt, M. K. Savage, J. H. Johnson, C. H. Thurber, K. Unglert, K. N. Allan, S. Karaliyadda, and M. Henderson (2012), Temporal and spatial evolution of hypocentres and anisotropy from the Darfield 
aftershock sequence: Implications for fault geometry and age, New Zealand Journal of Geology and Geophysics, doi:10.1080/00288306.2012.690766.

Tadokoro, K., and M. Ando (2002), Evidence for rapid fault healing derived from temporal changes in S wave splitting, Geophysical Research Letters, 29, 2001 GL013644.

Tarantola, A., and B. Valette (1982), Inverse problems = quest for information, Journal of Geophysics, 50, 159-170.

Teanby, N., J. M. Kendall, and M. van der Baan (2004), Automation of shear-wave splitting measurements using cluster analysis, Bulletin of the Seismological Society of America, 94, 453-463.

Townend, J., and M. D. Zoback (2001), Implications of earthquake focal mechanisms for the frictional strength of the San Andreas fault system, Geological Society, London, Special Publication, 186, 13-21.

Townend, J., and M. D. Zoback (2004), Regional tectonic stress near the San Andreas fault in central and southern California, Geophysical Research Letters, 31(L15S11), doi:10.1029/2003GL018918.

Townend, J., S. Sherburn, R. Arnold, C. Boese, and L. Woods (2012), Threedimensional variations in present-day tectonic stress along the AustraliaPacific plate boundary in central New Zealand, Earth and Planetary Science Letters, 353-354, 47-59.

Unglert, K., M. K. Savage, M. Fournier, T. Okhura, and Y. Abe (2011), Shear-wave splitting, Vp/Vs and GPS During a Time of Enhanced Activity at Aso Caldera, Kyushu, Journal Of Geophysical Research, 116(B11203), doi:10.1029/2011JB008520.

Wallace, R. (1951), Geometry of shearing stress and relation to faulting, Journal of Geology, 59, 118-130. 
Walsh, D. (2008), Directional statistics, Bayesian methods of earthquake focal mechanism estimation, and their application to New Zealand seismicity data, Master's thesis, Victoria University of Wellington, New Zealand.

Walsh, D., R. Arnold, and J. Townend (2009), A Bayesian approach to determining and parametrizing earthquake focal mechanisms., Geophysical Journal International, 176, 235-255, doi:10.1111/j.1365246X.2008.03979.x.

Wessel, A. (2010), Automatic shear wave splitting measurements at Mt. Ruapehu volcano, New Zealand, Master's thesis, Victoria University of Wellington, New Zealand.

Wessel, P., and W. H. F. Smith (1995), New version of the Generic Mapping Tools released, EOS Transactions American Geophysical Union, 76, 329.

Zhang, Z., and S. Schwartz (1994), Seismic anisotropy in the shallow crust of the Loma Prieta segment of the San Andreas fault system, Journal of Geophysical Research, 99(B5), 9651-9661.

Zhao, D., H. Kanamori, and D. Wiens (1997), State of stress before and after the 1994 Northridge earthquake, Geophysical Research Letters, 24, $519-522$.

Zinke, J. C., and M. D. Zoback (2000), Structure-related and stress-induced shear-wave velocity anisotropy: observations from microearthquakes near the Calaveras Fault in central California, Bulletin of the Seismological Society of America, 90, 1305-1312.

Zoback, M. D., and M. L. Zoback (2002), Stress in the Earth's Lithosphere, Academic Press, 16, 143-154.

Zoback, M. L. (1992), First- and Second-Order Patterns of Stress in the Lithosphere: The World Stress Map Project, Journal of Geophysical Research, 97 (B8), 11,703-11,728. 


\section{Appendix A}

\section{Glossary of variables}

\section{A.1 Glossary of variables}

The following table gives a brief description of all variables used for analysis in this research:

\section{A.1.1 $\beta_{S W S}$ and $\beta_{F M}$}

There are two uses of the term "initial polarisation" in this research. One $\left(\beta_{S W S}\right)$ refers to the polarisation estimated for a given wave by the MFAST shear-wave splitting program (described in Chapter 3) before the wave is split. The other $\left(\beta_{F M}\right)$ refers to the polarisation of a shear-wave at the source, estimated using focal mechanism parameters (see above). The distinction is necessary as the wave may split more than once along the raypath, thus $\beta_{S W S}$ could represent the fast/slow polarisation of an earlier splitting occurrence rather than an estimate of $\beta_{F M}$. 


\begin{tabular}{ll}
\hline Symbol & Explanation \\
\hline$S_{H \text { max }}$ & Maximum horizontal compressive stress \\
$\phi$ & Fast azimuth of anisotropy \\
$\delta \mathrm{t}$ & Delay time between two split shear waves \\
$S_{1}\left(S_{\max }\right)$ & Maximum compressive stress \\
$S_{2}\left(S_{\text {mid }}\right)$ & Intermediate compressive stress \\
$S_{3}\left(S_{\text {min }}\right)$ & Minimum compressive stress \\
$\xi, \delta, \lambda$ & Strike,Dip and Rake angles for focal mechanisms \\
$i_{n}$ & Take-off angle for event measured at a given station (see Fig. 2.4) \\
$\theta_{n}$ & Event-station azimuth \\
$\beta_{S W S}$ & Initial polarisation of wave determined by shear wave splitting code \\
$\beta_{F M}$ & Initial polarisation of wave determined from focal mechanism data \\
$\nu$ & Stress ratio \\
$i_{c}$ & Critical angle of incidence (see Fig. 3.5) \\
$i_{t}$ & Angle of incidence (see Fig. 3.5) \\
$i_{s}$ & Straight-line angle of incidence(see Fig. 3.5) \\
$\kappa$ & Concentration parameter/uncertainty of focal mechanism \\
$f_{s}$ & Dominant shear-wave frequency \\
\hline
\end{tabular}

Table A.1: List of variables used in this Thesis 


\section{Appendix B}

\section{Correlation tables}

The following are tables detailing the correlation coefficients and P-values for a number of variables from the shear-wave splitting data. $\delta$ t is normalised by hypocentral distance. 'dist.' is hypocentral distance. 'baz' is back azimuth. $l_{\max }$ is maximum eigenvalue of the covariance matrix from the shear-wave splitting algorithm. $f_{s}$ is dominant shear-wave frequency. $\beta_{S W S}$ is incoming polarisation determined shear-wave splitting estimates. Both axes show the same set of parameters.

\begin{tabular}{|c|c|c|c|c|c|c|c|c|c|c|}
\hline & $\begin{array}{l}V_{P} / V_{S} \\
\text { ratio }\end{array}$ & $\delta \mathrm{t}$ & depth & $\phi$ & $\begin{array}{l}\text { S-wave } \\
\text { travel } \\
\text { time }\end{array}$ & $\begin{array}{l}\text { back } \\
\text { az- } \\
\text { imuth }\end{array}$ & dist. & $l_{\max }$ & $\beta_{S W S}$ & $f_{s}$ \\
\hline$V_{P} / V_{S}$ & 1.000 & -0.137 & $-0.331^{*}$ & -0.145 & $0.381^{*}$ & $-0.221^{*}$ & $0.402^{*}$ & 0.032 & 0.091 & -0.047 \\
\hline$\delta \mathrm{t}$ & -0.137 & 1.000 & 0.013 & 0.005 & $-0.372^{*}$ & $0.291 *$ & $-0.366^{*}$ & -0.109 & 0.009 & $-0.308^{*}$ \\
\hline depth & $-0.331^{*}$ & 0.013 & 1.000 & 0.100 & $-0.248^{*}$ & $0.366^{*}$ & $-0.273^{*}$ & -0.056 & -0.021 & 0.038 \\
\hline$\phi$ & -0.145 & 0.005 & 0.100 & 1.000 & 0.028 & 0.107 & 0.002 & -0.036 & -0.130 & -0.027 \\
\hline S-time & $0.381^{*}$ & $-0.372^{*}$ & $-0.248^{*}$ & 0.028 & 1.000 & $-0.275^{*}$ & $0.989^{*}$ & 0.017 & 0.010 & -0.065 \\
\hline baz & $-0.221^{*}$ & $0.291^{*}$ & $0.366^{*}$ & 0.107 & $-0.275^{*}$ & 1.000 & $-0.313^{*}$ & -0.036 & 0.023 & $-0.210^{*}$ \\
\hline dist. & $0.402^{*}$ & $-0.366^{*}$ & $-0.273^{*}$ & 0.002 & $0.989^{*}$ & $-0.313^{*}$ & 1.000 & 0.020 & 0.021 & -0.041 \\
\hline$l_{\max }$ & 0.032 & -0.109 & -0.056 & -0.036 & 0.017 & -0.036 & 0.020 & 1.000 & 0.024 & $0.176^{*}$ \\
\hline$\beta_{S W S}$ & 0.091 & 0.009 & -0.021 & -0.130 & 0.010 & 0.023 & 0.021 & 0.024 & 1.000 & -0.015 \\
\hline$f_{s}$ & -0.047 & $-0.308^{*}$ & 0.038 & -0.027 & -0.065 & $-0.210^{*}$ & -0.041 & $0.176^{*}$ & -0.015 & 1.000 \\
\hline
\end{tabular}

Table B.1: Correlation coefficients for all correlations for station Bnk1. Starred $(*)$ values are significant correlations $(\mathrm{P} \leq 0.05)$ 


\begin{tabular}{|c|c|c|c|c|c|c|c|c|c|c|}
\hline & $\begin{array}{l}V_{P} / V_{S} \\
\text { ratio }\end{array}$ & $\delta \mathrm{t}$ & depth & $\phi$ & $\begin{array}{l}\text { S-wave } \\
\text { travel } \\
\text { time }\end{array}$ & $\begin{array}{l}\text { back } \\
\text { az- } \\
\text { imuth }\end{array}$ & dist. & $l_{\max }$ & $\beta_{S W S}$ & $f_{s}$ \\
\hline$V_{P} / V_{S}$ & 1.000 & $0.218^{*}$ & $-0.232^{*}$ & -0.016 & $-0.295^{*}$ & -0.090 & $-0.394^{*}$ & 0.044 & -0.083 & -0.144 \\
\hline$\delta \mathrm{t}$ & $0.218^{*}$ & 1.000 & -0.063 & -0.113 & -0.041 & -0.042 & $-0.248^{*}$ & -0.087 & -0.024 & -0.115 \\
\hline depth & $-0.232^{*}$ & -0.063 & 1.000 & $0.188^{*}$ & $0.323^{*}$ & $0.374^{*}$ & $0.359^{*}$ & $-0.206^{*}$ & 0.100 & 0.083 \\
\hline$\phi$ & -0.016 & -0.113 & $0.188^{*}$ & 1.000 & 0.122 & $0.165^{*}$ & $0.177^{*}$ & $-0.169^{*}$ & -0.019 & -0.076 \\
\hline S-time & $-0.295^{*}$ & -0.041 & $0.323^{*}$ & 0.122 & 1.000 & $0.455^{*}$ & $0.826^{*}$ & -0.069 & -0.081 & $-0.209^{*}$ \\
\hline baz & -0.090 & -0.042 & $0.374 *$ & $0.165^{*}$ & $0.455^{*}$ & 1.000 & $0.522 *$ & $-0.199^{*}$ & -0.015 & -0.115 \\
\hline dist. & $-0.394 *$ & $-0.248^{*}$ & $0.359^{*}$ & $0.177^{*}$ & $0.826^{*}$ & $0.522 *$ & 1.000 & 0.017 & -0.073 & $-0.175^{*}$ \\
\hline$l_{\max }$ & 0.044 & -0.087 & $-0.206^{*}$ & $-0.169^{*}$ & -0.069 & $-0.199 *$ & 0.017 & 1.000 & $-0.174^{*}$ & 0.085 \\
\hline$\beta_{S W S}$ & -0.083 & -0.024 & 0.100 & -0.019 & -0.081 & -0.015 & -0.073 & $-0.174^{*}$ & 1.000 & 0.072 \\
\hline$f_{s}$ & -0.144 & -0.115 & 0.083 & -0.076 & $-0.209 *$ & -0.115 & $-0.175^{*}$ & 0.085 & 0.072 & 1.000 \\
\hline
\end{tabular}

Table B.2: Correlation coefficients for all correlations for station Cch1. Starred $(*)$ values are significant correlations $(\mathrm{P} \leq 0.05)$

\begin{tabular}{|c|c|c|c|c|c|c|c|c|c|c|}
\hline & $\begin{array}{l}V_{P} / V_{S} \\
\text { ratio }\end{array}$ & $\delta \mathrm{t}$ & depth & $\phi$ & $\begin{array}{l}\text { S-wave } \\
\text { travel } \\
\text { time }\end{array}$ & $\begin{array}{l}\text { back } \\
\text { az- } \\
\text { imuth }\end{array}$ & dist. & $l_{\max }$ & $\beta_{S W S}$ & $f_{s}$ \\
\hline$\overline{V_{P} / V_{S}}$ & 1.000 & -0.041 & 0.002 & 0.068 & $0.292^{*}$ & 0.005 & 0.002 & 0.046 & -0.087 & $-0.211^{*}$ \\
\hline$\delta \mathrm{t}$ & -0.041 & 1.000 & 0.112 & $-0.169^{*}$ & -0.060 & 0.104 & 0.108 & -0.038 & -0.018 & $-0.212^{*}$ \\
\hline depth & 0.002 & 0.112 & 1.000 & 0.064 & -0.077 & $0.998^{*}$ & $1.000 *$ & 0.025 & -0.131 & 0.057 \\
\hline$\phi$ & 0.068 & $-0.169^{*}$ & 0.064 & 1.000 & 0.048 & 0.062 & 0.064 & $-0.153^{*}$ & -0.059 & -0.024 \\
\hline S-time & $0.292^{*}$ & -0.060 & -0.077 & 0.048 & 1.000 & -0.066 & -0.069 & -0.059 & -0.131 & -0.145 \\
\hline baz & 0.005 & 0.104 & $0.998^{*}$ & 0.062 & -0.066 & 1.000 & $0.998^{*}$ & 0.023 & -0.124 & 0.047 \\
\hline dist. & 0.002 & 0.108 & $1.000 *$ & 0.064 & -0.069 & $0.998^{*}$ & 1.000 & 0.026 & -0.133 & 0.055 \\
\hline$l_{\max }$ & 0.046 & -0.038 & 0.025 & $-0.153^{*}$ & -0.059 & 0.023 & 0.026 & 1.000 & -0.110 & 0.039 \\
\hline$\beta_{S W S}$ & -0.087 & -0.018 & -0.131 & -0.059 & -0.131 & -0.124 & -0.133 & -0.110 & 1.000 & 0.133 \\
\hline$f_{s}$ & $-0.211^{*}$ & $-0.212^{*}$ & 0.057 & -0.024 & -0.145 & 0.047 & 0.055 & 0.039 & 0.133 & 1.000 \\
\hline
\end{tabular}

Table B.3: Correlation coefficients for all correlations for station Cch2. Starred $(*)$ values are significant correlations $(\mathrm{P} \leq 0.05)$

\begin{tabular}{|c|c|c|c|c|c|c|c|c|c|c|}
\hline & $\begin{array}{l}V_{P} / V_{S} \\
\text { ratio }\end{array}$ & $\delta \mathrm{t}$ & depth & $\phi$ & $\begin{array}{l}\text { S-wave } \\
\text { travel } \\
\text { time }\end{array}$ & $\begin{array}{l}\text { back } \\
\text { az- } \\
\text { imuth }\end{array}$ & dist. & $l_{\max }$ & $\beta_{S W S}$ & $f_{s}$ \\
\hline$V_{P} / V_{S}$ & 1.000 & 0.084 & -0.005 & -0.033 & $0.106^{*}$ & -0.004 & $0.104^{*}$ & -0.012 & -0.094 & 0.004 \\
\hline$\delta \mathrm{t}$ & 0.084 & 1.000 & -0.071 & -0.071 & $-0.465^{*}$ & $0.179^{*}$ & $-0.531 *$ & -0.068 & 0.084 & $-0.117^{*}$ \\
\hline depth & -0.005 & -0.071 & 1.000 & 0.078 & $0.104^{*}$ & $0.108^{*}$ & $0.178^{*}$ & 0.059 & 0.049 & -0.015 \\
\hline$\phi$ & -0.033 & -0.071 & 0.078 & 1.000 & 0.077 & -0.071 & $0.116^{*}$ & 0.072 & -0.038 & -0.016 \\
\hline S-time & $0.106^{*}$ & $-0.465^{*}$ & $0.104^{*}$ & 0.077 & 1.000 & $-0.114^{*}$ & $0.877^{*}$ & 0.047 & -0.053 & $0.119^{*}$ \\
\hline baz & -0.004 & $0.179^{*}$ & $0.108^{*}$ & -0.071 & $-0.114^{*}$ & 1.000 & $-0.214^{*}$ & -0.022 & 0.085 & -0.021 \\
\hline dist. & $0.104^{*}$ & $-0.531 *$ & $0.178^{*}$ & $0.116^{*}$ & $0.877^{*}$ & $-0.214^{*}$ & 1.000 & 0.064 & $-0.114^{*}$ & $0.118^{*}$ \\
\hline$l_{\max }$ & -0.012 & -0.068 & 0.059 & 0.072 & 0.047 & -0.022 & 0.064 & 1.000 & -0.005 & 0.065 \\
\hline$\beta_{S W S}$ & -0.094 & 0.084 & 0.049 & -0.038 & -0.053 & 0.085 & $-0.114^{*}$ & -0.005 & 1.000 & -0.037 \\
\hline$f_{s}$ & 0.004 & $-0.117^{*}$ & -0.015 & -0.016 & $0.119^{*}$ & -0.021 & $0.118^{*}$ & 0.065 & -0.037 & 1.000 \\
\hline
\end{tabular}

Table B.4: Correlation coefficients for all correlations for station Cch3. Starred $(*)$ values are significant correlations $(\mathrm{P} \leq 0.05)$ 


\begin{tabular}{|c|c|c|c|c|c|c|c|c|c|c|}
\hline & $\begin{array}{l}V_{P} / V_{S} \\
\text { ratio }\end{array}$ & $\delta \mathrm{t}$ & depth & $\phi$ & $\begin{array}{l}\text { S-wave } \\
\text { travel } \\
\text { time }\end{array}$ & $\begin{array}{l}\text { back } \\
\text { az- } \\
\text { imuth }\end{array}$ & dist. & $l_{\max }$ & $\beta_{S W S}$ & $f_{s}$ \\
\hline$V_{P} / V_{S}$ & 1.000 & 0.019 & 0.034 & 0.010 & -0.064 & 0.033 & 0.031 & 0.036 & 0.048 & -0.082 \\
\hline$\delta \mathrm{t}$ & 0.019 & 1.000 & 0.117 & -0.148 & -0.048 & 0.099 & 0.114 & -0.066 & -0.067 & $-0.289^{*}$ \\
\hline depth & 0.034 & 0.117 & 1.000 & -0.014 & 0.026 & $0.995^{*}$ & $1.000 *$ & 0.040 & 0.047 & 0.077 \\
\hline$\phi$ & 0.010 & -0.148 & -0.014 & 1.000 & 0.039 & -0.015 & -0.014 & -0.078 & -0.083 & 0.068 \\
\hline S-time & -0.064 & -0.048 & 0.026 & 0.039 & 1.000 & 0.048 & 0.033 & -0.065 & -0.110 & $-0.189^{*}$ \\
\hline baz & 0.033 & 0.099 & $0.995^{*}$ & -0.015 & 0.048 & 1.000 & $0.995^{*}$ & 0.030 & 0.058 & 0.069 \\
\hline dist. & 0.031 & 0.114 & $1.000^{*}$ & -0.014 & 0.033 & $0.995^{*}$ & 1.000 & 0.040 & 0.046 & 0.076 \\
\hline$l_{\max }$ & 0.036 & -0.066 & 0.040 & -0.078 & -0.065 & 0.030 & 0.040 & 1.000 & -0.108 & $0.178^{*}$ \\
\hline$\beta_{S W S}$ & 0.048 & -0.067 & 0.047 & -0.083 & -0.110 & 0.058 & 0.046 & -0.108 & 1.000 & $0.171^{*}$ \\
\hline$f_{s}$ & -0.082 & $-0.289^{*}$ & 0.077 & 0.068 & $-0.189^{*}$ & 0.069 & 0.076 & $0.178^{*}$ & $0.171^{*}$ & 1.000 \\
\hline
\end{tabular}

Table B.5: Correlation coefficients for all correlations for station Cch4. Starred $(*)$ values are significant correlations $(\mathrm{P} \leq 0.05)$

\begin{tabular}{|c|c|c|c|c|c|c|c|c|c|c|}
\hline & $\begin{array}{l}V_{P} / V_{S} \\
\text { ratio }\end{array}$ & $\delta \mathrm{t}$ & depth & $\phi$ & $\begin{array}{l}\text { S-wave } \\
\text { travel } \\
\text { time }\end{array}$ & $\begin{array}{l}\text { back } \\
\text { az- } \\
\text { imuth }\end{array}$ & dist. & $l_{\max }$ & $\beta_{S W S}$ & $f_{s}$ \\
\hline$V_{P} / V_{S}$ & 1.000 & -0.079 & -0.110 & -0.000 & $0.187^{*}$ & -0.072 & $0.178^{*}$ & -0.017 & -0.028 & -0.036 \\
\hline$\delta \mathrm{t}$ & -0.079 & 1.000 & -0.005 & 0.029 & $-0.281^{*}$ & 0.075 & $-0.259^{*}$ & -0.050 & $0.186^{*}$ & -0.049 \\
\hline depth & -0.110 & -0.005 & 1.000 & 0.035 & $-0.117^{*}$ & $0.324^{*}$ & -0.090 & -0.058 & -0.037 & 0.005 \\
\hline$\phi$ & -0.000 & 0.029 & 0.035 & 1.000 & -0.003 & 0.028 & -0.003 & 0.027 & 0.054 & -0.005 \\
\hline S-time & $0.187^{*}$ & $-0.281^{*}$ & $-0.117^{*}$ & -0.003 & 1.000 & 0.077 & $0.943^{*}$ & -0.000 & -0.101 & -0.000 \\
\hline baz & -0.072 & 0.075 & $0.324^{*}$ & 0.028 & 0.077 & 1.000 & 0.084 & -0.019 & -0.093 & -0.021 \\
\hline dist. & $0.178^{*}$ & $-0.259^{*}$ & -0.090 & -0.003 & $0.943^{*}$ & 0.084 & 1.000 & -0.019 & -0.083 & $-0.309 *$ \\
\hline$l_{\max }$ & -0.017 & -0.050 & -0.058 & 0.027 & -0.000 & -0.019 & -0.019 & 1.000 & $-0.121^{*}$ & 0.016 \\
\hline$\beta_{S W S}$ & -0.028 & $0.186^{*}$ & -0.037 & 0.054 & -0.101 & -0.093 & -0.083 & $-0.121^{*}$ & 1.000 & -0.038 \\
\hline$f_{S}$ & -0.036 & -0.049 & 0.005 & -0.005 & -0.000 & -0.021 & $-0.309^{*}$ & 0.016 & -0.038 & 1.000 \\
\hline
\end{tabular}

Table B.6: Correlation coefficients for all correlations for station Dar1. Starred $(*)$ values are significant correlations $(\mathrm{P} \leq 0.05)$

\begin{tabular}{|c|c|c|c|c|c|c|c|c|c|c|}
\hline & $\begin{array}{l}V_{P} / V_{S} \\
\text { ratio }\end{array}$ & $\delta \mathrm{t}$ & depth & $\phi$ & $\begin{array}{l}\text { S-wave } \\
\text { travel } \\
\text { time }\end{array}$ & $\begin{array}{l}\text { back } \\
\text { az- } \\
\text { imuth }\end{array}$ & dist. & $l_{\max }$ & $\beta_{S W S}$ & $f_{s}$ \\
\hline$\overline{V_{P} / V_{S}}$ & 1.000 & $-0.240^{*}$ & 0.004 & 0.100 & $0.216^{*}$ & 0.019 & $0.231^{*}$ & 0.027 & $0.124^{*}$ & 0.001 \\
\hline$\delta \mathrm{t}$ & $-0.240 *$ & 1.000 & -0.081 & -0.008 & $-0.292^{*}$ & -0.023 & $-0.282^{*}$ & $-0.177^{*}$ & $-0.146 *$ & -0.016 \\
\hline depth & 0.004 & -0.081 & 1.000 & -0.050 & -0.057 & $0.119^{*}$ & -0.054 & 0.106 & 0.006 & -0.058 \\
\hline$\phi$ & 0.100 & -0.008 & -0.050 & 1.000 & $0.193^{*}$ & $-0.185^{*}$ & $0.190^{*}$ & 0.057 & 0.071 & -0.052 \\
\hline S-time & $0.216^{*}$ & $-0.292^{*}$ & -0.057 & $0.193^{*}$ & 1.000 & $-0.346^{*}$ & $0.993^{*}$ & 0.029 & 0.002 & -0.113 \\
\hline baz & 0.019 & -0.023 & $0.119^{*}$ & $-0.185^{*}$ & $-0.346^{*}$ & 1.000 & $-0.348^{*}$ & -0.086 & 0.056 & 0.029 \\
\hline dist. & $0.231^{*}$ & $-0.282^{*}$ & -0.054 & $0.190^{*}$ & $0.993^{*}$ & $-0.348^{*}$ & 1.000 & 0.026 & -0.012 & $-0.117^{*}$ \\
\hline$l_{\max }$ & 0.027 & $-0.177^{*}$ & 0.106 & 0.057 & 0.029 & -0.086 & 0.026 & 1.000 & $0.135^{*}$ & $0.123^{*}$ \\
\hline$\beta_{S W S}$ & $0.124^{*}$ & $-0.146^{*}$ & 0.006 & 0.071 & 0.002 & 0.056 & -0.012 & $0.135^{*}$ & 1.000 & -0.016 \\
\hline$f_{s}$ & 0.001 & -0.016 & -0.058 & -0.052 & -0.113 & 0.029 & $-0.117^{*}$ & $0.123^{*}$ & -0.016 & 1.000 \\
\hline
\end{tabular}

Table B.7: Correlation coefficients for all correlations for station Dar2. Starred $(*)$ values are significant correlations $(\mathrm{P} \leq 0.05)$ 


\begin{tabular}{|c|c|c|c|c|c|c|c|c|c|c|}
\hline & $\begin{array}{l}V_{P} / V_{S} \\
\text { ratio }\end{array}$ & $\delta \mathrm{t}$ & depth & $\phi$ & $\begin{array}{l}\text { S-wave } \\
\text { travel } \\
\text { time }\end{array}$ & $\begin{array}{l}\text { back } \\
\text { az- } \\
\text { imuth }\end{array}$ & dist. & $l_{\max }$ & $\beta_{S W S}$ & $f_{s}$ \\
\hline$V_{P} / V_{S}$ & 1.000 & $-0.164^{*}$ & -0.108 & 0.028 & $0.352^{*}$ & -0.017 & $0.358^{*}$ & $-0.136^{*}$ & -0.018 & -0.005 \\
\hline$\delta \mathrm{t}$ & $-0.164^{*}$ & 1.000 & $-0.132^{*}$ & $0.124^{*}$ & $-0.331^{*}$ & 0.020 & $-0.325^{*}$ & $-0.144^{*}$ & -0.030 & $-0.309^{*}$ \\
\hline depth & -0.108 & $-0.132^{*}$ & 1.000 & 0.018 & $-0.192^{*}$ & 0.012 & $-0.201^{*}$ & 0.047 & 0.021 & $0.160^{*}$ \\
\hline$\phi$ & 0.028 & $0.124^{*}$ & 0.018 & 1.000 & 0.083 & $-0.184^{*}$ & 0.073 & -0.103 & -0.094 & -0.111 \\
\hline S-time & $0.352^{*}$ & $-0.331 *$ & $-0.192 *$ & 0.083 & 1.000 & 0.062 & $0.994^{*}$ & -0.053 & 0.018 & 0.075 \\
\hline baz & -0.017 & 0.020 & 0.012 & $-0.184^{*}$ & 0.062 & 1.000 & 0.083 & $0.120^{*}$ & 0.016 & 0.095 \\
\hline dist. & $0.358^{*}$ & $-0.325^{*}$ & $-0.201^{*}$ & 0.073 & $0.994^{*}$ & 0.083 & 1.000 & -0.046 & 0.013 & 0.069 \\
\hline$l_{\max }$ & $-0.136^{*}$ & $-0.144^{*}$ & 0.047 & -0.103 & -0.053 & $0.120^{*}$ & -0.046 & 1.000 & -0.010 & 0.017 \\
\hline$\beta_{S W S}$ & -0.018 & -0.030 & 0.021 & -0.094 & 0.018 & 0.016 & 0.013 & -0.010 & 1.000 & 0.051 \\
\hline$f_{s}$ & -0.005 & $-0.309^{*}$ & $0.160^{*}$ & -0.111 & 0.075 & 0.095 & 0.069 & 0.017 & 0.051 & 1.000 \\
\hline
\end{tabular}

Table B.8: Correlation coefficients for all correlations for station Dar3. Starred $(*)$ values are significant correlations $(\mathrm{P} \leq 0.05)$

\begin{tabular}{|c|c|c|c|c|c|c|c|c|c|c|}
\hline & $\begin{array}{l}V_{P} / V_{S} \\
\text { ratio }\end{array}$ & $\delta \mathrm{t}$ & depth & $\phi$ & $\begin{array}{l}\text { S-wave } \\
\text { travel } \\
\text { time }\end{array}$ & $\begin{array}{l}\text { back } \\
\text { az- } \\
\text { imuth }\end{array}$ & dist. & $l_{\max }$ & $\beta_{S W S}$ & $f_{s}$ \\
\hline$V_{P} / V_{S}$ & 1.000 & 0.064 & 0.008 & -0.054 & 0.084 & -0.000 & 0.009 & -0.029 & 0.044 & 0.027 \\
\hline$\delta \mathrm{t}$ & 0.064 & 1.000 & 0.065 & $-0.194^{*}$ & $-0.226^{*}$ & 0.098 & 0.056 & -0.065 & 0.046 & -0.078 \\
\hline depth & 0.008 & 0.065 & 1.000 & 0.020 & -0.050 & $0.993^{*}$ & $1.000^{*}$ & -0.026 & -0.010 & 0.049 \\
\hline$\phi$ & -0.054 & $-0.194^{*}$ & 0.020 & 1.000 & 0.105 & 0.018 & 0.022 & -0.038 & $-0.236^{*}$ & $0.155^{*}$ \\
\hline S-time & 0.084 & $-0.226^{*}$ & -0.050 & 0.105 & 1.000 & -0.089 & -0.035 & -0.067 & -0.063 & $0.198^{*}$ \\
\hline baz & -0.000 & 0.098 & $0.993^{*}$ & 0.018 & -0.089 & 1.000 & $0.992^{*}$ & -0.027 & -0.008 & 0.050 \\
\hline dist. & 0.009 & 0.056 & $1.000^{*}$ & 0.022 & -0.035 & $0.992^{*}$ & 1.000 & -0.025 & -0.012 & 0.052 \\
\hline$l_{\max }$ & -0.029 & -0.065 & -0.026 & -0.038 & -0.067 & -0.027 & -0.025 & 1.000 & 0.026 & $0.124^{*}$ \\
\hline$\beta_{S W S}$ & 0.044 & 0.046 & -0.010 & $-0.236^{*}$ & -0.063 & -0.008 & -0.012 & 0.026 & 1.000 & $-0.161^{*}$ \\
\hline$f_{s}$ & 0.027 & -0.078 & 0.049 & $0.155^{*}$ & $0.198^{*}$ & 0.050 & 0.052 & $0.124^{*}$ & $-0.161^{*}$ & 1.000 \\
\hline
\end{tabular}

Table B.9: Correlation coefficients for all correlations for station Dar4. Starred $(*)$ values are significant correlations $(\mathrm{P} \leq 0.05)$

\begin{tabular}{|c|c|c|c|c|c|c|c|c|c|c|}
\hline & $\begin{array}{l}V_{P} / V_{S} \\
\text { ratio }\end{array}$ & $\delta \mathrm{t}$ & depth & $\phi$ & $\begin{array}{l}\text { S-wave } \\
\text { travel } \\
\text { time }\end{array}$ & $\begin{array}{l}\text { back } \\
\text { az- } \\
\text { imuth }\end{array}$ & dist. & $l_{\max }$ & $\beta_{S W S}$ & $f_{s}$ \\
\hline$V_{P} / V_{S}$ & 1.000 & 0.027 & 0.006 & -0.040 & 0.091 & -0.008 & 0.006 & -0.039 & 0.041 & 0.043 \\
\hline$\delta \mathrm{t}$ & 0.027 & 1.000 & 0.067 & -0.072 & $-0.419^{*}$ & $0.107^{*}$ & 0.055 & -0.086 & 0.019 & $-0.121^{*}$ \\
\hline depth & 0.006 & 0.067 & 1.000 & 0.009 & -0.076 & $0.988^{*}$ & $1.000^{*}$ & -0.026 & -0.014 & 0.039 \\
\hline$\phi$ & -0.040 & -0.072 & 0.009 & 1.000 & $0.190^{*}$ & -0.001 & 0.013 & -0.024 & $-0.161^{*}$ & 0.092 \\
\hline S-time & 0.091 & $-0.419^{*}$ & -0.076 & $0.190^{*}$ & 1.000 & -0.086 & -0.059 & 0.032 & -0.008 & 0.026 \\
\hline baz & -0.008 & $0.107^{*}$ & $0.988^{*}$ & -0.001 & -0.086 & 1.000 & $0.987^{*}$ & -0.045 & -0.025 & 0.003 \\
\hline dist. & 0.006 & 0.055 & $1.000^{*}$ & 0.013 & -0.059 & $0.987^{*}$ & 1.000 & -0.023 & -0.015 & 0.039 \\
\hline$l_{\max }$ & -0.039 & -0.086 & -0.026 & -0.024 & 0.032 & -0.045 & -0.023 & 1.000 & 0.056 & 0.093 \\
\hline$\beta_{S W S}$ & 0.041 & 0.019 & -0.014 & $-0.161^{*}$ & -0.008 & -0.025 & -0.015 & 0.056 & 1.000 & $-0.142^{*}$ \\
\hline$f_{S}$ & 0.043 & $-0.121^{*}$ & 0.039 & 0.092 & 0.026 & 0.003 & 0.039 & 0.093 & $-0.142^{*}$ & 1.000 \\
\hline
\end{tabular}

Table B.10: Correlation coefficients for all correlations for station Dar5. Starred $(*)$ values are significant correlations $(\mathrm{P} \leq 0.05)$ 


\begin{tabular}{|c|c|c|c|c|c|c|c|c|c|c|}
\hline & $\begin{array}{l}V_{P} / V_{S} \\
\text { ratio }\end{array}$ & $\delta \mathrm{t}$ & depth & $\phi$ & $\begin{array}{l}\text { S-wave } \\
\text { travel } \\
\text { time }\end{array}$ & $\begin{array}{l}\text { back } \\
\text { az- } \\
\text { imuth }\end{array}$ & dist. & $l_{\max }$ & $\beta_{S W S}$ & $f_{s}$ \\
\hline$V_{P} / V_{S}$ & 1.000 & $0.153^{*}$ & 0.015 & -0.023 & -0.055 & $0.174^{*}$ & 0.039 & -0.029 & -0.011 & -0.011 \\
\hline$\delta \mathrm{t}$ & $0.153^{*}$ & 1.000 & 0.033 & 0.031 & $-0.381^{*}$ & -0.025 & $-0.467^{*}$ & -0.064 & $0.124^{*}$ & $-0.262^{*}$ \\
\hline depth & 0.015 & 0.033 & 1.000 & 0.043 & $-0.219^{*}$ & $-0.120^{*}$ & $-0.175^{*}$ & 0.003 & 0.061 & 0.059 \\
\hline$\phi$ & -0.023 & 0.031 & 0.043 & 1.000 & -0.077 & $-0.154^{*}$ & -0.063 & -0.078 & -0.088 & 0.035 \\
\hline S-time & -0.055 & $-0.381^{*}$ & $-0.219 *$ & -0.077 & 1.000 & $0.358^{*}$ & $0.896^{*}$ & 0.021 & -0.062 & $0.191 *$ \\
\hline baz & $0.174^{*}$ & -0.025 & $-0.120^{*}$ & $-0.154^{*}$ & $0.358^{*}$ & 1.000 & $0.320 *$ & -0.006 & -0.061 & $0.112 *$ \\
\hline dist. & 0.039 & $-0.467^{*}$ & $-0.175^{*}$ & -0.063 & $0.896^{*}$ & $0.320^{*}$ & 1.000 & 0.035 & -0.065 & $0.212^{*}$ \\
\hline$l_{\max }$ & -0.029 & -0.064 & 0.003 & -0.078 & 0.021 & -0.006 & 0.035 & 1.000 & -0.017 & 0.039 \\
\hline$\beta_{S W S}$ & -0.011 & $0.124^{*}$ & 0.061 & -0.088 & -0.062 & -0.061 & -0.065 & -0.017 & 1.000 & $-0.105^{*}$ \\
\hline$f_{s}$ & -0.011 & $-0.262^{*}$ & 0.059 & 0.035 & $0.191 *$ & $0.112^{*}$ & $0.212^{*}$ & 0.039 & $-0.105^{*}$ & 1.000 \\
\hline
\end{tabular}

Table B.11: Correlation coefficients for all correlations for station Dar6. Starred $(*)$ values are significant correlations $(\mathrm{P} \leq 0.05)$

\begin{tabular}{|c|c|c|c|c|c|c|c|c|c|c|}
\hline & $\begin{array}{l}V_{P} / V_{S} \\
\text { ratio }\end{array}$ & $\delta \mathrm{t}$ & depth & $\phi$ & $\begin{array}{l}\text { S-wave } \\
\text { travel } \\
\text { time }\end{array}$ & $\begin{array}{l}\text { back } \\
\text { az- } \\
\text { imuth }\end{array}$ & dist. & $l_{\max }$ & $\beta_{S W S}$ & $f_{s}$ \\
\hline$V_{P} / V_{S}$ & 1.000 & $0.215^{*}$ & 0.035 & $0.110^{*}$ & $0.120^{*}$ & -0.030 & 0.073 & -0.062 & -0.082 & -0.090 \\
\hline$\delta \mathrm{t}$ & $0.215^{*}$ & 1.000 & $0.124^{*}$ & $0.161^{*}$ & $-0.389^{*}$ & $-0.204^{*}$ & $-0.498^{*}$ & 0.026 & -0.048 & $-0.173^{*}$ \\
\hline depth & 0.035 & $0.124^{*}$ & 1.000 & 0.083 & $-0.261 *$ & $-0.171^{*}$ & $-0.112^{*}$ & -0.005 & 0.027 & -0.005 \\
\hline$\phi$ & $0.110^{*}$ & $0.161^{*}$ & 0.083 & 1.000 & 0.022 & $-0.167^{*}$ & 0.040 & -0.072 & -0.086 & -0.004 \\
\hline S-time & $0.120^{*}$ & $-0.389^{*}$ & $-0.261 *$ & 0.022 & 1.000 & $0.203^{*}$ & $0.824^{*}$ & 0.025 & -0.027 & -0.077 \\
\hline baz & -0.030 & $-0.204^{*}$ & $-0.171 *$ & $-0.167^{*}$ & $0.203^{*}$ & 1.000 & $0.243^{*}$ & -0.062 & $0.115^{*}$ & $0.217^{*}$ \\
\hline dist. & 0.073 & $-0.498^{*}$ & $-0.112 *$ & 0.040 & $0.824^{*}$ & $0.243^{*}$ & 1.000 & -0.040 & -0.059 & -0.079 \\
\hline$l_{\max }$ & -0.062 & 0.026 & -0.005 & -0.072 & 0.025 & -0.062 & -0.040 & 1.000 & 0.049 & -0.005 \\
\hline$\beta_{S W S}$ & -0.082 & -0.048 & 0.027 & -0.086 & -0.027 & $0.115^{*}$ & -0.059 & 0.049 & 1.000 & $0.134^{*}$ \\
\hline$f_{s}$ & -0.090 & $-0.173^{*}$ & -0.005 & -0.004 & -0.077 & $0.217^{*}$ & -0.079 & -0.005 & $0.134^{*}$ & 1.000 \\
\hline
\end{tabular}

Table B.12: Correlation coefficients for all correlations for station Dar7. Starred $(*)$ values are significant correlations $(\mathrm{P} \leq 0.05)$

\begin{tabular}{|c|c|c|c|c|c|c|c|c|c|c|}
\hline & $\begin{array}{l}V_{P} / V_{S} \\
\text { ratio }\end{array}$ & $\delta \mathrm{t}$ & depth & $\phi$ & $\begin{array}{l}\text { S-wave } \\
\text { travel } \\
\text { time }\end{array}$ & $\begin{array}{l}\text { back } \\
\text { az- } \\
\text { imuth }\end{array}$ & dist. & $l_{\max }$ & $\beta_{S W S}$ & $f_{s}$ \\
\hline$\overline{V_{P} / V_{S}}$ & 1.000 & $0.120^{*}$ & -0.011 & 0.021 & 0.051 & 0.029 & 0.054 & -0.075 & -0.050 & -0.008 \\
\hline$\delta \mathrm{t}$ & $0.120 *$ & 1.000 & -0.001 & 0.096 & $-0.377^{*}$ & 0.098 & $-0.465^{*}$ & -0.081 & 0.084 & -0.089 \\
\hline depth & -0.011 & -0.001 & 1.000 & 0.038 & -0.022 & 0.022 & $0.106 *$ & $0.251 *$ & 0.022 & 0.071 \\
\hline$\phi$ & 0.021 & 0.096 & 0.038 & 1.000 & 0.012 & -0.017 & 0.043 & -0.038 & -0.052 & -0.016 \\
\hline S-time & 0.051 & $-0.377^{*}$ & -0.022 & 0.012 & 1.000 & 0.045 & $0.812^{*}$ & -0.001 & -0.024 & 0.007 \\
\hline baz & 0.029 & 0.098 & 0.022 & -0.017 & 0.045 & 1.000 & -0.065 & 0.030 & $0.103^{*}$ & -0.043 \\
\hline dist. & 0.054 & $-0.465^{*}$ & $0.106^{*}$ & 0.043 & $0.812^{*}$ & -0.065 & 1.000 & $0.104^{*}$ & -0.100 & 0.030 \\
\hline$l_{\max }$ & -0.075 & -0.081 & $0.251 *$ & -0.038 & -0.001 & 0.030 & $0.104^{*}$ & 1.000 & -0.014 & $0.116^{*}$ \\
\hline$\beta_{S W S}$ & -0.050 & 0.084 & 0.022 & -0.052 & -0.024 & $0.103^{*}$ & -0.100 & -0.014 & 1.000 & -0.033 \\
\hline$f_{s}$ & -0.008 & -0.089 & 0.071 & -0.016 & 0.007 & -0.043 & 0.030 & $0.116^{*}$ & -0.033 & 1.000 \\
\hline
\end{tabular}

Table B.13: Correlation coefficients for all correlations for station Dar8. Starred $(*)$ values are significant correlations $(\mathrm{P} \leq 0.05)$ 


\begin{tabular}{|c|c|c|c|c|c|c|c|c|c|c|}
\hline & $\begin{array}{l}V_{P} / V_{S} \\
\text { ratio }\end{array}$ & $\delta \mathrm{t}$ & depth & $\phi$ & $\begin{array}{l}\text { S-wave } \\
\text { travel } \\
\text { time }\end{array}$ & $\begin{array}{l}\text { back } \\
\text { az- } \\
\text { imuth }\end{array}$ & dist. & $l_{\max }$ & $\beta_{S W S}$ & $f_{s}$ \\
\hline$V_{P} / V_{S}$ & 1.000 & -0.041 & 0.028 & -0.041 & $0.156^{*}$ & 0.003 & $0.151^{*}$ & -0.058 & -0.008 & 0.036 \\
\hline$\delta \mathrm{t}$ & -0.041 & 1.000 & -0.072 & $0.173^{*}$ & $-0.447^{*}$ & $0.114^{*}$ & $-0.491^{*}$ & -0.026 & -0.040 & 0.029 \\
\hline depth & 0.028 & -0.072 & 1.000 & 0.037 & 0.006 & 0.078 & $0.169^{*}$ & $0.420^{*}$ & 0.021 & -0.015 \\
\hline$\phi$ & -0.041 & $0.173^{*}$ & 0.037 & 1.000 & $-0.180^{*}$ & -0.014 & $-0.140 *$ & 0.027 & $-0.113^{*}$ & 0.051 \\
\hline S-time & $0.156^{*}$ & $-0.447^{*}$ & 0.006 & $-0.180^{*}$ & 1.000 & -0.079 & $0.880^{*}$ & $-0.121 *$ & $0.198^{*}$ & $-0.255^{*}$ \\
\hline baz & 0.003 & $0.114^{*}$ & 0.078 & -0.014 & -0.079 & 1.000 & $-0.164^{*}$ & 0.025 & -0.030 & $0.131 *$ \\
\hline dist. & $0.151^{*}$ & $-0.491 *$ & $0.169 *$ & $-0.140 *$ & $0.880^{*}$ & $-0.164^{*}$ & 1.000 & -0.010 & $0.134^{*}$ & $-0.255^{*}$ \\
\hline$l_{\max }$ & -0.058 & -0.026 & $0.420 *$ & 0.027 & $-0.121^{*}$ & 0.025 & -0.010 & 1.000 & -0.039 & $0.138^{*}$ \\
\hline$\beta_{S W S}$ & -0.008 & -0.040 & 0.021 & $-0.113^{*}$ & $0.198^{*}$ & -0.030 & $0.134^{*}$ & -0.039 & 1.000 & -0.031 \\
\hline$f_{s}$ & 0.036 & 0.029 & -0.015 & 0.051 & $-0.255^{*}$ & $0.131 *$ & $-0.255^{*}$ & $0.138^{*}$ & -0.031 & 1.000 \\
\hline
\end{tabular}

Table B.14: Correlation coefficients for all correlations for station CARD. Starred $(*)$ values are significant correlations $(\mathrm{P} \leq 0.05)$

\begin{tabular}{|c|c|c|c|c|c|c|c|c|c|c|}
\hline & $\begin{array}{l}V_{P} / V_{S} \\
\text { ratio }\end{array}$ & $\delta \mathrm{t}$ & depth & $\phi$ & $\begin{array}{l}\text { S-wave } \\
\text { travel } \\
\text { time }\end{array}$ & $\begin{array}{l}\text { back } \\
\text { az- } \\
\text { imuth }\end{array}$ & dist. & $l_{\max }$ & $\beta_{S W S}$ & $f_{s}$ \\
\hline$\overline{V_{P} / V_{S}}$ & 1.000 & 0.003 & -0.005 & $0.122^{*}$ & $0.210^{*}$ & $-0.191^{*}$ & $0.237^{*}$ & -0.077 & 0.011 & -0.081 \\
\hline$\delta \mathrm{t}$ & 0.003 & 1.000 & -0.069 & $0.219^{*}$ & $-0.270^{*}$ & -0.009 & $-0.309^{*}$ & -0.090 & $0.192^{*}$ & 0.029 \\
\hline depth & -0.005 & -0.069 & 1.000 & 0.036 & -0.082 & -0.025 & 0.084 & $0.213^{*}$ & -0.018 & -0.064 \\
\hline$\phi$ & $0.122^{*}$ & $0.219^{*}$ & 0.036 & 1.000 & 0.007 & $-0.146^{*}$ & 0.050 & -0.068 & 0.022 & -0.048 \\
\hline S-time & $0.210^{*}$ & $-0.270^{*}$ & -0.082 & 0.007 & 1.000 & -0.099 & $0.855^{*}$ & -0.082 & 0.083 & $-0.156^{*}$ \\
\hline baz & $-0.191^{*}$ & -0.009 & -0.025 & $-0.146^{*}$ & -0.099 & 1.000 & $-0.179^{*}$ & $0.105^{*}$ & 0.009 & $0.136^{*}$ \\
\hline dist. & $0.237^{*}$ & $-0.309^{*}$ & 0.084 & 0.050 & $0.855^{*}$ & $-0.179^{*}$ & 1.000 & 0.001 & 0.036 & $-0.149 *$ \\
\hline$l_{\max }$ & -0.077 & -0.090 & $0.213^{*}$ & -0.068 & -0.082 & $0.105^{*}$ & 0.001 & 1.000 & 0.020 & $0.126^{*}$ \\
\hline$\beta_{S W S}$ & 0.011 & $0.192^{*}$ & -0.018 & 0.022 & 0.083 & 0.009 & 0.036 & 0.020 & 1.000 & 0.007 \\
\hline$f_{s}$ & -0.081 & 0.029 & -0.064 & -0.048 & $-0.156^{*}$ & $0.136^{*}$ & $-0.149^{*}$ & $0.126^{*}$ & 0.007 & 1.000 \\
\hline
\end{tabular}

Table B.15: Correlation coefficients for all correlations for station CTND. Starred $(*)$ values are significant correlations $(\mathrm{P} \leq 0.05)$

\begin{tabular}{|c|c|c|c|c|c|c|c|c|c|c|}
\hline & $\begin{array}{l}V_{P} / V_{S} \\
\text { ratio }\end{array}$ & $\delta \mathrm{t}$ & depth & $\phi$ & $\begin{array}{l}\text { S-wave } \\
\text { travel } \\
\text { time }\end{array}$ & $\begin{array}{l}\text { back } \\
\text { az- } \\
\text { imuth }\end{array}$ & dist. & $l_{\max }$ & $\beta_{S W S}$ & $f_{s}$ \\
\hline$V_{P} / V_{S}$ & 1.000 & 0.020 & 0.031 & 0.058 & $0.127^{*}$ & $-0.161^{*}$ & $0.167^{*}$ & $\begin{array}{l}-0.062 \\
\end{array}$ & 0.026 & -0.076 \\
\hline$\delta \mathrm{t}$ & 0.020 & 1.000 & -0.089 & $0.226^{*}$ & $-0.265^{*}$ & -0.011 & $-0.305^{*}$ & $-0.127^{*}$ & $0.103^{*}$ & 0.030 \\
\hline depth & 0.031 & -0.089 & 1.000 & 0.003 & -0.008 & -0.046 & $0.150^{*}$ & $0.244^{*}$ & 0.055 & -0.058 \\
\hline$\phi$ & 0.058 & $0.226^{*}$ & 0.003 & 1.000 & -0.009 & -0.053 & 0.044 & -0.078 & -0.019 & -0.010 \\
\hline S-time & $0.127^{*}$ & $-0.265^{*}$ & -0.008 & -0.009 & 1.000 & -0.045 & $0.862^{*}$ & -0.090 & $0.128^{*}$ & $-0.171^{*}$ \\
\hline baz & $-0.161^{*}$ & -0.011 & -0.046 & -0.053 & -0.045 & 1.000 & $-0.121^{*}$ & 0.016 & -0.014 & $0.158^{*}$ \\
\hline dist. & $0.167^{*}$ & $-0.305^{*}$ & $0.150^{*}$ & 0.044 & $0.862^{*}$ & $-0.121 *$ & 1.000 & -0.035 & 0.078 & $-0.162^{*}$ \\
\hline$l_{\max }$ & -0.062 & $-0.127^{*}$ & $0.244^{*}$ & -0.078 & -0.090 & 0.016 & -0.035 & 1.000 & -0.093 & 0.076 \\
\hline$\beta_{S W S}$ & 0.026 & $0.103^{*}$ & 0.055 & -0.019 & 0.128 & -0.014 & 0.078 & -0.093 & 1.000 & -0.035 \\
\hline$f_{s}$ & -0.076 & 0.030 & -0.058 & -0.010 & $-0.171^{*}$ & $0.158^{*}$ & $-0.162^{*}$ & 0.076 & -0.035 & 1.000 \\
\hline
\end{tabular}

Table B.16: Correlation coefficients for all correlations for station ESND. Starred $(*)$ values are significant correlations $(\mathrm{P} \leq 0.05)$ 


\begin{tabular}{|c|c|c|c|c|c|c|c|c|c|c|}
\hline & $\begin{array}{l}V_{P} / V_{S} \\
\text { ratio }\end{array}$ & $\delta \mathrm{t}$ & depth & $\phi$ & $\begin{array}{l}\text { S-wave } \\
\text { travel } \\
\text { time }\end{array}$ & $\begin{array}{l}\text { back } \\
\text { az- } \\
\text { imuth }\end{array}$ & dist. & $l_{\max }$ & $\beta_{S W S}$ & $f_{s}$ \\
\hline$\overline{V_{P} / V_{S}}$ & 1.000 & $0.110^{*}$ & 0.006 & 0.087 & $0.164^{*}$ & $0.221^{*}$ & $0.153^{*}$ & -0.026 & $-0.176^{*}$ & 0.060 \\
\hline$\delta \mathrm{t}$ & $0.110^{*}$ & 1.000 & $-0.147^{*}$ & $0.113^{*}$ & $-0.197^{*}$ & $-0.105^{*}$ & $-0.247^{*}$ & -0.069 & 0.028 & -0.035 \\
\hline depth & 0.006 & $-0.147^{*}$ & 1.000 & 0.055 & 0.020 & $0.138^{*}$ & $0.173^{*}$ & $0.219^{*}$ & 0.022 & -0.017 \\
\hline$\phi$ & 0.087 & $0.113^{*}$ & 0.055 & 1.000 & 0.029 & $0.107^{*}$ & 0.068 & -0.023 & $-0.187^{*}$ & 0.090 \\
\hline S-time & $0.164^{*}$ & $-0.197^{*}$ & 0.020 & 0.029 & 1.000 & 0.089 & $0.831^{*}$ & -0.061 & -0.091 & $-0.186^{*}$ \\
\hline baz & $0.221 *$ & $-0.105^{*}$ & $0.138^{*}$ & $0.107 *$ & 0.089 & 1.000 & -0.031 & 0.076 & -0.076 & $0.237^{*}$ \\
\hline dist. & $0.153^{*}$ & $-0.247^{*}$ & $0.173^{*}$ & 0.068 & $0.831^{*}$ & -0.031 & 1.000 & -0.032 & $-0.139 *$ & $-0.209^{*}$ \\
\hline$l_{\max }$ & -0.026 & -0.069 & $0.219^{*}$ & -0.023 & -0.061 & 0.076 & -0.032 & 1.000 & -0.016 & $0.171^{*}$ \\
\hline$\beta_{S W S}$ & $-0.176^{*}$ & 0.028 & 0.022 & $-0.187^{*}$ & -0.091 & -0.076 & $-0.139 *$ & -0.016 & 1.000 & -0.023 \\
\hline$f_{s}$ & 0.060 & -0.035 & -0.017 & 0.090 & $-0.186^{*}$ & $0.237^{*}$ & $-0.209^{*}$ & $0.171^{*}$ & -0.023 & 1.000 \\
\hline
\end{tabular}

Table B.17: Correlation coefficients for all correlations for station LNSD. Starred $(*)$ values are significant correlations $(\mathrm{P} \leq 0.05)$

\begin{tabular}{|c|c|c|c|c|c|c|c|c|c|c|}
\hline & $\begin{array}{l}V_{P} / V_{S} \\
\text { ratio }\end{array}$ & $\delta \mathrm{t}$ & depth & $\phi$ & $\begin{array}{l}\text { S-wave } \\
\text { travel } \\
\text { time }\end{array}$ & $\begin{array}{l}\text { back } \\
\text { az- } \\
\text { imuth }\end{array}$ & dist. & $l_{\max }$ & $\beta_{S W S}$ & $f_{s}$ \\
\hline$V_{P} / V_{S}$ & 1.000 & 0.077 & $-0.106^{*}$ & 0.041 & 0.038 & -0.001 & 0.047 & -0.064 & -0.033 & 0.048 \\
\hline$\delta \mathrm{t}$ & 0.077 & 1.000 & -0.072 & $-0.151^{*}$ & $-0.456^{*}$ & $0.210^{*}$ & $-0.467^{*}$ & -0.015 & -0.088 & -0.001 \\
\hline depth & $-0.106^{*}$ & -0.072 & 1.000 & $0.114^{*}$ & -0.041 & -0.044 & -0.037 & $0.184 *$ & 0.040 & $0.109 *$ \\
\hline$\phi$ & 0.041 & $-0.151^{*}$ & $0.114^{*}$ & 1.000 & $0.206^{*}$ & $-0.281^{*}$ & $0.209^{*}$ & $-0.128^{*}$ & -0.054 & 0.039 \\
\hline S-time & 0.038 & $-0.456^{*}$ & -0.041 & $0.206^{*}$ & 1.000 & $-0.201 *$ & $0.992 *$ & $-0.161^{*}$ & 0.008 & -0.082 \\
\hline baz & -0.001 & $0.210^{*}$ & -0.044 & $-0.281^{*}$ & $-0.201 *$ & 1.000 & $-0.191^{*}$ & -0.030 & -0.034 & $0.107^{*}$ \\
\hline dist. & 0.047 & $-0.467^{*}$ & -0.037 & $0.209^{*}$ & $0.992 *$ & $-0.191^{*}$ & 1.000 & $-0.161^{*}$ & -0.007 & -0.080 \\
\hline$l_{\max }$ & -0.064 & -0.015 & $0.184^{*}$ & $-0.128^{*}$ & $-0.161 *$ & -0.030 & $-0.161^{*}$ & 1.000 & 0.000 & $0.111^{*}$ \\
\hline$\beta_{S W S}$ & -0.033 & -0.088 & 0.040 & -0.054 & 0.008 & -0.034 & -0.007 & 0.000 & 1.000 & -0.046 \\
\hline$f_{s}$ & 0.048 & -0.001 & $0.109^{*}$ & 0.039 & -0.082 & $0.107^{*}$ & -0.080 & $0.111^{*}$ & -0.046 & 1.000 \\
\hline
\end{tabular}

Table B.18: Correlation coefficients for all correlations for station MCHD. Starred $(*)$ values are significant correlations $(\mathrm{P} \leq 0.05)$ 


\begin{tabular}{|c|c|c|c|c|c|c|c|c|c|c|}
\hline & $\begin{array}{l}V_{P} / V_{S} \\
\text { ratio }\end{array}$ & $\delta \mathrm{t}$ & depth & $\phi$ & $\begin{array}{l}\text { S-wave } \\
\text { travel } \\
\text { time }\end{array}$ & $\begin{array}{l}\text { back } \\
\text { az- } \\
\text { imuth }\end{array}$ & dist. & $l_{\max }$ & $\beta_{S W S}$ & $f_{S}$ \\
\hline$V_{P} / V_{S}$ & 1.000 & 0.052 & -0.052 & 0.059 & 0.066 & 0.063 & 0.073 & -0.045 & -0.098 & 0.017 \\
\hline$\delta \mathrm{t}$ & 0.052 & 1.000 & 0.056 & 0.058 & $-0.369^{*}$ & $0.109^{*}$ & $-0.379^{*}$ & -0.071 & 0.037 & -0.051 \\
\hline depth & -0.052 & 0.056 & 1.000 & 0.033 & -0.064 & 0.097 & -0.082 & 0.033 & -0.024 & 0.029 \\
\hline$\phi$ & 0.059 & 0.058 & 0.033 & 1.000 & 0.028 & $-0.236 *$ & 0.036 & -0.001 & $-0.140 *$ & 0.082 \\
\hline S-time & 0.066 & $-0.369^{*}$ & -0.064 & 0.028 & 1.000 & $0.107^{*}$ & $0.989^{*}$ & -0.050 & -0.055 & -0.028 \\
\hline baz & 0.063 & $0.109^{*}$ & 0.097 & $-0.236^{*}$ & $0.107^{*}$ & 1.000 & 0.097 & -0.058 & -0.071 & -0.028 \\
\hline dist. & 0.073 & $-0.379^{*}$ & -0.082 & 0.036 & $0.989^{*}$ & 0.097 & 1.000 & -0.045 & -0.063 & -0.029 \\
\hline$l_{\max }$ & -0.045 & -0.071 & 0.033 & -0.001 & -0.050 & -0.058 & -0.045 & 1.000 & 0.008 & $0.270^{*}$ \\
\hline$\beta_{S W S}$ & -0.098 & 0.037 & -0.024 & $-0.140^{*}$ & -0.055 & -0.071 & -0.063 & 0.008 & 1.000 & 0.048 \\
\hline$f_{s}$ & 0.017 & -0.051 & 0.029 & 0.082 & -0.028 & -0.028 & -0.029 & $0.270^{*}$ & 0.048 & 1.000 \\
\hline
\end{tabular}

Table B.19: Correlation coefficients for all correlations for station MKYD. Starred $(*)$ values are significant correlations $(\mathrm{P} \leq 0.05)$

\begin{tabular}{|c|c|c|c|c|c|c|c|c|c|c|}
\hline & $\begin{array}{l}V_{P} / V_{S} \\
\text { ratio }\end{array}$ & $\delta \mathrm{t}$ & depth & $\phi$ & $\begin{array}{l}\text { S-wave } \\
\text { travel } \\
\text { time }\end{array}$ & $\begin{array}{l}\text { back } \\
\text { az- } \\
\text { imuth }\end{array}$ & dist. & $l_{\max }$ & $\beta_{S W S}$ & $f_{s}$ \\
\hline$V_{P} / V_{S}$ & 1.000 & 0.046 & $-0.141^{*}$ & -0.034 & 0.069 & $0.258^{*}$ & 0.097 & $-0.112^{*}$ & -0.004 & -0.012 \\
\hline$\delta \mathrm{t}$ & 0.046 & 1.000 & -0.057 & 0.081 & $-0.377^{*}$ & -0.032 & $-0.379^{*}$ & -0.067 & 0.034 & -0.076 \\
\hline depth & $-0.141^{*}$ & -0.057 & 1.000 & -0.033 & -0.033 & -0.064 & -0.077 & $0.167^{*}$ & -0.052 & 0.030 \\
\hline$\phi$ & -0.034 & 0.081 & -0.033 & 1.000 & -0.094 & $-0.135^{*}$ & -0.071 & $-0.135^{*}$ & $-0.174 *$ & 0.042 \\
\hline S-time & 0.069 & $-0.377^{*}$ & -0.033 & -0.094 & 1.000 & $0.352^{*}$ & $0.986^{*}$ & -0.032 & -0.028 & -0.006 \\
\hline baz & $0.258^{*}$ & -0.032 & -0.064 & $-0.135^{*}$ & $0.352 *$ & 1.000 & $0.295^{*}$ & -0.048 & -0.073 & 0.052 \\
\hline dist. & 0.097 & $-0.379 *$ & -0.077 & -0.071 & $0.986^{*}$ & $0.295^{*}$ & 1.000 & -0.035 & -0.018 & -0.013 \\
\hline$l_{\max }$ & $-0.112^{*}$ & -0.067 & $0.167^{*}$ & $-0.135^{*}$ & -0.032 & -0.048 & -0.035 & 1.000 & $0.118^{*}$ & 0.046 \\
\hline$\beta_{S W S}$ & -0.004 & 0.034 & -0.052 & $-0.174^{*}$ & -0.028 & -0.073 & -0.018 & $0.118^{*}$ & 1.000 & 0.075 \\
\hline$f_{s}$ & -0.012 & -0.076 & 0.030 & 0.042 & -0.006 & 0.052 & -0.013 & 0.046 & 0.075 & 1.000 \\
\hline
\end{tabular}

Table B.20: Correlation coefficients for all correlations for station MNSD. Starred $(*)$ values are significant correlations $(\mathrm{P} \leq 0.05)$

\begin{tabular}{|c|c|c|c|c|c|c|c|c|c|c|}
\hline & $\begin{array}{l}V_{P} / V_{S} \\
\text { ratio }\end{array}$ & $\delta \mathrm{t}$ & depth & $\phi$ & $\begin{array}{l}\text { S-wave } \\
\text { travel } \\
\text { time }\end{array}$ & $\begin{array}{l}\text { back } \\
\text { az- } \\
\text { imuth }\end{array}$ & dist. & $l_{\max }$ & $\beta_{S W S}$ & $f_{s}$ \\
\hline$\overline{V_{P} / V_{S}}$ & 1.000 & 0.071 & $-0.106^{*}$ & 0.087 & 0.079 & $0.174^{*}$ & $0.118^{*}$ & -0.017 & -0.032 & 0.065 \\
\hline$\delta \mathrm{t}$ & 0.071 & 1.000 & $-0.167^{*}$ & $0.198^{*}$ & $-0.241^{*}$ & 0.073 & $-0.241^{*}$ & 0.021 & -0.019 & $-0.135^{*}$ \\
\hline depth & $-0.106^{*}$ & $-0.167^{*}$ & 1.000 & $-0.151^{*}$ & $-0.182^{*}$ & $-0.157^{*}$ & $-0.286 *$ & -0.034 & $0.165^{*}$ & $0.117^{*}$ \\
\hline$\phi$ & 0.087 & $0.198^{*}$ & $-0.151^{*}$ & 1.000 & 0.006 & 0.094 & 0.018 & -0.028 & $-0.133^{*}$ & 0.046 \\
\hline S-time & 0.079 & $-0.241^{*}$ & $-0.182^{*}$ & 0.006 & 1.000 & $0.337^{*}$ & $0.973^{*}$ & $-0.145^{*}$ & -0.097 & 0.017 \\
\hline baz & $0.174 *$ & 0.073 & $-0.157^{*}$ & 0.094 & $0.337^{*}$ & 1.000 & $0.302^{*}$ & 0.010 & -0.070 & -0.070 \\
\hline dist. & $0.118^{*}$ & $-0.241 *$ & $-0.286^{*}$ & 0.018 & $0.973^{*}$ & $0.302^{*}$ & 1.000 & $-0.150 *$ & -0.096 & 0.013 \\
\hline$l_{\max }$ & -0.017 & 0.021 & -0.034 & -0.028 & $-0.145^{*}$ & 0.010 & $-0.150 *$ & 1.000 & -0.037 & $0.150 *$ \\
\hline$\beta_{S W S}$ & -0.032 & -0.019 & $0.165^{*}$ & $-0.133^{*}$ & -0.097 & -0.070 & -0.096 & -0.037 & 1.000 & -0.039 \\
\hline$f_{s}$ & 0.065 & $-0.135 *$ & $0.117^{*}$ & 0.046 & 0.017 & -0.070 & 0.013 & $0.150^{*}$ & -0.039 & 1.000 \\
\hline
\end{tabular}

Table B.21: Correlation coefficients for all correlations for station SAND. Starred $(*)$ values are significant correlations $(\mathrm{P} \leq 0.05)$ 


\begin{tabular}{|c|c|c|c|c|c|c|c|c|c|c|}
\hline & $\begin{array}{l}V_{P} / V_{S} \\
\text { ratio }\end{array}$ & $\delta \mathrm{t}$ & depth & $\phi$ & $\begin{array}{l}\text { S-wave } \\
\text { travel } \\
\text { time }\end{array}$ & $\begin{array}{l}\text { back } \\
\text { az- } \\
\text { imuth }\end{array}$ & dist. & $l_{\max }$ & $\beta_{S W S}$ & $f_{s}$ \\
\hline$V_{P} / V_{S}$ & 1.000 & $0.115^{*}$ & -0.076 & 0.034 & -0.089 & $0.108^{*}$ & -0.022 & $-0.153^{*}$ & -0.022 & -0.065 \\
\hline$\delta \mathrm{t}$ & $0.115^{*}$ & 1.000 & $-0.159^{*}$ & $0.251^{*}$ & $-0.386^{*}$ & 0.012 & $-0.393^{*}$ & -0.043 & $-0.240^{*}$ & -0.063 \\
\hline depth & -0.076 & $-0.159^{*}$ & 1.000 & -0.087 & $-0.123^{*}$ & $-0.169 *$ & $-0.160 *$ & 0.048 & $0.218^{*}$ & $0.163^{*}$ \\
\hline$\phi$ & 0.034 & $0.251 *$ & -0.087 & 1.000 & $-0.202 *$ & -0.072 & $-0.202^{*}$ & -0.056 & $-0.326^{*}$ & 0.009 \\
\hline S-time & -0.089 & $-0.386^{*}$ & $-0.123^{*}$ & $-0.202^{*}$ & 1.000 & $0.156^{*}$ & $0.983^{*}$ & 0.002 & 0.068 & -0.041 \\
\hline baz & $0.108^{*}$ & 0.012 & $-0.169^{*}$ & -0.072 & $0.156^{*}$ & 1.000 & $0.179^{*}$ & -0.018 & $-0.244^{*}$ & -0.084 \\
\hline dist. & -0.022 & $-0.393^{*}$ & $-0.160^{*}$ & $-0.202^{*}$ & $0.983^{*}$ & $0.179^{*}$ & 1.000 & 0.012 & 0.035 & -0.036 \\
\hline$l_{\max }$ & $-0.153^{*}$ & -0.043 & 0.048 & -0.056 & 0.002 & -0.018 & 0.012 & 1.000 & -0.055 & 0.019 \\
\hline$\beta_{S W S}$ & -0.022 & $-0.240^{*}$ & $0.218^{*}$ & $-0.326^{*}$ & 0.068 & $-0.244^{*}$ & 0.035 & -0.055 & 1.000 & -0.050 \\
\hline$f_{s}$ & -0.065 & -0.063 & $0.163^{*}$ & 0.009 & -0.041 & -0.084 & -0.036 & 0.019 & -0.050 & 1.000 \\
\hline
\end{tabular}

Table B.22: Correlation coefficients for all correlations for station SKTD. Starred $(*)$ values are significant correlations $(\mathrm{P} \leq 0.05)$

\begin{tabular}{l|llllllllll} 
& $\begin{array}{l}V_{P} / V_{S} \\
\text { ratio }\end{array}$ & $\delta \mathrm{t}$ & depth & $\phi$ & $\begin{array}{l}\text { S-wave } \\
\text { travel } \\
\text { time }\end{array}$ & $\begin{array}{l}\text { back } \\
\text { az- } \\
\text { imuth }\end{array}$ & dist. & $l_{\max }$ & $\beta_{S W S}$ & $f_{S}$ \\
\hline$V_{P} / V_{S}$ & 1.000 & $-0.139^{*}$ & -0.069 & 0.001 & $0.147^{*}$ & -0.087 & $0.130^{*}$ & -0.042 & 0.056 & 0.038 \\
$\delta \mathrm{t}$ & $-0.139^{*}$ & 1.000 & $-0.171^{*}$ & 0.019 & $-0.447^{*}$ & 0.003 & $-0.442^{*}$ & $-0.102^{*}$ & $-0.129^{*}$ & $-0.112^{*}$ \\
depth & -0.069 & $-0.171^{*}$ & 1.000 & 0.039 & -0.083 & $0.233^{*}$ & -0.071 & $0.099^{*}$ & -0.003 & $0.143^{*}$ \\
$\phi$ & 0.001 & 0.019 & 0.039 & 1.000 & -0.054 & -0.021 & -0.047 & -0.044 & $-0.211^{*}$ & 0.087 \\
S-time & $0.147^{*}$ & $-0.447^{*}$ & -0.083 & -0.054 & 1.000 & 0.002 & $0.990^{*}$ & -0.016 & $0.093^{*}$ & $-0.106^{*}$ \\
baz & -0.087 & 0.003 & $0.233^{*}$ & -0.021 & 0.002 & 1.000 & -0.004 & 0.021 & -0.086 & $-0.104^{*}$ \\
dist. & $0.130^{*}$ & $-0.442^{*}$ & -0.071 & -0.047 & $0.990^{*}$ & -0.004 & 1.000 & -0.023 & 0.085 & $-0.102^{*}$ \\
$l_{\max }$ & -0.042 & $-0.102^{*}$ & $0.099^{*}$ & -0.044 & -0.016 & 0.021 & -0.023 & 1.000 & $0.140^{*}$ & 0.009 \\
$\beta_{S W S}$ & 0.056 & $-0.129^{*}$ & -0.003 & $-0.211^{*}$ & $0.093^{*}$ & -0.086 & 0.085 & $0.140^{*}$ & 1.000 & -0.056 \\
$f_{S}$ & 0.038 & $-0.112^{*}$ & $0.143^{*}$ & 0.087 & $-0.106^{*}$ & $-0.104^{*}$ & $-0.102^{*}$ & 0.009 & -0.056 & 1.000
\end{tabular}

Table B.23: Correlation coefficients for all correlations for station STLD. Starred $(*)$ values are significant correlations $(\mathrm{P} \leq 0.05)$

\begin{tabular}{|c|c|c|c|c|c|c|c|c|c|c|}
\hline & $\begin{array}{l}V_{P} / V_{S} \\
\text { ratio }\end{array}$ & $\delta \mathrm{t}$ & depth & $\phi$ & $\begin{array}{l}\text { S-wave } \\
\text { travel } \\
\text { time }\end{array}$ & $\begin{array}{l}\text { back } \\
\text { az- } \\
\text { imuth }\end{array}$ & dist. & $l_{\max }$ & $\beta_{S W S}$ & $f_{s}$ \\
\hline$V_{P} / V_{S}$ & 1.000 & $0.126^{*}$ & -0.022 & 0.045 & 0.074 & $-0.136^{*}$ & 0.060 & $-0.104^{*}$ & 0.044 & 0.052 \\
\hline$\delta \mathrm{t}$ & $0.126^{*}$ & 1.000 & -0.049 & 0.085 & $-0.384^{*}$ & -0.027 & $-0.472^{*}$ & -0.020 & 0.086 & -0.051 \\
\hline depth & -0.022 & -0.049 & 1.000 & 0.063 & -0.014 & 0.039 & 0.092 & $0.125^{*}$ & -0.018 & -0.022 \\
\hline$\phi$ & 0.045 & 0.085 & 0.063 & 1.000 & 0.019 & -0.036 & 0.048 & -0.019 & -0.075 & -0.076 \\
\hline S-time & 0.074 & $-0.384^{*}$ & -0.014 & 0.019 & 1.000 & $0.228^{*}$ & $0.854 *$ & -0.039 & 0.087 & 0.038 \\
\hline baz & $-0.136 *$ & -0.027 & 0.039 & -0.036 & $0.228^{*}$ & 1.000 & $0.182^{*}$ & 0.064 & $-0.112 *$ & $-0.145^{*}$ \\
\hline dist. & 0.060 & $-0.472^{*}$ & 0.092 & 0.048 & $0.854^{*}$ & $0.182^{*}$ & 1.000 & 0.011 & -0.005 & 0.022 \\
\hline$l_{\max }$ & $-0.104^{*}$ & -0.020 & $0.125 *$ & -0.019 & -0.039 & 0.064 & 0.011 & 1.000 & -0.030 & $0.154 *$ \\
\hline$\beta_{S W S}$ & 0.044 & 0.086 & -0.018 & -0.075 & 0.087 & $-0.112^{*}$ & -0.005 & -0.030 & 1.000 & $0.130 *$ \\
\hline$f_{s}$ & 0.052 & -0.051 & -0.022 & -0.076 & 0.038 & $-0.145^{*}$ & 0.022 & $0.154 *$ & $0.130^{*}$ & 1.000 \\
\hline
\end{tabular}

Table B.24: Correlation coefficients for all correlations for station CRLZ. Starred $(*)$ values are significant correlations $(\mathrm{P} \leq 0.05)$ 


\begin{tabular}{|c|c|c|c|c|c|c|c|c|c|c|}
\hline & $\begin{array}{l}V_{P} / V_{S} \\
\text { ratio }\end{array}$ & $\delta \mathrm{t}$ & depth & $\phi$ & $\begin{array}{l}\text { S-wave } \\
\text { travel } \\
\text { time }\end{array}$ & $\begin{array}{l}\text { back } \\
\text { az- } \\
\text { imuth }\end{array}$ & dist. & $l_{\max }$ & $\beta_{S W S}$ & $f_{s}$ \\
\hline$V_{P} / V_{S}$ & 1.000 & 0.083 & 0.030 & -0.057 & $0.214^{*}$ & $-0.142^{*}$ & $0.201^{*}$ & $-0.143^{*}$ & 0.042 & 0.075 \\
\hline$\delta \mathrm{t}$ & 0.083 & 1.000 & -0.028 & -0.055 & $-0.424^{*}$ & $-0.267^{*}$ & $-0.503^{*}$ & -0.047 & $0.229^{*}$ & 0.084 \\
\hline depth & 0.030 & -0.028 & 1.000 & -0.001 & -0.053 & -0.069 & 0.035 & $0.146^{*}$ & 0.009 & 0.083 \\
\hline$\phi$ & -0.057 & -0.055 & -0.001 & 1.000 & 0.051 & $0.199^{*}$ & 0.079 & $0.127^{*}$ & -0.086 & -0.051 \\
\hline S-time & $0.214^{*}$ & $-0.424 *$ & -0.053 & 0.051 & 1.000 & $0.314^{*}$ & $0.883^{*}$ & -0.078 & -0.070 & $-0.163^{*}$ \\
\hline baz & $-0.142^{*}$ & $-0.267^{*}$ & -0.069 & $0.199^{*}$ & $0.314^{*}$ & 1.000 & $0.282^{*}$ & 0.047 & $-0.144^{*}$ & $-0.146^{*}$ \\
\hline dist. & $0.201^{*}$ & $-0.503^{*}$ & 0.035 & 0.079 & $0.883^{*}$ & $0.282^{*}$ & 1.000 & -0.006 & $-0.132 *$ & $-0.170^{*}$ \\
\hline$l_{\max }$ & $-0.143^{*}$ & -0.047 & $0.146^{*}$ & $0.127^{*}$ & -0.078 & 0.047 & -0.006 & 1.000 & -0.074 & 0.101 \\
\hline$\beta_{S W S}$ & 0.042 & $0.229^{*}$ & 0.009 & -0.086 & -0.070 & $-0.144^{*}$ & $-0.132^{*}$ & -0.074 & 1.000 & $0.138^{*}$ \\
\hline$f_{s}$ & 0.075 & 0.084 & 0.083 & -0.051 & $-0.163^{*}$ & $-0.146^{*}$ & $-0.170^{*}$ & 0.101 & $0.138^{*}$ & 1.000 \\
\hline
\end{tabular}

Table B.25: Correlation coefficients for all correlations for station MQZ. Starred $(*)$ values are significant correlations $(\mathrm{P} \leq 0.05)$

\begin{tabular}{l|llllllllll} 
& $\begin{array}{l}V_{P} / V_{S} \\
\text { ratio }\end{array}$ & $\delta \mathrm{t}$ & depth & $\phi$ & $\begin{array}{l}\text { S-wave } \\
\text { travel } \\
\text { time }\end{array}$ & \multicolumn{9}{c}{$\begin{array}{l}\text { back } \\
\text { az- } \\
\text { imuth }\end{array}$} & dist. & $l_{\max }$ & $\beta_{S W S}$ & $f_{S}$ \\
\hline$V_{P} / V_{S}$ & 1.000 & 0.100 & 0.053 & -0.030 & $0.109^{*}$ & -0.050 & $0.111^{*}$ & -0.042 & 0.046 & 0.077 \\
$\delta \mathrm{t}$ & 0.100 & 1.000 & -0.066 & -0.001 & $-0.395^{*}$ & $-0.149^{*}$ & $-0.475^{*}$ & -0.094 & $0.185^{*}$ & $0.110^{*}$ \\
depth & 0.053 & -0.066 & 1.000 & 0.077 & 0.044 & -0.021 & $0.140^{*}$ & $0.131^{*}$ & -0.037 & 0.068 \\
$\phi$ & -0.030 & -0.001 & 0.077 & 1.000 & -0.043 & $0.178^{*}$ & -0.010 & 0.001 & $-0.115^{*}$ & 0.031 \\
S-time & $0.109^{*}$ & $-0.395^{*}$ & 0.044 & -0.043 & 1.000 & $0.125^{*}$ & $0.876^{*}$ & 0.043 & $-0.140^{*}$ & $-0.221^{*}$ \\
baz & -0.050 & $-0.149^{*}$ & -0.021 & $0.178^{*}$ & $0.125^{*}$ & 1.000 & 0.059 & 0.000 & -0.070 & -0.011 \\
dist. & $0.111^{*}$ & $-0.475^{*}$ & $0.140^{*}$ & -0.010 & $0.876^{*}$ & 0.059 & 1.000 & $0.107^{*}$ & $-0.197^{*}$ & $-0.240^{*}$ \\
$l_{\max }$ & -0.042 & -0.094 & $0.131^{*}$ & 0.001 & 0.043 & 0.000 & $0.107^{*}$ & 1.000 & -0.068 & -0.062 \\
$\beta_{S W S}$ & 0.046 & $0.185^{*}$ & -0.037 & $-0.115^{*}$ & $-0.140^{*}$ & -0.070 & $-0.197^{*}$ & -0.068 & 1.000 & $0.124^{*}$ \\
$f_{S}$ & 0.077 & $0.110^{*}$ & 0.068 & 0.031 & $-0.221^{*}$ & -0.011 & $-0.240^{*}$ & -0.062 & $0.124^{*}$ & 1.000
\end{tabular}

Table B.26: Correlation coefficients for all correlations for station OXZ. Starred $(*)$ values are significant correlations $(\mathrm{P} \leq 0.05)$ 


\section{Appendix C}

\section{GNS Science data}

\section{C.1 GNS Science temporary stations}

The following plots show average $\phi, \delta \mathrm{t}$ and $V_{P} / V_{S}$-ratio plotted against time for the 10 temporary stations deployed by GNS which ran for the month of September 2010. The averages were calculated as 20pt moving averages and the data used was chosen using the same restrictions as for the data in the preceding chapters ( MFAST grade: A or B, $\delta \mathrm{t} \leq 0.4 \mathrm{~s}$ ). The majority of stations showed no variation in $\phi$ or $\delta$ t with time e.g. Fig C.1, but some showed apparent variation in $\phi$ with time. Station CARD (Fig. C.2) appears to show a $180^{\circ}$ rotation, but as the data is circular and axial this rotation is only a change of a few degrees. The rotation appears to be due to an increased proportion of NE-SW $\phi$ measurements (see blue rose diagram in Fig. C.2), which is not due to any directional dependence (Fig C.2). Station LNSD shows continuous rotation of the average $\phi$, but with no clear change in the distribution of $\phi$ (see rose diagrams in Fig. C.3). There is no clear directional dependence of $\phi$ for station LNSD (Fig C.3). 


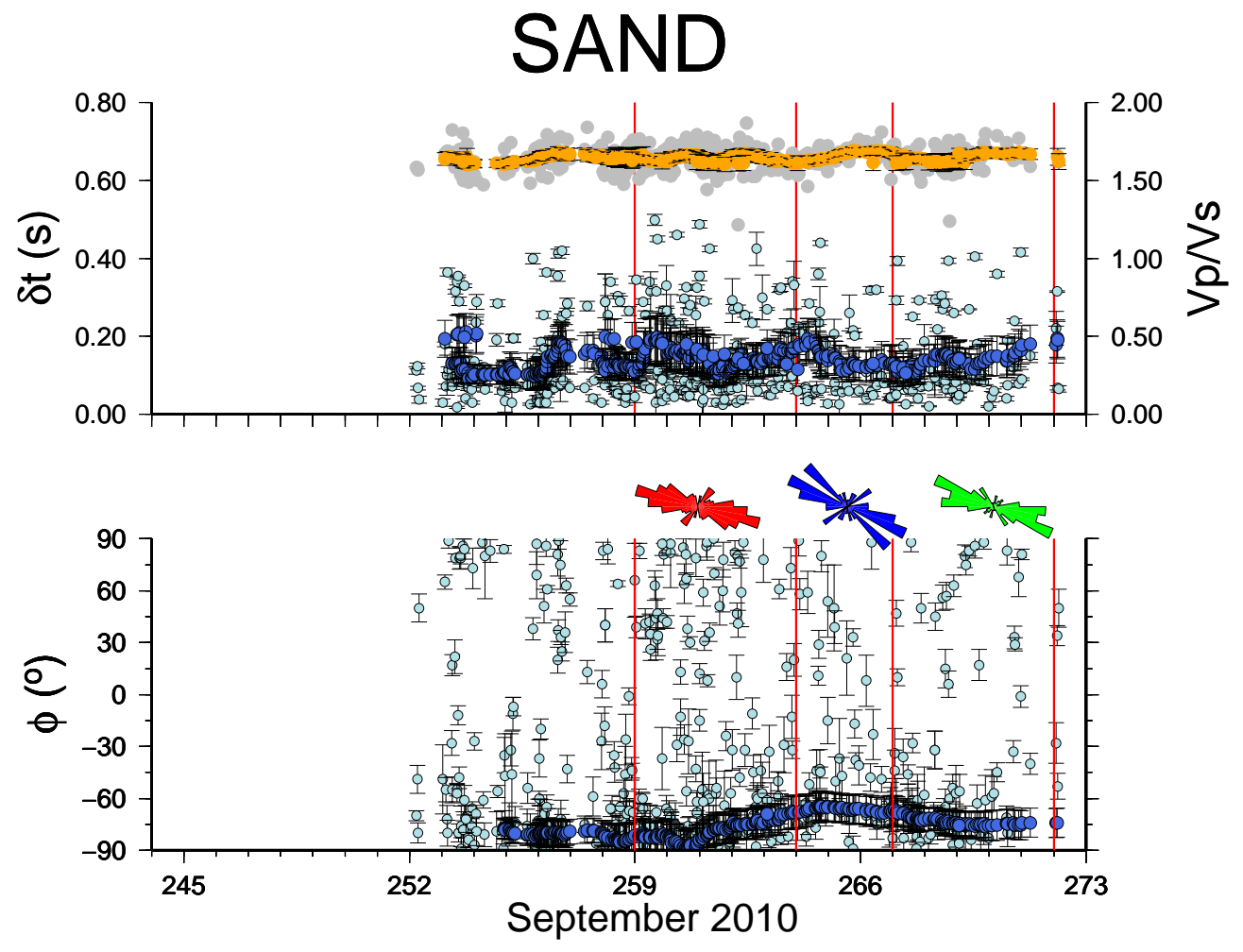

Figure C.1: $\phi$ and $\delta$ t vs. time for station SAND. Light blue are individual measurements. Dark blue points are 20pt moving averages. Grey and orange points represent individual and 20pt moving averages for $V_{P} / V_{S}$-ratio. Error bars shown in black. X-axis shows Julian day (1 Sept. = 244 etc.). 

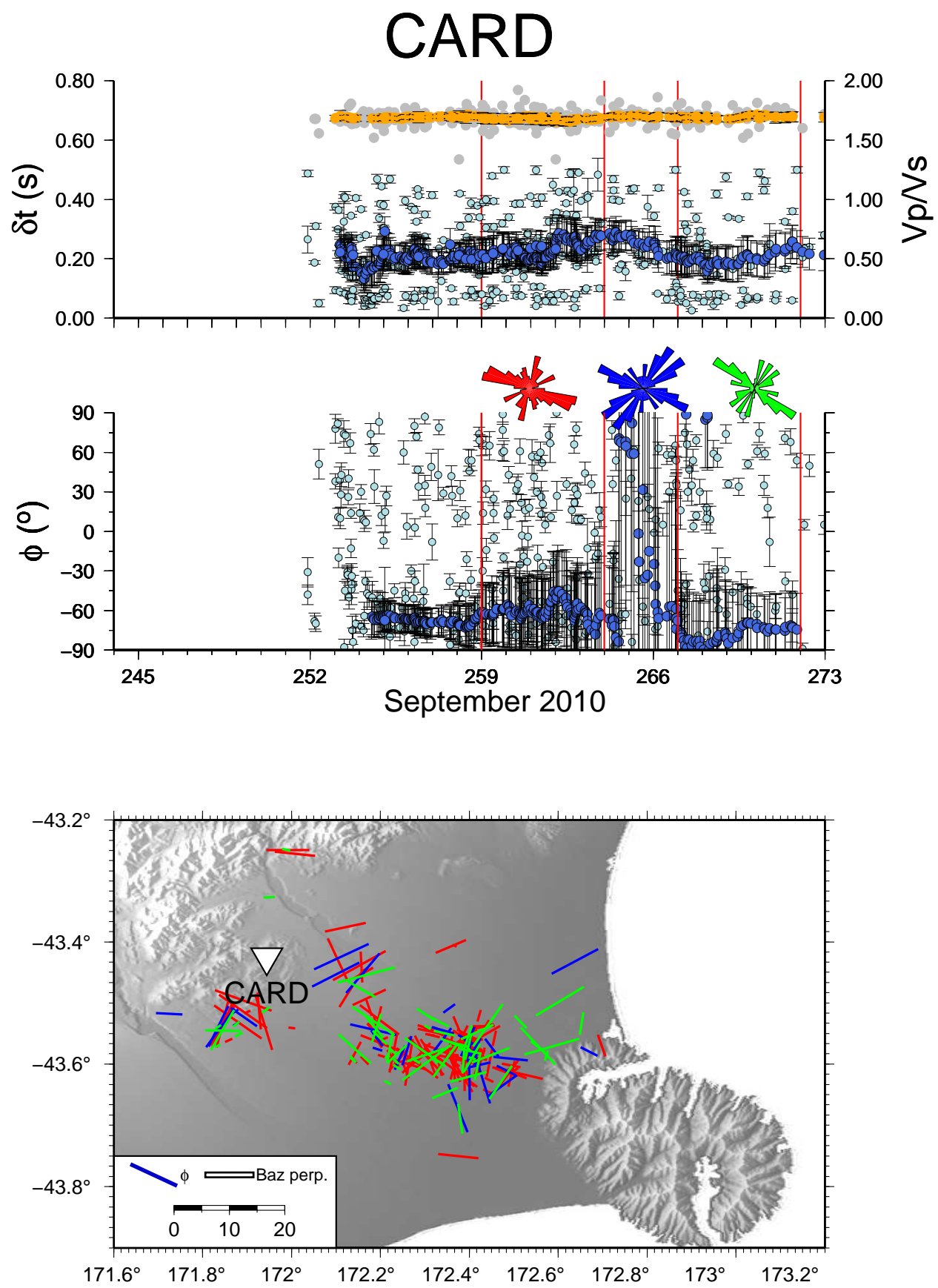

Figure C.2: UPPER: $\phi$ and $\delta$ t vs. time for station CARD. Light blue are individual measurements. Dark blue points are 20pt moving averages. Grey and orange points represent individual and 20pt moving averages for $V_{P} / V_{S^{-}}$ ratio. Error bars shown in black. Rose diagrams represent distribution of $\phi$ for the sections delineated by red lines. X-axis shows Julian day (1 Sept. $=244$ etc.). LOWER: $\phi$ plotted at event location for station CARD. Length of vectors determined by $\delta$ t and direction corresponds to $\phi$. Colour of bar indicates which time segment $\phi$ measurement is from. 

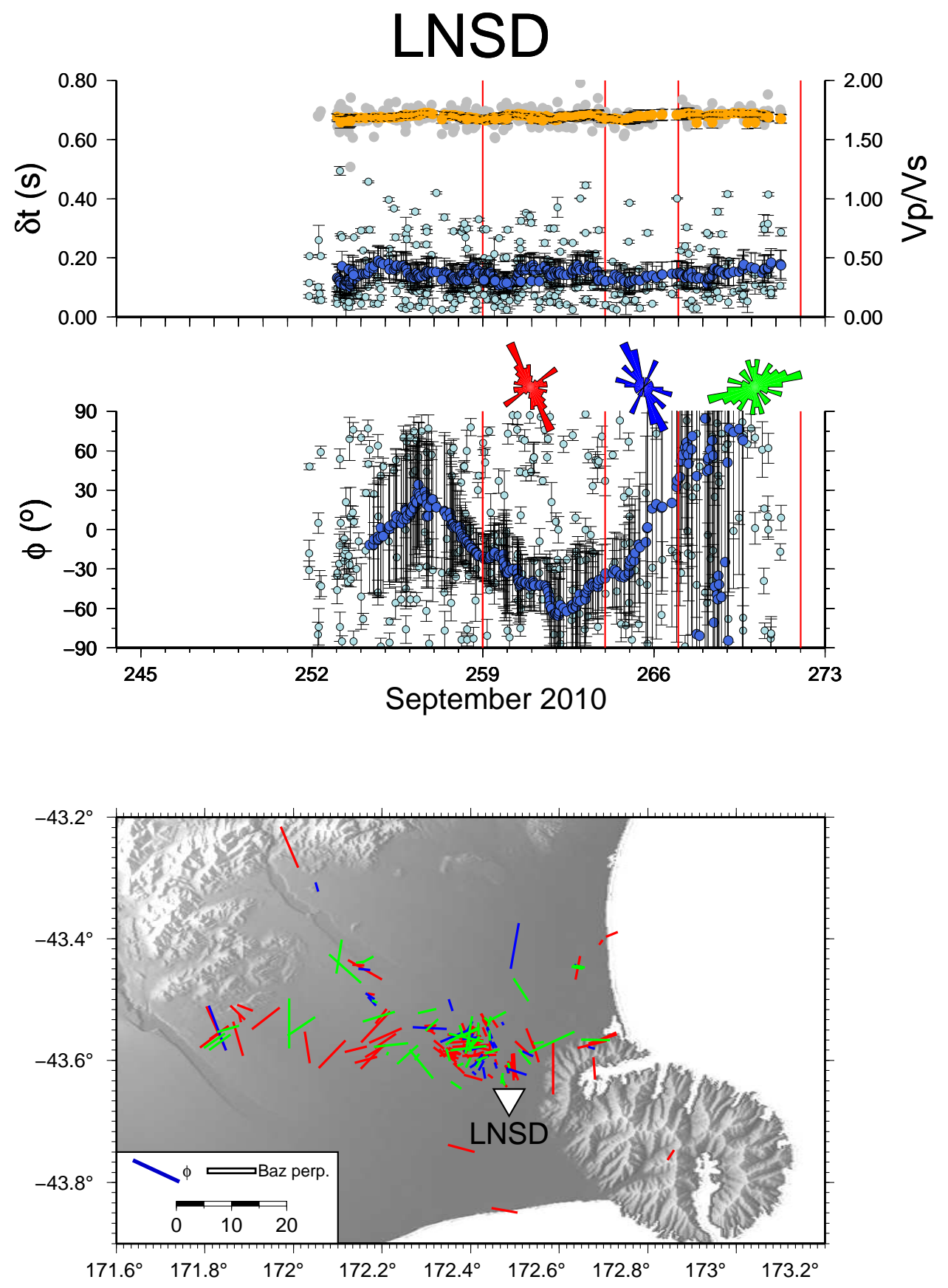

Figure C.3: UPPER: $\phi$ and $\delta$ t vs. time for station LNSD. Light blue are individual measurements. Dark blue points are 20pt moving averages. Grey and orange points represent individual and 20pt moving averages for $V_{P} / V_{S^{-}}$ ratio. Error bars shown in black. Rose diagrams represent distribution of $\phi$ for the sections delineated by red lines. X-axis shows Julian day (1 Sept. $=244$ etc.). LOWER: $\phi$ plotted at event location for station LNSD. Length of vectors determined by $\delta \mathrm{t}$ and direction corresponds to $\phi$. Colour of bar indicates which time segment $\phi$ measurement is from. 


\section{C.2 GeoNet permanent stations}

Temporal changes for the permanent GeoNet stations have been investigated for the time period 8 September 2010 to 13 January 2011. SWS measurements for events after this period were also estimated to see if there was a change in $\phi$ or $\delta$ t with time before or after the 22 Feb 2011 Christchurch earthquake. Two of the three stations (CRLZ, OXZ) show variation in $\delta \mathrm{t}$ around the time of the Christchurch earthquake (Figs. C.4, C.6). These changes are caused by a spatial variation as the vast majority of the events surrounding the earthquake (blue vectors in Figs. C.4, C.6) are in the same location. $V_{P} / V_{S}$-ratios are not available post Jan 13, 2011 as there is no relocation data to provide accurate travel times. 

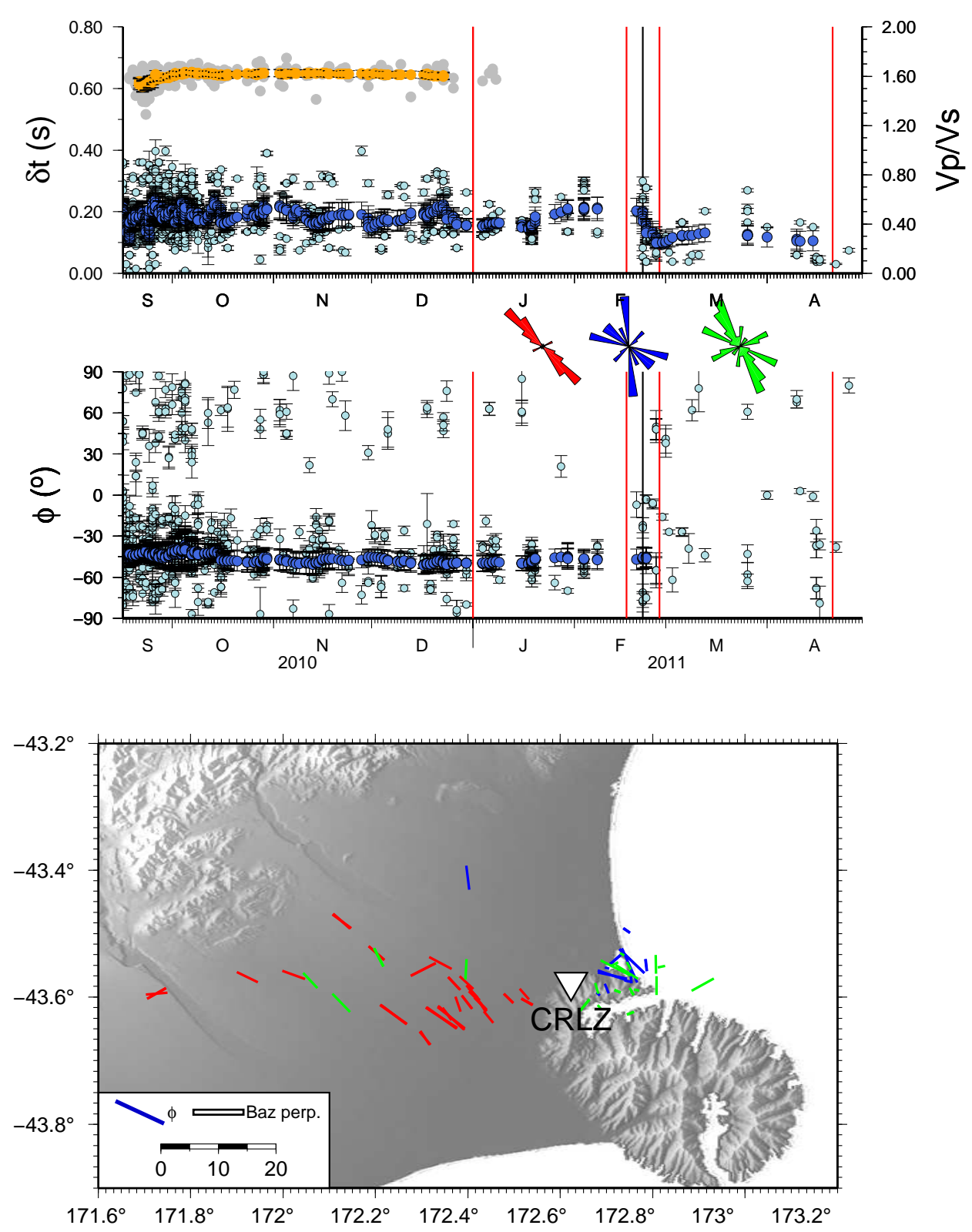

Figure C.4: UPPER: $\phi$ and $\delta$ t vs. time for station CRLZ. Light blue are individual measurements. Dark blue points are 20pt moving averages. Grey and orange points represent individual and 20pt moving averages for $V_{P} / V_{S^{-}}$ ratio. Error bars shown in black. Rose diagrams represent distribution of $\phi$ for the sections delineated by red lines. LOWER: $\phi$ plotted at event location for station CRLZ. Length of vectors determined by $\delta$ t and direction corresponds to $\phi$. Colour of bar indicates which time segment $\phi$ measurement is from. 

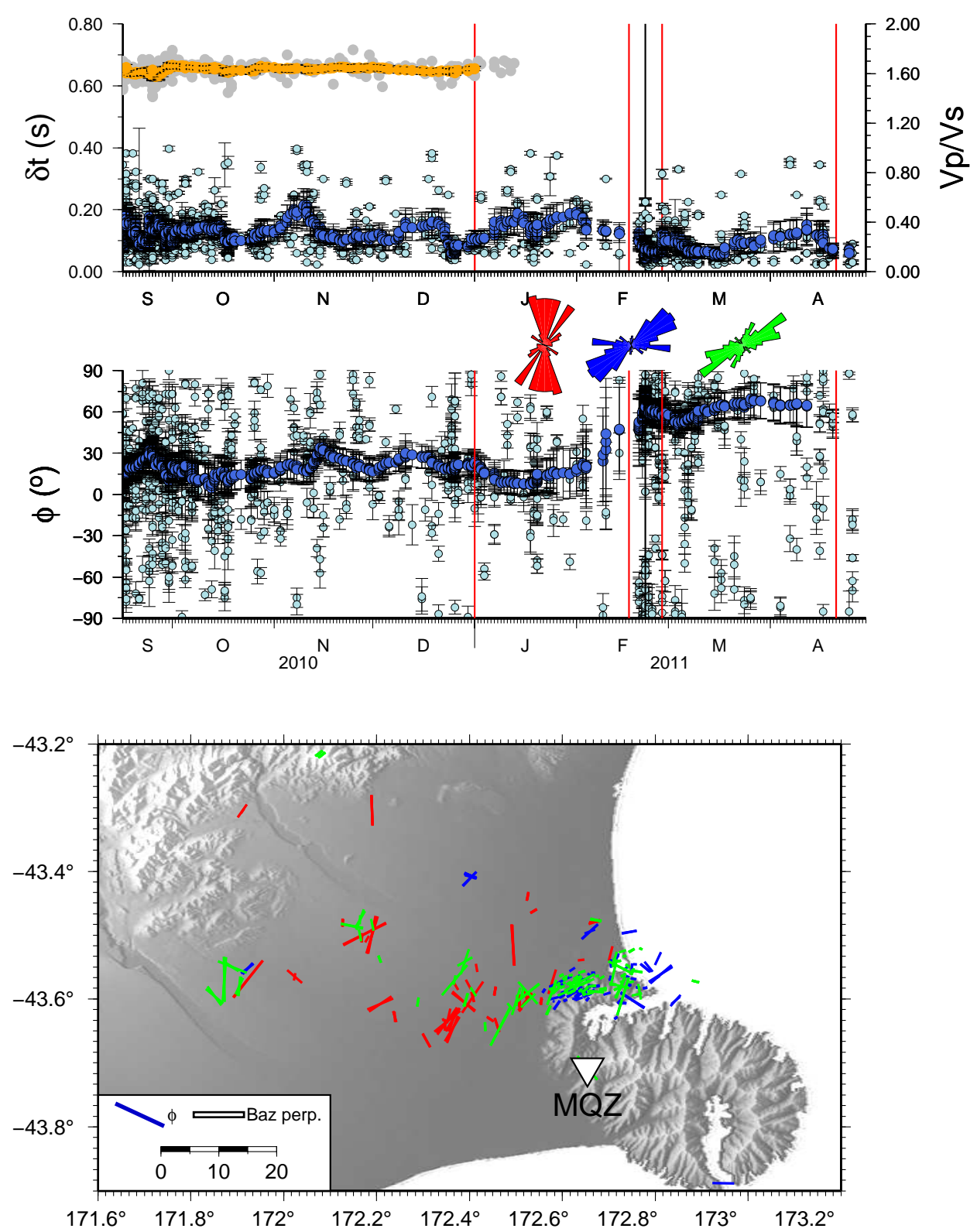

Figure C.5: UPPER: $\phi$ and $\delta$ t vs. time for station MQZ. Light blue are individual measurements. Dark blue points are 20pt moving averages. Grey and orange points represent individual and 20pt moving averages for $V_{P} / V_{S}$-ratio. Error bars shown in black. Rose diagrams represent distribution of $\phi$ for the sections delineated by red lines. LOWER: $\phi$ plotted at event location for station MQZ. Length of vectors determined by $\delta$ t and direction corresponds to $\phi$. Colour of bar indicates which time segment $\phi$ measurement is from. 

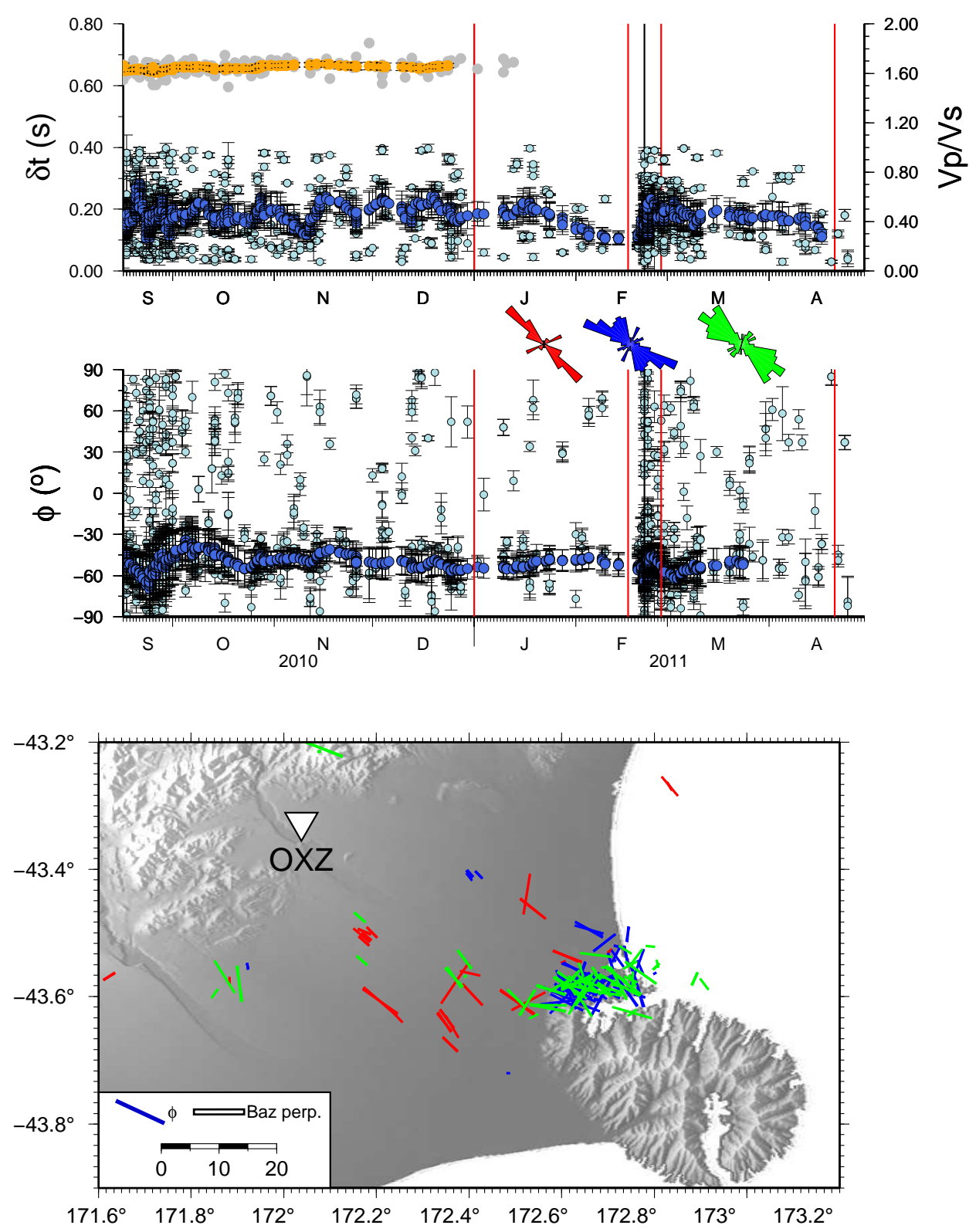

Figure C.6: UPPER: $\phi$ and $\delta$ t vs. time for station OXZ. Light blue are individual measurements. Dark blue points are 20pt moving averages. Grey and orange points represent individual and 20pt moving averages for $V_{P} / V_{S}$-ratio. Error bars shown in black. Rose diagrams represent distribution of $\phi$ for the sections delineated by red lines. LOWER: $\phi$ plotted at event location for station OXZ. Length of vectors determined by $\delta \mathrm{t}$ and direction corresponds to $\phi$. Colour of bar indicates which time segment $\phi$ measurement is from. 